\title{
THE INFLUENCE OF CHARACTER'S \\ GENDER AND THE BASIC EMOTIONS \\ OF "HAPPINESS" AND "SADNESS" \\ ON VOICE PITCH IN THE READING \\ OF FICTION
}

Brno Studies in English

Volume 46, No. 1, 2020

ISSN 0524-6881 | e-ISSN 1805-0867

https://doi.org/10.5817/BSE2020-1-3

\section{ŁUKASZ STOLARSKI}

\begin{abstract}
This paper examines the way in which two basic emotions and the character's gender are rendered in the reading aloud of prose in terms of the fundamental frequency and the variability of the fundamental frequency. When female characters express happiness or male characters express sadness, the effects of the two variables reinforce each other. However, when female characters express sadness or male characters express happiness, the two characteristics, theoretically, cancel each other. The results of this study indicate that the happy-sad dichotomy has priority over the character's gender. These findings could potentially be extended to the more general claim that the broad category of emotion has a greater influence than the character's sex on the reader's voice.
\end{abstract}

Key words

Affective speech; affect vocalisation; emotional expression; pitch; fundamental frequency

\section{Background}

\subsection{Definitions of the term "emotion"}

Griffiths (1990) has suggested that even in our everyday discourse the term "emotion" is interpreted in two different ways. According to the first, the notion is contrasted with rational thinking and it is assumed to be "passive" and "involuntary". In this interpretation, emotions interfere with rational action and are naturally linked to various physiological events, such as flinching or sweating. Alternatively, emotions may be treated as intentional states which involve conscious judgements. This strand of thought is found in philosophical cognitivism which assumes that propositional attitudes are necessary for the occurrence of emotions (Kenny, 1963; Lyons, 1980; Solomon, 1976; Stocker, 1987). For instance, in order to react to something with fear, one needs to believe that it is dangerous.

In scholarly discussions the term is even more confounding. It has been observed that since the twentieth century more than 90 definitions of emotion have been proposed (Klainginna and Kleinginna, 1981; Plutchik, 2001a, 2001b); however, it is possible that the number of different interpretations of the term is probably much higher. In some publications the definition is rather vague. 
For instance, Gobl and Ní Chasaide (2003) use the term alongside such related notions as "speaker mood" and "attitude" in a way that suggests a continuum of human affects, among which emotions were treated as the strongest, moods as weaker and attitudes as the weakest. Mozziconacci (1998), on the other hand, uses the term to refer both to emotions and attitudes. Many other authors have suggested narrower interpretations. For example, Griffiths $(1989,1990)$ makes a clear distinction between emotions and moods, and states that the former are typically brief and their onset may be regarded as near instantaneous. Plutchik (2001a, 2001b) also provides a clear definition, one directly connected to his psychoevolutionary approach in which an emotion is treated as "a complex chain of loosely connected events" (2001b: 345-346). Such a chain involves a stimulus event, inferred cognition, a feeling state, an impulse to action, overt behaviour displays and final effects. For instance, the complex chain of events defining "fear" includes the threat of a predator, the realisation of danger, feeling the state of fear, the impulse to run, the action of running and the effect of being protected from the attack.

In the present paper the word "emotion" will be used synonymously with the word "feeling" and the meaning of both will be interpreted as a "feeling state" understood in the sense defined by Plutchik (2001a, 2001b). Both "happiness" and "sadness" will be interpreted as subjective, reportable states which constitute only a small part of the complex chain of events mentioned in the previous paragraph.

\subsection{Taxonomy of emotions}

The categorisation of emotions is a subject broadly discussed in scholarly publications. It has been noted that there is no consensus on one preferred taxonomy (cf. Gobl and N1 Chasaide, 2003; Mason and Capitanio, 2012; Scherer, 1986). Some researchers have even suggested that such a clear categorisation may not really exist (Nesse and Ellsworth, 2009). Nevertheless, various emotion labels have been proposed in numerous publications and any taxonomy of this kind automatically relies on a given theory.

One generalisation which may be drawn about the theories of emotion is that they follow either the idea that the expression of emotions is mostly genetically determined (Eibl-Eibesfeldt, 1973; Ekman, 1980; Ekman and Friesen, 1971; Frijda and Parrott, 2011; Fulcher, 1942; Plutchik, 1980, 2001a, 2001b; Thompson, 1941; Tooby and Cosmides, 1990) or that emotions are mainly conditioned by culture (Averill, 2009; Birdwhistell, 1963; Ekman, 1999; Harré, 1986; Labarre, 1947). An intermediate approach which recognises that both of these factors have a direct influence on emotional behaviour is also encountered (Ekman, 1999; Griffiths, 1990; Izard, 2007; Mason and Capitanio, 2012; Panksepp, 2007). For methodological reasons, the first position is most crucial to the current paper. It can be traced back to Darwin's pioneering work The expression of the emotions in man and animals, in which he concentrated on the facial expression of emotions. Among other things, he used the term "chief movements of expression" (1998: 345), which in numerous later publications have frequently been referred to as "basic emotions" (Clark, 2010; Costa et al., 2014; Farinelli et al., 2015; Fernández-Sán- 
chez, Giménez-Dasí, and Quintanilla, 2014; Frijda and Parrott, 2011; Glass, Lingg, and Heuberger, 2014; Griffiths, 1990; Kennedy, 2012; Lewinski, Tim and Butler, 2014; Mason and Capitanio, 2012; Saarimäki et al., 2015; Scheff, 2015; Takagi, Hiramatsu, Tabei and Tanaka, 2015) and which are usually assumed to "provide the biological foundations for all emotions, to be genetically determined, and to have acquired their adaptive functions in response to recurrent challenges to the individual and the species over generations of evolutionary history" (Mason and Capitanio, 2012: 238). Some empirical studies support the universal nature of human emotions. For instance, in the experiment performed by Ekman and Friesen (1971) on the Fore language group in New Guinea, the subjects were capable of adequately recognizing various emotions from photographs showing prototypical facial expressions, although the informants had no contact with the western culture which would influence their responses. Another example which corroborates this approach is the study examining facial expression of emotions in deaf and blind children by Eibl-Eibesfeldt (1973). He established that the patterns of muscular activity for selected emotions were similar to those of sighted and hearing children.

The concept of basic emotions has also drawn criticism (Barret, 2006; Frijda and Parrott, 2011; Ortony and Turner, 1990; Reisenzein, 2000; Russell, 2003; Russell and Barrett, 1999); hence, uncritical relying on it in the form proposed in initial studies would be objectionable. One needs to accept that the degree to which emotional behaviour is predestined by genetic makeup is limited. Nevertheless, the theory offers useful analytical tools, which has even been noted by some critics of the idea of basic emotions (Ortony and Turner, 1990). The fact that the exact set of such basic categories is different in almost each publication dealing with the topic is another problem. A possible solution would be just to choose one specific proposal. An example of a theory which could potentially serve the purpose of a reliable methodological framework for projects similar to the current one is the psychoevolutionary approach developed by Plutchik (1980, 1997, 2000, 2001a, 2001b). The approach assumes that the process of adaptation of organisms to environment results in 8 basic emotions (joy, trust, fear, surprise, sadness, disgust, anger and anticipation), which in turn are treated as building blocks of other, more complex emotions, referred to as "primary", "secondary" and "tertiary dyads". It is interesting to note that some basic categories used in Plutchik's theory are also present in many other taxonomies of emotions reported in the literature. Nesse (1990) has observed that most such lists contain the notions of fear, anger, happiness, sadness and love. Indeed, this opinion may be easily substantiated by the summary of such classifications provided in Ortony and Turner (1990) and the methodology described in Section 3 is based the notion, that some emotion categories seem to be widely accepted.

\subsection{Vocal expression of emotions}

The way in which emotions are expressed in language has been discussed in a broad body of literature. Comprehensive surveys of such studies are provided in Frick (1985), Kappas, Hess and Scherer (1991) and Scherer (1986). 
They include investigations of various acoustic aspects of speech by means of which emotions may be conveyed. Among the frequently discussed aspects one should mention the intensity of sound waves, which corresponds closely to our perception of loudness (Bezooijen, 1984; Costanzo, Markel and Costanzo, 1969; Davitz, 1964; Eldred and Price, 1958; Hargreaves, Starkweather and Blacker, 1965; Huttar, 1968; Kaiser, 1962; Kotlyar and Morozov, 1976; Moses, 1954; Ostwald, 1963; Skinner, 1935; Tolkmitt, Helfrich, Standke and Scherer, 1982; Whitman and Flicker, 1966; Williams and Stevens, 1969). It has been established that an increase in intensity tends to be associated with such emotions as anger or joy, and a decrease with those of sadness or boredom. An alternative interpretation would be to assume that an increase in loudness is dependent more on the intensity of a given emotion than on its kind. While most authors agree that this is generally lowered in sad utterances, it is actually the opposite in expressions of rage. According to the model of emotions proposed by Plutchik (1980, 1997, 2000, 2001a, 2001b), rage is actually the same emotion as sadness, but it is simply more intense. Another good example is the relationship between serenity and joy, which, again, are treated as one kind of emotion. The sound level typically associated with serenity is lower than the one ascribed to joy.

Another frequently examined acoustic feature in the literature on the vocal expression of emotions is the rate of speech (Bergmann, Goldbeck and Scherer, 1988; Breitenstein, Van Lancker and Daum, 2001; Carlson, Granström and Karlsson, 1991; Coleman and Williams, 1979; Davitz, 1964; Eldred and Price, 1958; Ellgring and Scherer, 1996; Fairbanks and Pronovost, 1939; Johnson, Emde, Scherer and Klinnert, 1986; Kotlyar and Morozov, 1976; Markel, Bein and Phillis, 1973; Mozziconacci, 1995, 1998; Murray and Arnott, 1995; Scherer, 1981, 1986, 1989; Scherer and Oshinsky, 1977; Stibbard, 2000; Williams and Stevens, 1972). In general, it has been noted that slower tempo tends to correlate with sadness, while a faster rate is typical for emotions such as fear or anger. As in the case of intensity, such associations may also be explained by referring to the relative level of emotional arousal (cf. Breitenstein et al., 2001; Ellgring and Scherer, 1996). The speech rate in expressions involving emotions with high sympathetic arousal tends to be generally higher than in other cases.

Further acoustic properties analysed in connection with emotions include voice quality (Alter et al., 1999; Bezooijen, 1984; Boves, 1984; Cummings and Clements, 1995; Gobl and Ní Chasaide, 2003; Johnstone and Scherer, 1999; Ladd, Silverman, Tolkmitt, Bergmann and Scherer, 1985; Murray and Arnott, 1995), extralinguistic interjections (Scherer, 1994; Schröder, 2003), pausing structure (Cahn, 1989, 1990), and intonation contours (Höffe, 1960; Kaiser, 1962; Ladd et al., 1985; Rodero, 2011). Nevertheless, the most frequently described acoustic feature of speech in related discussions is the fundamental frequency. It is significantly more common for at least two reasons. Firstly, as suggested by Scherer (1986), F0 is one of the acoustic variables which is relatively easy to measure. Secondly, it has been reported to be among the attributes exerting the greatest effect (Banse and Scherer, 1996; Frick, 1985; Murray and Arnott, 1993, 1995; Pell, 1999; Scherer, 1982, 1995; Scherer and Oshinsky, 1977; Vroomen, Collier and Mozziconacci, 1993). It is important to stress that this feature may be considered from 
at least two different points of view. On the one hand, one may be interested in its mean value for a given utterance. On the other hand, the focus of attention could be the variability of F0. Both of these aspects are central to the current paper and the way they may be measured is explained in Section 3.

Possible associations between F0 and emotions have been discussed in a great number of publications and reviewing them in detail is beyond the scope of this paper. However, it is necessary to point out the results concerning the behaviour of F0 in expressions involving happiness and sadness because the two emotions are analysed in Section 4. It has been confirmed that the mean value of the fundamental frequency tends to be relatively lower in sad utterances (Coleman and Williams, 1979; Collier and Hubbard, 1998; Davitz, 1964; Fairbanks and Pronovost, 1939; Fonagy, 1978; Huron, 2008; Huron, Yim and Chordia, 2010; Kaiser, 1962; Leinonen, Hiltunen, Linnankoski and Laakso, 1997; Razak, Abidin and Komiya, 2003; Sobin and Alpert, 1999; Wallbott and Scherer, 1986; Wu, Zheng, $\mathrm{Xu}$ and Bao, 2006) and higher in expressions involving the emotion of happiness (Bezooijen, 1984; Coleman and Williams, 1979; Collier and Hubbard, 1998, 2001; Davitz, 1964; Fonagy, 1978; Havrdová and Morávek, 1979; Razak et al., 2003; Skinner, 1935; Sobin and Alpert, 1999; Wu et al., 2006). Similarly, the variability of pitch is lowered in utterances expressing the former (Breitenstein et al., 2001; Havrdová and Morávek, 1979; Ladd et al., 1985; Skinner, 1935; Wu et al., 2006) and raised in the latter (Breitenstein et al., 2001; Fairbanks and Pronovost, 1939; Kaiser, 1962; Ladd et al., 1985; Wu et al., 2006). These observations are in accordance with the aforementioned association between sympathetic arousal and an increase in speech rate and volume. Again, more intensive emotions evoke higher values of the acoustic features under consideration.

\subsection{Acoustic differences between male and female voices}

One of the variables used in the experiment described in Section 4 is the gender of the characters whose dialogues are analysed. Consequently, the topic of acoustic differences between male and female voices should also be addressed.

Although the early work on acoustic phonetics focused primarily on male speakers, possible differences between acoustic characteristics of male and female speech have since been widely discussed. For instance, the classical study by Peterson and Barney (1952) reported data on acoustic differences of vowels produced by men, women and children. Since then various other aspects have been analysed, including abruptness of flow termination, symmetricalness and duration of vocal pulses, sound pressure level, the amount of noise fill in interformant regions, the size of formant bandwidths, etc. (cf. the summary in Kent and Read, 1992). A number of studies also examined the assumption that a woman's voice involves more breathiness than a man's (Henton and Bladon, 1985; Holmberg, Hillman and Perkell, 1988; Klatt, 1987; Klatt and Klatt, 1990) and the notion of "timbre", broadly defined as a "multidimensional waste-basket category for everything that cannot be labelled pitch or loudness" (McAdams and Bregman, 1979, p. 34), has also received some attention in the discussion (cf. Pernet and Belin, 2012). Nevertheless, the major acoustic feature which has repeatedly been 
reported to differentiate women's voices from men's is the fundamental frequency (Childers and Wu, 1991; Fitzsimons, Sheahan, and Staunton, 2001; Gelfer and Mikos, 2005; Kent and Read, 1992; Latinus and Taylor, 2012; Machado, Duarte, Teles, Reis, and Rebelo, 2012; Ohara, 2003; Yuasa, 2008). Even though F0 may be not sufficient by itself to discriminate male and female voices and additional acoustic information may be required (Childers and Wu, 1991; Klatt and Klatt, 1990), it has been used as a primary cue for gender identification in a number of voice recognition systems (Abdulla and Kasabov, 2001; $\mathrm{Hu}, \mathrm{Wu}$, and Nucci, 2012; Jung, Schwarzbacher, Humphreys and Lawlor, 2002; Parris and Carey, 1996).

The height of the fundamental frequency largely depends on the membranous length of the vocal folds (Kent and Read, 1992; Titze, 1989). Therefore, F0 is directly connected with the biological differences between men and women. The average male larynx is 1.7 times larger than the average female larynx, resulting in the average female voice being 1.7 times higher than the average male voice (Childers and Wu, 1991; Jung et al., 2002). There is, obviously, much individual variability and the actual acoustic values of $\mathrm{F} 0$ vary from $100 \mathrm{~Hz}$ to $200 \mathrm{~Hz}$ for men, and from $120 \mathrm{~Hz}$ to $350 \mathrm{~Hz}$ for women (Titze, 1989).

Possible differences in the variability of the fundamental frequency of male and female voice have also been debated. The discussion is somewhat confusing because the phenomenon may be measured in different ways. One of these is by calculating the range of pitch, understood as the difference between the maximum and minimum value of the fundamental frequency of voice measured in Hertz among a group of participants. This method has been frequently applied, most likely because the pitch range is easy to determine. It has been concluded that the voice pitch range of women is higher than the voice pitch range of men (Childers and Wu, 1991; Fitzsimons et al., 2001; Kent and Read, 1992; McConnellGinet, 1983; Waksler, 2001). A detailed survey of studies including such data has been provided by Henton (1989) and the claim of the larger pitch range in the female voice as measured on the linear Hertz scale is valid. Nevertheless, Henton has argued that such a method for comparing male and female voices is misleading because "the ear is known to judge pitch range not by measuring hertz, but by using a logarithmic, on non-linear scale, such as semitones" (1989: 301). Consequently, she has converted the values of the range measured in Hertz into semitones using the formula applied earlier by Graddol (1982). The new values on the logarithmic scale do not support the former conclusion that the male voice involves less variability than the female voice. In fact, Henton's results indicate that it is the male voice which involves greater pitch range.

Another way of measuring variability is to calculate standard deviation. In Henton (1995) this method was associated with the term "pitch variability" and contrasted with the notion of "speaker's pitch range", which had been the focal point in her previous publication described above. The major advantage of using standard deviation rather than range is that the former summarises the exact average distance from the mean, while the latter takes into account only two marginal values in a dataset, which tend not to be representative of the data. A partial solution to this problem is to calculate the range from less than the total range, e.g. from the data within four standard deviations (Jassem, 1971). This would 
help to eliminate extreme outliers, but the obtained marginal values could still be unrepresentative of the whole dataset.

Even though range has been regarded as a statistic of severely limited use (Rumsey, 2011), choosing between the two methods depends on a study's aims. If one just wants to investigate the actual range of pitch for a given group of subjects, then the very range is, obviously, the right choice. However, if the aim is to evaluate the level of variability of pitch in the speech of such a group, then range is not the right statistical measurement and the standard deviation of pitch should be chosen instead. For this reason, the results reported in Henton (1989) should be treated with caution. One of the major aims of her study was to disprove the derogatory terms "over-emotional" and "swoopy" which had been used to describe female speech in the past. By choosing range of pitch as the major acoustic cue, it was difficult to objectively disprove the variability of voice implied in those pejorative terms. Apart from that, from the phonetic point of view there is nothing negative in having more pitch variability in one's speech; thus, any derogatory descriptions of such tendencies are not encountered in modern linguistics.

Studies which provide data on the standard deviation of pitch indicate that, in general, it is actually larger in female speech than in male speech (Schötz, 2006, 2007; Xue and Deliyski, 2001), although further investigation into this topic could help to provide more in-depth answers.

Finally, it must be emphasized at this point that the category of gender used in this study refers to the "character's sex", and not to "the reader's sex". Consequently, it affects the acoustic measurements discussed in Section 4 only indirectly. It is not concerned with the actual differences between the male voice and the female voice resulting from dissimilar characteristics of vocal track anatomy. Instead, this explanatory variable is associated with the reader's idea of what men and women sound like and how these differences should be conveyed when reading dialogues (see also Section 3.1).

\section{Aims}

This paper continues the investigation of the ways in which the emotions of happiness and sadness are expressed in the reading of prose as begun in Stolarski (2015). It was established that they are conveyed according to the predicted tendencies. The average value and standard deviation of readers' F0 tends to be raised in expressions involving the former category, and both acoustic variables are lowered in fragments involving the latter emotion. Nevertheless, these acoustic cues are utilised to varying degrees. Although signalling happiness includes an increase in both the mean F0 and the standard deviation of F0, sadness is primarily marked by a lower variability of F0; decrease in F0 level is less influential.

The present publication extends the scope of Stolarski (2015) by including a crucial new variable. Each of the extracts analysed in the previous experiment was a part of a dialogue in which a given character in a novel took part. 
In addition to the clearly specified emotion of happiness or sadness relevant to the excerpt, the readers were also aware of the gender of the character. In the previous study the potential influence of this important additional factor was partially mitigated by choosing exactly the same number of male and female characters in each sample. Nonetheless, the impact of a person's gender on the way his/her speech is rendered when reading aloud should be closely investigated.

The initial predictions are that parts of dialogues in which male characters express sadness will be read with a lower mean F0 and a lower variability of F0. Conversely, the parts in which female characters express happiness should result with an increase in the two acoustic features. The predictions are based on the data discussed in Sections 1.3 and 1.4. The mutual influence of the two factors is, however, difficult to guess in the other two contexts. Namely, it is unclear what the resulting readers' mean F0 and standard deviation of F0 will be in cases of male characters expressing happiness and female characters expressing sadness. In these contexts, the two variables act in opposition to one another; thus, it is by examining such cases that the relative degree of influence of these two sociolinguistic aspects on the above mentioned acoustic features may be estimated.

It is worth emphasizing that the "happy/sad" dichotomy may be treated as a prototypical emotion continuum (see the discussion in Section 3.1 below). Consequently, the results obtained in this paper could also be interpreted in a more general sociolinguistic context. The potential of "happy/sad" to be dominant over "gender" (or vice versa) could be extended to a more general claim replacing "happy/sad" with the broad category of "emotion". Such a conclusion would have to be verified in future research, but it would be highly probable.

\section{Methods}

\subsection{Variables included in the study}

The response variables in the experiment described in Section 4 are the average fundamental frequency and the variability of the fundamental frequency (measured as the standard deviation of the fundamental frequency) of the readers' voices. In the current study, the former is usually referred to as "F0", and the latter as "SD of F0". As discussed earlier (see Section 1.3), both are basic acoustic cues used in studies on the vocal expression of emotion and both have been shown to exert the greatest effect. Additionally, F0 is also frequently included in literature on acoustic differences between male and female speech (see Section 1.4). Both of the response variables are numerical and are measured in Hertz.

There are also two categorical explanatory variables. The first is the gender of the characters (male or female). As mentioned at the end of Section 1.4, this variable is assumed to affect acoustic measurements indirectly. It refers only to the way in which the reader perceives the differences between the male and the female voice and also the manner in which he or she wants to convey these differences. The actual acoustic characteristics typical for men and women should be treated only as a theoretical point of reference for what the readers may be 
attempting to reproduce. As a consequence, the statistical analysis performed in this study is based on the relative differences between the mean values measured in the whole chapters and the mean values obtained in the extracts (see Section 4.1). This normalization of the data is necessary to observe the changes for a given reader, regardless of his or her natural voice characteristics.

The second explanatory variable is the contrast between the opposing emotions of happiness and sadness. These two emotion categories appear in almost any taxonomy of emotions (see the discussion in Section 1.2) and their existence is rarely questioned.

It must be emphasised that all of these variables have been chosen not only to investigate the interaction between the literary character's sex and the way happiness and sadness are expressed. As mentioned in Section 2, the intention of this study is also to explore the more universal relationship between the category of emotion and the character's gender in the reading aloud of novels. By choosing "prototypical" emotions as well as the most quintessential acoustic characteristics of the human voice, one may, to a certain degree, make more general estimates regarding the effects of emotions and the literary character's sex on the fiction reader's voice.

Data on the readers' gender and dialect was also collected, but the influence of these variables on the resulting pitch values, discussed in Section 4.2, is not the primary focus of this article. They were analysed only to exclude possible confounding effects.

\subsection{Materials}

The materials analysed in the present study comprise fragments of audiobooks selected according to criteria which allowed testing the influence of the two explanatory variables on the two response variables specified in Section 3.1. The process of their selection was essentially the same as that applied in Stolarski (2015). Below is a summary of the procedures followed in the previous research.

1. A reasonably large corpus of novels had to be created. Initially, only books written by Charles Dickens were taken into account. He wrote over 40 works, most of which are large novels. They were downloaded in electronic format from "www.gutenberg.org".

2. The corresponding audiobooks were sought at "www.librevox.com". 28 titles were found, and some of the novels were recorded in several versions by different readers.

3. Appropriate lexical cues associated with the semantic categories of happiness and sadness had to be established. Phrases containing adjectives, such as "cried a cheerful voice" (Charles Dickens, A Christmas Carol, Stave 1), or nouns, as in "cried Biddy, in a burst of happiness" (Charles Dickens, Great Expectations, Chapter 58), could have been used, but it was found that the most suitable were expressions including adverbs. The list of the adverbs included close synonyms of "happily" (joyfully, joyously, amusingly, cheerily, cheerfully, gleefully, gaily, merrily, buoyantly, ebulliently, avidly, jovially, 
blithely, radiantly) and "sadly" (unhappily, gloomily, cheerlessly, sorrowfully, despondently, dejectedly, dismally, dolefully, joylessly, morosely).

4. A search was conducted with the use of AntConc (Anthony, 2014). Due to restrictions resulting from the applied statistical methods (see below) only 20 examples were found for each of the two emotion categories. Most of the examples followed the pattern "first part of a character's utterance + expression involving one of the emotional adverbs + second part of the same character's utterance". The acoustic analysis was performed solely on the part following the adverb specifying the emotion with which the fragment was meant to be read. Additionally, only those examples were chosen which indicated one of the emotions in a clear and unambiguous way. Cases in which a given emotion was expressed only up to a point (e.g. "he added more cheerfully" - Charles Dickens, The Life and Adventures of Nicholas Nickleby, Chapter 55) or was mixed with another emotion (e.g. "said Mr. Lorry, joyfully relieved after reading this note aloud" - Charles Dickens, A Tale of Two Cities, Book 3, Chapter 3) were excluded. Similarly, examples chosen for the analysis included reporting verbs that were either neutral, e.g. "said" or "answered", or implied a feeling consistent with the emotion signalled by the character. All this guaranteed that the reader was left with no doubt about the character's emotional intentions.

5. The statistical methods applied in the study included the sign test for the mean difference with matched-pairs data and the Wilcoxon signed rank test for paired data. This choice was dictated by the need to cope with the problem of speaker normalization, but it introduced an important restriction. On the one hand, the same example could actually be analysed several times if it was read by different readers (cf. Appendix C for the extract from A Christmas Carroll by Charles Dickens which was scrutinised 5 times). On the other, for each of the emotion categories the samples could not contain recordings by the same reader. This restriction limited the number of available examples to 20 for each emotion label and this was not enough to obtain statistically relevant results. As a consequence, other novels written by other twentieth century authors were included in the search and, finally, 30 appropriate extracts for each emotion category were found and analysed.

The aims of the current study demand twice as many examples as in the previous case. There are four groups to be examined: 1) male characters expressing happiness, 2) female characters expressing happiness, 3) male characters expressing sadness and 4) female characters expressing sadness. Assuming that 30 is the minimum number of elements in a single sample in order for the results to be statistically reliable, the total number of examples should be 120. Among the excerpts used in Stolarski (2015) the first group was represented by 27 expressions, the second by 3 , the third by 27 and the fourth by 3 . Therefore, the examples that needed to be added included: 3 for male characters expressing happiness, 27 for female characters expressing happiness, 3 for male characters expressing sadness and 27 for female characters expressing sadness. The search for these additional 
extracts followed the same procedures as before and only a few new aspects were introduced. One of them was, obviously, gender of the characters. Other aspects were characters' names and age. The latter variable was quite important because it also has a direct influence on the speaker's voice (Linville, 1996; Reubold, Harrington and Kleber, 2010; Schötz, 2006, 2007; Xue and Deliyski, 2001) and it could also alter the resulting quality of the readers' voice. In order to control for this variable, all of the examples selected for the current paper involved characters who were neither children nor elderly, at least not at the time in the novel when the dialogues analysed took place. The final set of 120 excerpts gathered for the analysis discussed in Section 4 is presented in the Appendices.

All of the recordings used in this study were downloaded as mp3 files with a bit rate of 64 or $128 \mathrm{kbit} / \mathrm{s}$.

\subsection{Acoustic measurements}

The acoustic measurements were performed using Praat (Boersma and Weenink, 2014). As mentioned in Section 3.2, the analysis of the extracts concerns only those fragments that follow an adverb suggesting emotional content. They are underlined in the Appendices. In each of these expressions, the mean F0 was measured and the pitch contour was extracted in order to obtain the standard deviation of F0. Additionally, the values of F0 and SD of F0 were calculated for the whole chapter in which a given extract was found. This allowed a comparison between the values in the extracts with emotional content and the values typical for a given speaker.

All of the measurements collected for the present study are summarised in Appendices A, B, C and D.

\subsection{Statistical techniques}

The discussion of the results is divided into two major parts. In the first (Section 4.1 , cases are analysed in which the two major explanatory variables function simultaneously and have a potential influence on the response variables. The statistical methods used in this analysis involve paired t-tests for samples that follow a normal distribution, and both the sing test and the Wilcoxon signed rank test for samples which do not fit a normal distribution. The normality of the samples was established by a visual inspection of the corresponding normal probability plots as well as the results of the Anderson-Darling test for normality.

In the second part of the discussion (Section 4.2) the readers' gender and dialect are analysed. They are treated as additional variables and are not the focus of the present study; however, their potential confounding effects need to be examined. The statistical methods used in this part of the paper, which are the Kruskal-Wallis test and a four-way analysis of variance, also make it possible to examine potential interaction between all explanatory variables under investigation.

The statistical tests in Section 4.1 were performed using Minitab 16.2.3 (2012) and the analysis summarised in Section 4.2 was conducted in R 3.0.3 (2013). 


\section{Results}

\subsection{Effects of characters' gender and expressed emotion}

Appendices A and B present the data such that the two explanatory variables act concurrently and, theoretically, should reinforce each other. The combination of a female character and the emotion of happiness (Appendix A) should result in an increase in the two response variables, whereas in the examples in which male characters express sadness (Appendix B) both F0 and SD of F0 should decrease. Appendices $\mathrm{C}$ and $\mathrm{D}$, on the other hand, include examples in which the two explanatory variables cancel each other and the resulting values of the response variables are difficult to predict. As mentioned in Section 2, the answer to this problem constitutes the major aim of the current paper.

Each appendix contains samples of mean F0 and SD of F0 from the chosen fragments as well as the corresponding values from the whole chapters. Consequently, there are four samples in each appendix, 16 samples in total. It must be emphasised that the tests discussed in Sections 4.1 and 4.2 were conducted on the differences between the mean F0 in the whole chapters and the mean F0 in the extracts (the penultimate column in each appendix) and the differences between $\mathrm{SD}$ of F0 in the whole chapters and SD of F0 in the extracts (the last column in each appendix).

Examples in which the explanatory variables reinforce each other

The 30 examples in Appendix A involve female characters who express the emotion of happiness. 17 of these were read by females and 13 by males. Among the females, 12 are native speakers of American English and 5 are native speakers of British English. The male readers include 5 native speakers of American English, 7 native speakers of British English and 1 speaker of Irish English. Appendix B includes 30 examples of male characters vocalizing the emotion of sadness. The excerpts were read by 17 male readers ( 8 speakers of American English, 8 speakers of British English and 1 speaker of Irish English) and 13 female readers (10 speakers of American English and 3 speakers of British English).

The upper left graph in Figure 1 depicts the normal probability plot for the differences between mean readers' F0 and the F0 measured in the extracts involving female characters expressing happiness (the penultimate column in Appendix A). Some of the data points do not closely follow a normal distribution as represented by the straight diagonal line in the middle of the picture. The corresponding statistic of the Anderson-Darling test, included in the quantitative summary to the right of the graphs, is large (0.866), and the p-value is below the $\alpha$ level of 0.05 (0.023). Because of this, the sign test as well as the Wilcoxon signed rank test were used to examine whether the median of the dataset is different from 0 .

In the end, the results fully support the assumption that the readers' F0 tends to increase in extracts involving female characters expressing happiness. The median for the difference between the mean readers' F0 measured for whole 
chapters and the corresponding values measured for the excerpts is $-15.83 \mathrm{~Hz}$. Moreover, the results of the sing test indicate that this difference is statistically significant $(p=0.0014)$. This is also substantiated by the Wilcoxon signed rank test $(\mathrm{W}=33, \mathrm{p}<0.0001)$.

The normality tests for the other three samples analysed in the present section indicate that parametric methods may be applied (see the upper right and both bottom graphs in Figure 1). The data follow a normal distribution rather closely, which is also indicated in the results of the Anderson-Darling test summarised in the box to the right of the graphs.

Paired t-test for cases in which mean readers' SD of F0 is compared to the SD of F0 in the extracts in which female characters express the emotion of happiness indicates a difference of $-5.23 \mathrm{~Hz}(95 \%$ CI: $-9.61 \mathrm{~Hz},-0.85 \mathrm{~Hz})$ and p-value of 0.021 . Thus, the predicted tendency in which the two explanatory variables reinforce each other has been confirmed once again. On average, SD of F0 tends to be higher in the extracts than in the corresponding chapters. Likewise, the results concerning the data on male characters expressing sadness follow the assumptions mentioned in Section 4.1. F0 tends to be lower by $9.49 \mathrm{~Hz}(95 \%$ CI: $3.40 \mathrm{~Hz}$, $15.58 \mathrm{~Hz})$ in such extracts and this difference is statistically significant $(\mathrm{p}=0.003)$. The SD of F0 is also relatively lower. The results suggest an average difference of $10.43 \mathrm{~Hz}(95 \%$ CI: $4.61 \mathrm{~Hz}, 16.25 \mathrm{~Hz})$ at a high level of significance $(\mathrm{p}=0.001)$.

Figure 1: Normal probability plots for samples involving female characters expressing happiness and male characters expressing sadness on which the statistical tests were performed

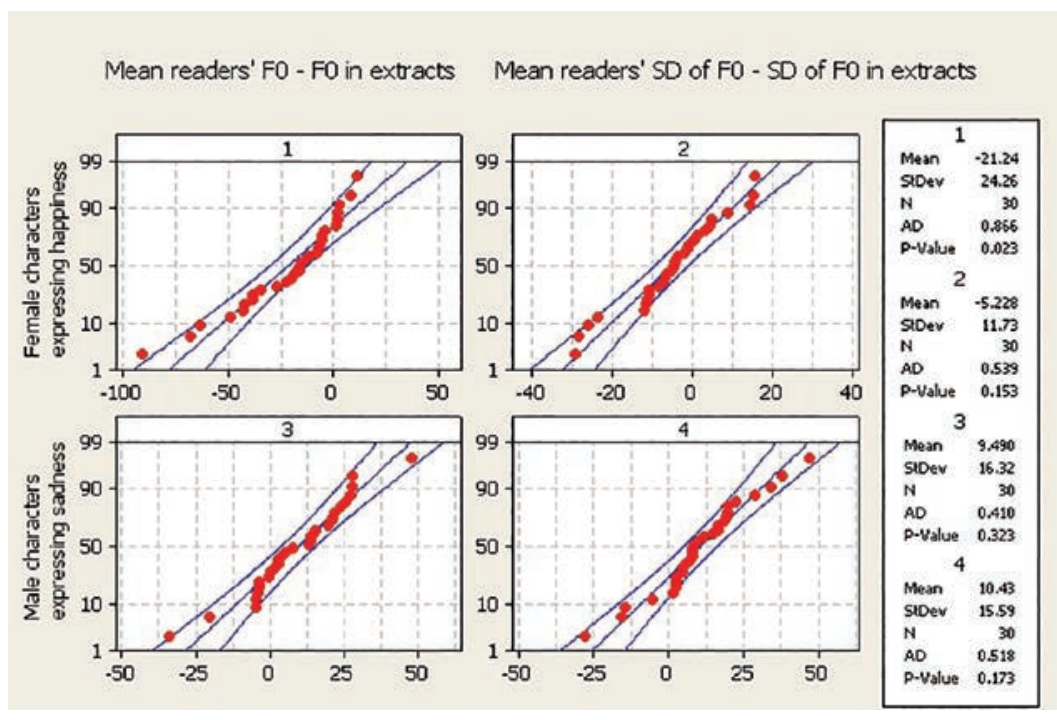

Examples in which the explanatory variables cancel each other.

Appendix C contains fragments exemplifying the way in which the expression of happiness in male characters is rendered in the reading aloud of prose. 20 of the 
excerpts were read by male readers (11 speakers of American English, 8 speakers of British English and 1 speaker of Irish English) and 10 by female readers ( 7 speakers of American English and 3 speakers of British English). Finally, Appendix D includes cases in which female characters vocalise the emotion of sadness. The fragments were read by 10 men and 20 women. The male readers included 6 speakers of American English, 3 speakers of British English and 1 speaker of Irish English. In the group of female participants there were 13 speakers of American English and 7 speakers of British English.

As in the case of the data analysed in the section above, the Anderson-Darling test of normality indicates that most of the samples follow a normal distribution (see Figure 2). The only case in which nonparametric methods are preferable is the data set containing the differences between the mean F0 in fragments with male characters expressing happiness and corresponding values of F0 in whole chapters (see the penultimate column in Appendix C and the graph in the upper left-hand corner in Figure 2). The Anderson-Darling test statistic for this group amounts to 1.08 and the p-value to 0.007 , which is strong evidence against normality. In all other cases, however, parametric tests may be applied.

Figure 2: Normal probability plots for samples involving male characters expressing happiness and female characters expressing sadness on which the statistical tests were performed

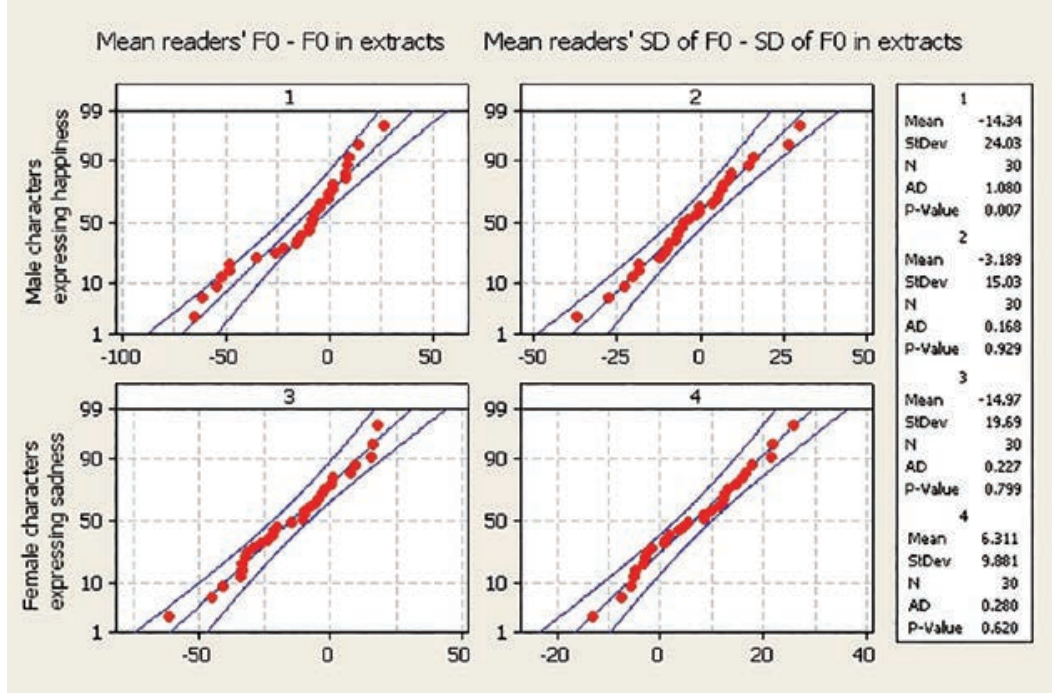

The average $\mathrm{F} 0$ tends to increase in extracts in which male characters are expressing happiness. On the basis of the sample analysed in Appendix C, the median for this difference is $-15.83 \mathrm{~Hz}$ and the sing test suggests that it is statistically relevant $(\mathrm{p}=0.0014)$. The Wicoxon signed rank test also confirms the significance of this result $(\mathrm{W}=100, \mathrm{p}=0.007)$. The conclusion to be drawn from this is that the changes in F0 tend to be more dependent on the variable of emotion than gender. Such an observation is additionally supported by the changes in SD of F0. The paired t-test for the sample listed in the last column in Appendix A shows 
an average difference of $-3.19 \mathrm{~Hz}$. In this case, the result may not be treated as statistically relevant $(\mathrm{p}=0.255)$, but it indicates a similar tendency. The variable that plays the leading role is the emotion of happiness. The fact that the characters whose utterances are read are male seems to have a relatively weaker influence on the characteristics of the readers' voice pitch.

The situation in the fragments in which female characters express sadness is more complex. First, the behaviour of F0 tends to be primarily influenced by the gender of the characters (see the penultimate column in Appendix D). The average difference of $-14.97 \mathrm{~Hz}(95 \% \mathrm{CI}:-22.32 \mathrm{~Hz},-7.61 \mathrm{~Hz})$ is highly statistically significant $(\mathrm{p}<0.0001)$. The readers tend to raise the pitch of their voice in order to imitate the relatively higher pitch of a given female character, whereas the reverse influence of the emotion of sadness is clearly weaker. Second, the changes in SD of F0 indicate an opposite pattern. The values of this variable are, on average, lower by $6.31 \mathrm{~Hz}(95 \%$ CI: $2.62 \mathrm{~Hz}, 10.00 \mathrm{~Hz})$ in extracts in comparison to the corresponding whole chapters and the difference should be treated as highly statistically significant $(p=0.002)$. This suggests that it is the emotion of sadness which plays here a more dominant role. The readers lower the variability of their pitch, which most probably results from the patterns found in the vocal expression of sadness. A possible raising of the variability in order to mark female voice is of secondary importance.

\subsection{Analysis including all explanatory variables}

Data on readers' gender and dialect which are included in the Appendices are not the primary focus of the present paper. Nonetheless, it is important to investigate possible confounding effects of these variables. What is more, it is crucial to consider the interaction between all explanatory variables used in the present study. To do this, a 4-way analysis of variance (ANOVA) could be conducted for both the differences between the mean F0 in the whole chapters and the mean F0 in the extracts (the penultimate column in each appendix), and the differences between the variability of F0 in the whole chapters and the variability of F0 in the extracts (the last column in each appendix). There are, however, certain problems with applying this method to the data under analysis. Many of the sets involving F0 that would be compared in ANOVA do not follow a normal distribution. This was already indicated in Figures 1 and 2, which suggest nonparametric methods for the samples of female characters expressing happiness and male characters expressing happiness. A closer inspection of other datasets that would be involved in ANOVA reveals numerous other instances which do not exhibit a normal distribution pattern. This problem relates to, for example, the sample of the $\mathrm{F} 0$ differences for all male characters $(\mathrm{n}=30, \mathrm{AD}=1.3751, \mathrm{p}$-value $=0.001328)$, all cases involving the emotion of happiness $(\mathrm{n}=30, \mathrm{AD}=1.6071$, $\mathrm{p}$-value $=0.0003519)$, or even the whole set of F0 differences $(\mathrm{n}=60, \mathrm{AD}=$ 1.2581, p-value $=0.002726$ ). An attempt to overcome this obstacle by applying "log transformation" was unsuccessful. The choice of nonparametric methods was the next logical step, but such a decision creates another problem. There is no direct, nonparametric counterpart for an n-way ANOVA. Instead, one may 
apply the Kruskal-Wallis rank sum test, but the effects of the four explanatory variables may only be analysed separately in four different tests. Therefore, the possible interaction between the four factors cannot be estimated. In conclusion, the analysis conducted in the first part of Section 4.2 involves, first and foremost, the Kruskal-Wallis test. The results of ANOVA are discussed later very briefly and suggest some interaction between the two variables.

The second part of Section 4.2 presents the results of a 4-way analysis of variance for the effects of the four explanatory variables on SD of F0. The samples compared in ANOVA do not reveal in this case any significant deviations from a normal distribution. Four of them were already summarised in Figures 1 and 2, and the Anderson-Darling tests for the others yielded p-values above 0.05 .

Figure 3: Boxplots comparing the Fo shifts according to the four explanatory variables
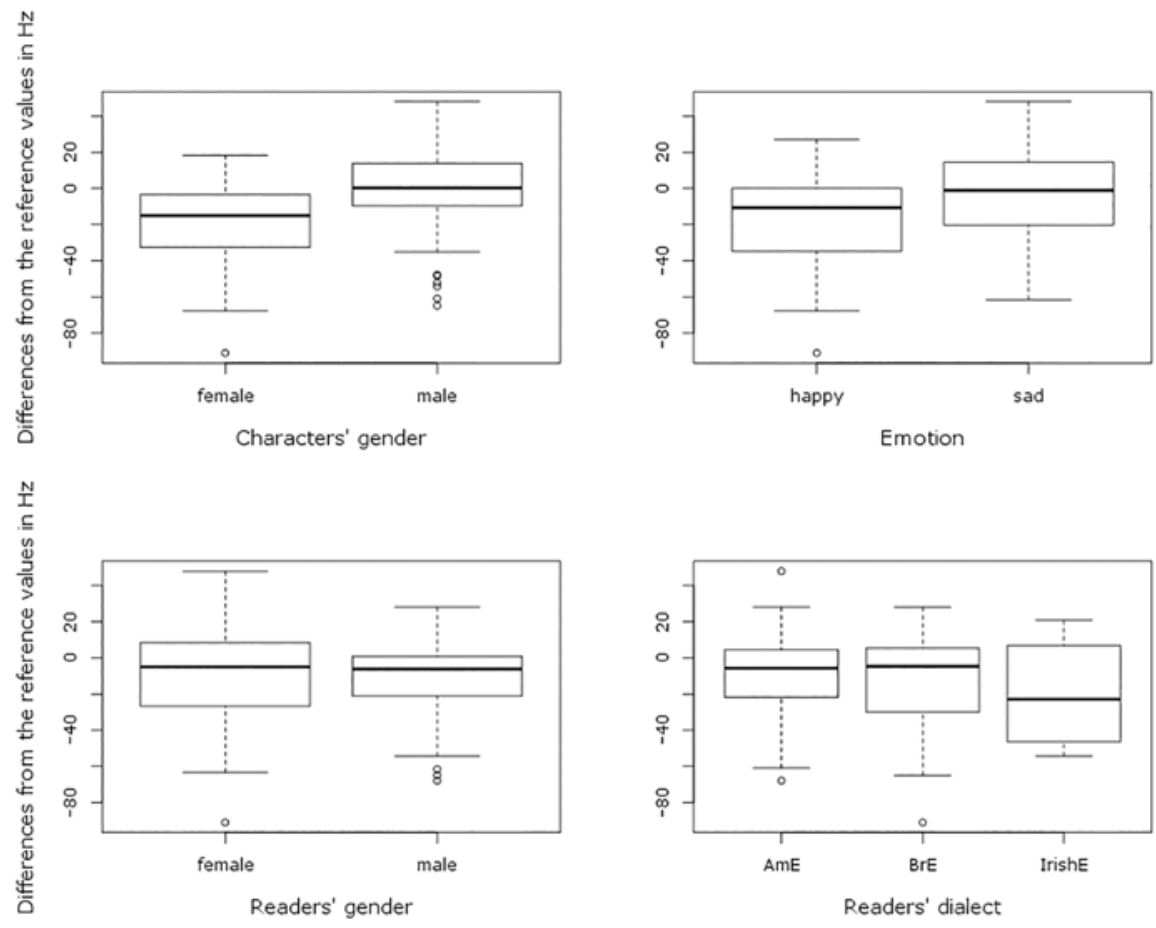

The effects of all four explanatory variables on F0 analysed with the KruskalWallis rank sum test

Figure 3 shows boxplots comparing the differences between the values of F0 in whole chapters and in extracts in terms of the four explanatory variables. It is readily visible that data divided according to readers' gender (see the boxplot in the lower left-hand corner in Figure 3) do not differ in any significant way. This is confirmed by the high p-value of 0.5271 obtained in the Kruskal-Wallis test summarised in Table 1 . All this suggests that any concerns regarding confound- 
ing effects of readers' gender on F0 differences under analysis may be rejected.

A similar conclusion should be drawn for readers' dialect. Both the boxplot in the lower right-hand corner in Figure 3 and the results of the Kruskal-Wallis test presented in Table $1(\mathrm{p}=0.7508)$ indicate that this variable neither affects the behaviour of F0. These findings make the conclusions reached in Section 4.1 more reliable. What is more, the results presented in Section 4.1 are further corroborated by the clear differences in the samples divided according to the characters' gender. The boxplot in the upper left-hand side of Figure 3 indicates that extracts with female characters are associated with a much higher F0 in comparison to the values measured in the corresponding whole chapters than is the case with extracts including male characters. This is confirmed by the result of the Kruskal-Wallis test presented in Table 1 ( $p<0.0001)$. Finally, the influence of the variable of emotion on F0 is also consistent with the tendency established in Section 4.1. The values of F0 in excerpts involving happiness are clearly higher than the corresponding values in whole chapters, while in fragments in which the emotion of sadness is expressed such a shift is not readily observable (see the graph in the upper right-hand corner in Figure 3). What is more important, the difference in the way the two levels of the explanatory variable affect F0 is statistically relevant. The Kruskal-Wallis test results summarised in Table 1 indicate that the p-value is only 0.0006 .

Despite the problems with the normality of the samples analysed in this section, it is worth mentioning that the results of ANOVA also indicate that both characters' gender and the emotion expressed have primary effects $(p=0.000126$ and 0.000224 , respectively). More importantly, interaction between the two factors is statistically relevant $(\mathrm{p}=0.026093)$. The corresponding interaction plot reveals the behaviour of these two factors, which was, to a certain extent, predicted before conducting the experiment (see the discussion in Section 2). Fragments with female characters expressing happiness represent the largest upward shift of F0 and male characters' expression of sadness has the opposite effect on F0. On the other hand, there is not much difference between the results for female characters expressing sadness and male characters expressing happiness. The discussion in the second part of Section 4.1 suggested that it is the variable of emotion which dominates over the variable of gender. However, this does not exclude the fact that the two factors mutually influence each other. Such a conclusion seems perfectly natural, although the exact results of ANOVA cited above should be interpreted with caution because of the problems with the normality of samples.

\begin{tabular}{ccccc} 
& $\begin{array}{c}\text { Characters' } \\
\text { gender }\end{array}$ & Emotion & $\begin{array}{c}\text { Readers' } \\
\text { gender }\end{array}$ & $\begin{array}{c}\text { Readers' } \\
\text { dialect }\end{array}$ \\
\cline { 2 - 5 } Kruskal-Wallis & 15.912 & 11.6571 & 0.4 & 0.5733 \\
$\begin{array}{c}\text { chi-squared } \\
\text { df }\end{array}$ & 1 & 1 & 1 & 2 \\
p-value & $<0.0001$ & 0.0006 & 0.5271 & 0.7508
\end{tabular}

Table 1. The Kruskal-Wallis rank sum test results for the effects of the four explanatory variables on the differences between the values of Fo measured in whole chapters and the values of Fo measured in extracts 
The effects of all explanatory variables on $\mathrm{SD}$ of $\mathrm{F} 0$ examined in a four-way analysis of variance (ANOVA)

Table 2 summarises the results of ANOVA for the effects of all four explanatory variables on pitch variability. It is plainly visible that neither readers' gender $(\mathrm{p}=$ $0.4018)$ nor their dialect $(p=0.5124)$ has any effect on the sample of differences between the variability of their voices in whole chapters and in the extracts cited in the appendices. In other words, these two additional explanatory variables do not influence the response variable of pitch variability. This reinforces the interpretation of the results reported in Section 4.1: because any confounding effects of speakers' gender and dialect on SD of F0 may safely be rejected.

Another interesting observation is that characters' gender does not affect SD of F0 either $(p=0.2138)$. This is in agreement with the results discussed in Section 4.1, where it was observed that pitch variability always depends on the emotion expressed and is never really controlled by the characters' gender.

The results summarised in Table 2 do not indicate any interactions between explanatory variables. The only significant result concerns the category of emotion $(\mathrm{p}<0.0001)$. All this suggests that as far as the behaviour of pitch variability is concerned, the explanatory variable of emotion is dominant in relation to other explanatory variables such as characters' gender (see also the discussion in Section 5).

\begin{tabular}{|c|c|c|c|c|c|}
\hline & Df & Sum Sq & Mean Sq & F value & $\operatorname{Pr}(>\mathrm{F})$ \\
\hline Characters' gender & 1 & 284.4 & 284.4 & 1.5651 & 0.2138 \\
\hline Emotion & 1 & 4746.9 & 4746.9 & 26.1221 & $1.54 \mathrm{E}-006$ \\
\hline Readers' gender & 1 & 128.8 & 128.8 & 0.7088 & 0.4018 \\
\hline Readers' dialect & 2 & 244.6 & 122.3 & 0.6731 & 0.5124 \\
\hline Characters' gender : Emotion & 1 & 28.3 & 28.3 & 0.1555 & 0.6941 \\
\hline Characters' gender : Readers' gender & 1 & 8 & 8 & 0.044 & 0.8343 \\
\hline Emotion : Readers' gender & 1 & 0.9 & 0.9 & 0.0049 & 0.9445 \\
\hline Characters' gender : Readers' dialect & 2 & 291.2 & 145.6 & 0.8012 & 0.4516 \\
\hline Emotion : Readers' dialect & 2 & 605.4 & 302.7 & 1.6658 & 0.1942 \\
\hline Readers' gender : Readers' dialect & 1 & 292.6 & 292.6 & 1.61 & 0.2074 \\
\hline Characters' gender : Emotion : Readers' gender & 1 & 319.8 & 319.8 & 1.7601 & 0.1876 \\
\hline Characters' gender : Emotion : Readers' dialect & 2 & 142 & 71 & 0.3907 & 0.6776 \\
\hline Characters' gender : Readers' gender : Readers' dialect & 1 & 138.1 & 138.1 & 0.7598 & 0.3855 \\
\hline Emotion : Readers' gender : Readers' dialect & 1 & 3.5 & 3.5 & 0.019 & 0.8906 \\
\hline Characters' gender : Emotion : Readers' gender : Readers' dialect & 1 & 79.7 & 79.7 & 0.4387 & 0.5093 \\
\hline Residuals & 100 & 18172.1 & 181.7 & & \\
\hline Significance codes: & & 0 ‘*** & 0.001 ‘** & $0.01^{\prime *}$ & 0.05 ‘’ \\
\hline
\end{tabular}

Table 2. ANOVA results for the effects of all four explanatory variables on shifts of pitch variability

\section{Discussion}

The results discussed in the second part of Section 4.1 revealed that in the fragments in which male characters express the emotion of happiness the mean values of both F0 and SD of F0 tend to increase. This suggests that in these contexts 
the "emotion" variable is the only influence on the response variables. It is worth adding that these results corroborate the findings on the vocal expression of happiness and sadness in the reading of prose reported in Stolarski (2015). One of the major conclusions reached in that paper was that the emotion of happiness is signalled by a distinct increase of both $\mathrm{F} 0$ and $\mathrm{SD}$ of $\mathrm{F} 0$. The results of the experiment described in the present study additionally suggest that this tendency seems considerably stronger than the opposite one which is, presumably, associated with the "gender" variable. The fact that the extracts are uttered by male characters does not result in the decrease of any of the response variables.

The analysis presented in the second part of Section 4.1 on female characters expressing the emotion of sadness yielded mixed results. On the one hand, the behaviour of F0 seems to be influenced mostly by the gender of the characters. The mean value of this variable tends to increase in comparison to the corresponding average values for entire chapters. On the other hand, SD of F0 is, again, dependent on the "emotion" variable and it tends to be lower. At first sight, such an outcome may appear somewhat confusing, but a closer examination of the results reported in Stolarski (2015) suggests a possible explanation. Namely, it was observed that sadness is signalled primarily by lowering SD of F0. Any decrease in the value of F0 is of secondary importance in expressing this emotion. The fact that in the present study SD of F0 is influenced by "sadness" rather than "female gender" and that both of the response variables are influenced by "happiness" rather than "male gender" could be explained by assuming that, in general, the variable of emotion is more influential than the other explanatory variable. In the cases involving "happiness" an increase in the values of F0 and SD of F0 may be observed because, typically, this emotion is associated with such phonetic changes. The opposite tendency for the "male gender" to lower the values of the two response variables is weaker and fully dominated by the emotion. In contrast, in examples which include "sadness" only changes in $\mathrm{SD}$ of $\mathrm{F} 0$ are caused by the emotion, because sadness is typically conveyed by a lower SD of F0. Any changes of F0 are secondary and the opposite tendency triggered by the "female gender" is in a position to take over the behaviour of this response variable. As a consequence, F0 tends to increase.

This interpretation of the evidence gathered in Section 4.1 is further supported by the results obtained in Section 4.2. The potential for the emotions of happiness and sadness to control the behaviour of SD of F0 has been proven statistically, while the corresponding potential of the "gender" category does not seem to affect the resulting values of SD of F0. Furthermore, it is worth recalling that the findings discussed in Section 4.2 exclude any possible confounding effects of additional factors such as readers' gender or dialect, which make the claims put forward in this study even stronger.

As indicated in Section 2, the results obtained in this paper may be interpreted in a more general sense. Even though further research is needed to conclusively prove such a suggestion, it is very likely that the broad category of emotion affects the reader's voice characteristics to a greater degree than the character's gender. To put it another way, other emotions, beyond happiness and sadness, may also play a dominant role in influencing the reader's voice. The particular emotion 
categories chosen in the present study are considered "prototypical" (see the discussion in Section 1.2) and it is highly probable that examining the interaction of the character's gender and other emotions would yield similar results.

In order to further corroborate the claims made above, future research needs to be conducted on audiobooks with the aim of exploring possible associations between the acoustic characteristics analysed in this study and other basic emotions. Moreover, the examination should be extended to include acoustic features other than the pitch. For example, not only is it important to take into consideration global statistics on the fundamental frequency in a given utterance, but also to observe intonation contours. Previous research has revealed that some patterns of this kind may be appropriate to express almost any emotion, but other contours are more suitable to signal only some affective states (Mozziconacci and Hermes, 1997). It has also been observed that intonation patterns may have independent effects on the way the emotional content of utterances are judged from other suprasegmental features (Ladd et al., 1985). Moreover, Rodero (2011) has proposed that contour type may be more representative of a given emotion than pitch level. The results reported in Bänziger and Scherer (2005) do not support such a claim, but the fact that intonation contours may play a crucial part in the vocal expression of emotions, especially in connection with other prosodic features, is clear.

An interesting example of an investigation which involves a large number of possible acoustic correlates of emotions is the study by Schuller, Wöllmer, Eyben and Rigoll (2009). They analysed expression of the "big six" emotions, as named by Ekman (1972), in terms of 1406 different features grouped into the three categories of prosodic, spectral and voice quality. Such a large number of response variables could be juxtaposed with a group of explanatory variables and a multiple regression analysis, similar to the one found in Banse and Scherer (1996), could be conducted.

\section{References}

Abdulla, Waleed H. and Nikola Kirilov Kasabov (2001) Improving speech recognition performance through gender separation. In: Proceedings of Artificial Neural Networks and Expert Systems International Conference (ANNES). Dunedin, New Zeland.

Alter, Kai, Erhard Rank, Sonja A. Kotz, Erdmut Pfeifer, Mireille Besson, Angela D. Friederici and Johannes Matiasek (1999) On the relations of semantic and acoustic properties of emotions. In: Proceedings of the 14th International Congress of Phonetic Sciences (ICPhS`99). San Francisco.

Anthony, Laurence (2014) AntConc (Version 3.4.3w) [Computer Software]. Tokyo: Waseda University.

Averill, James R. (2009) Constructivism (psychological perspectives). In: David Sander and Klaus R. Scherer (eds.) Oxford Companion to Emotion and the Affective Sciences. Oxford: Oxford University Press.

Banse, Rainer and Klaus R. Scherer (1996) Acoustic profiles in vocal emotion expression. Journal of Personality and Social Psychology 70(3), 614-636.

Bänziger, Tanja and Klaus R. Scherer (2005) The role of intonation in emotional expressions. Speech Communication 46(3), 252-267. 
Barret, Lisa Feldman (2006) Are emotions natural kinds? Perspectives on Psychological Science $1(1), 28-58$.

Bergmann, Günther, Thomas Goldbeck and Klaus R. Scherer (1988) Emotionale Eindruckswirkung von prosodischen Sprechmerkmalen. Zeitschrift Für Experimentelle Und Angewandte Psychologie 35(2), 167-200.

Bezooijen, Renée (1984) Characteristics and Recognizability of Vocal Expressions of Emotion. Dordrecht, Netherlands: Foris Publications.

Birdwhistell, Ray L. (1963) The kinesic level in the investigation of the emotions. In: P. H. Knapp (ed.) Expression of the Emotions in Man. New York: International Universities Press.

Boersma, Paul and David Weenink (2014) Praat, a System for Doing Phonetics by Computer (Version 5.4.01) [Computer Software]. Amsterdam: University of Amsterdam.

Boves, Lou (1984) The Phonetic Basis of Perceptual Ratings of Running Speech. Dordrecht, Holland; Cinnaminson, U.S.A: Foris Publications.

Breitenstein, Caterina, Diana Van Lancker and Irene Daum (2001) The contribution of speech rate and pitch variation to the perception of vocal emotions in a German and an American sample. Cognition and Emotion 15(1), 57-79.

Cahn, Janet Elizabeth (1989) Generating Expression in Synthesized Speech (Ph.D. thesis). Massachusetts Institute of Technology, Cambridge, Massachusetts.

Cahn, Janet Elizabeth (1990) The generation of affect in synthesized speech. Journal of the American Voice I/O Society 8, 1-19.

Carlson, Rolf, Björn Granström and Inger Karlsson (1991) Experiments with voice modelling in speech synthesis. Speech Communication 10(5-6), 481-489.

Childers, Donald G. and Ke Wu (1991) Gender recognition from speech. Part II: Fine analysis. The Journal of the Acoustical Society of America 90(4), 1841-1856.

Clark, Jason A. (2010) Relations of homology between higher cognitive emotions and basic emotions. Biology and Philosophy 25(1), 75-94.

Coleman, Robert F. and Robert Williams (1979) Identification of emotional states using perceptual and acoustic analyses. In: Transcript of the 8th Symposium: Care of the Professional Voice, Part I. The Voice Foundation, New York.

Collier, William G. and Timothy L. Hubbard (1998) Judgments of happiness, brightness, speed, and tempo change of auditory stimuli varying in pitch and tempo. Psychomusicology $17(1 / 2), 36-55$.

Collier, William G. and Timothy L. Hubbard (2001) Musical scales and evaluations of happiness and awkwardness: Effects of pitch, direction, and scale mode. American Journal of Psychology 114(3), 355-375.

Costa, Tommaso, Franco Cauda, Manuella Crini, Mona-Karina Tatu, Alessia Celeghin, Beatrice de Gelder and Marco Tamietto (2014) Temporal and spatial neural dynamics in the perception of basic emotions from complex scenes. Social Cognitive and Affective Neuroscience 9(11), 1690-1703.

Costanzo, Frances S., Norman N. Markel and Philip R. Costanzo (1969) Voice quality profile and perceived emotion. Journal of Counseling Psychology 16(3), 267.

Cummings, Kathleen E. and Mark A. Clements (1995) Analysis of the glottal excitation of emotionally styled and stressed speech. The Journal of the Acoustical Society of America 98(1), 88-98.

Darwin, Charles, Paul Ekman and Phillip Prodger (1998) The Expression of the Emotions in Man and Animals. Oxford: Oxford University Press (original work published 1872).

Davitz, Joel R. (1964) Auditory correlates of vocal expressions of emotional meaning. The Communication of Emotional Meaning 101-112.

Eibl-Eibesfeldt, Irenaus (1973) The expressive behavior of the deaf-and-blind born. In: M. Cranach and I. Vine (eds.) Social Communication and Movement. New York: Academic Press. 
Ekman, Paul (1972) Universal and cultural differences in facial expression of emotion. In: Nebraska Symposium on Motivation. Lincoln: University of Nebraska Press.

Ekman, Paul (1980) Biological and cultural contributions to body and facial movement in the expression of emotions. In: A. O. Rorty (ed.) Explaining Emotions. Berkeley: University of California Press.

Ekman, Paul (1999) Basic emotions. In: T. Dalgleish and M. Power (eds.) Handbook of Cognition and Emotion. Sussex, UK: John Wiley and Sons.

Ekman, Paul and W. V. Friesen (1971) Constants across cultures in the face and emotion. Journal Of Personality And Social Psychology 17(2), 124-129.

Eldred, Stanley H. and Douglas B. Price (1958) A linguistic evaluation of feeling states in psychotherapy. Psychiatry 21(2), 115-121.

Ellgring, Heiner and Klaus R. Scherer (1996) Vocal indicators of mood change in depression. Journal of Nonverbal Behavior 20(2), 83-110.

Fairbanks, Grant and Wilbert Pronovost (1939) An experimental study of the pitch characteristics of the voice during the expression of emotion. Speech Monographs 6(1), 87-104.

Farinelli, Marina, Jaak Panksepp, Daniela Cevolani, Laura Gestieri, Monica Maffei, Raffaele Agati, ... Georg Northoff (2015) Do brain lesions in stroke affect basic emotions and attachment? Journal of Clinical and Experimental Neuropsychology 1-19.

Fernández-Sánchez, Marta, Marta Giménez-Dasí and Laura Quintanilla (2014) Toddlers' understanding of basic emotions: Identification, labeling and causality / La comprensión temprana de las emociones básicas: Identificación, etiquetado y causalidad. Infancia y Aprendizaje 37(3), 569-601.

Fitzsimons, Mary, Noirin Sheahan and Hugh Staunton (2001) Gender and the integration of acoustic dimensions of prosody: Implications for clinical studies. Brain and Language 78(1), 94-108.

Fonagy, Ivan (1978) A new method of investigating the perception of prosodic features. Language and Speech 21(1), 34-49.

Frick, Robert W. (1985) Communicating emotion: The role of prosodic features. Psychological Bulletin 97(3), 412-429.

Frijda, Nico H. and W. Gerrod Parrott (2011) Basic emotions or ur-emotions? Emotion Review 3(4), 406-415.

Fulcher, John Scott (1942) 'Voluntary' facial expression in blind and seeing children. Archives of Psychology (Columbia University) 38(272), 1-49.

Gelfer, Marylou Pausewang and Victoria A. Mikos (2005) The relative contributions of speaking fundamental frequency and formant frequencies to gender identification based on isolated vowels. Journal of Voice 19(4), 544-554.

Glass, Sandra T., Elisabeth Lingg and Eva Heuberger (2014) Do ambient urban odors evoke basic emotions? Frontiers in Psychology 5, Article 340.

Gobl, Christer and Ailbhe Ní Chasaide (2003) The role of voice quality in communicating emotion, mood and attitude. Speech Communication 40(1/2), 189-212.

Graddol, David (1982) Understanding and describing long term pitch of voice: some methodological considerations. In: Intonation in Discourse. School of Education, The Open University.

Griffiths, Paul E. (1989) Folk, functional and neurochemical aspects of mood. Philosophical Psychology 2(1), 17-30.

Griffiths, Paul E. (1990) Modularity, and the psychoevolutionary theory of emotion. Biology and Philosophy 5(2), 175-196.

Hargreaves, William A., John A. Starkweather and K. H. Blacker (1965) Voice quality in depression. Journal of Abnormal Psychology 70(3), 218-220.

Harré, Rom (1986) The Social Construction of Emotions. Oxford, New York: Blackwell.

Havrdová, Z. and M. Morávek (1979) Changes of the voice expression during suggestively influenced states of experiencing. Activitas Nervosa Superior 21(1), 33-35. 
Henton, Caroline G. (1989) Fact and fiction in the description of female and male pitch. Language and Communication 9(4), 299-311.

Henton, Caroline G. (1995) Pitch dynamism in female and male speech. Language and Communication 15(1), 43-61.

Henton, Caroline G. and R. Anthony W. Bladon (1985) Breathiness in normal female speech: Inefficiency versus desirability. Language and Communication 5(3), 221-227.

Höffe, Wilhelm L. (1960) Über Beziehungen von Sprachmelodie und Lautstärke. Phonetica 5(3-4), 129-159.

Holmberg, Eva B., Robert E. Hillman and Joseph S. Perkell (1988) Glottal airflow and transglottal air pressure measurements for male and female speakers in soft, normal, and loud voice. The Journal of the Acoustical Society of America 84(2), 511-529.

$\mathrm{Hu}$, Yakun, Dapeng Wu and Antonio Nucci (2012) Pitch-based gender identification with two-stage classification. Security and Communication Networks 5(2), 211-225.

Huron, David (2008) A comparison of average pitch height and interval size in major-and minor-key themes: Evidence consistent with affect-related pitch prosody. Empirical Musicology Review 3(2), 59-63.

Huron, David, Gary Yim and Parag Chordia (2010) The effect of pitch exposure on sadness judgments: An association between sadness and lower than normal pitch. In: Proceedings of the 11th International Conference on Music Perception and Cognition.

Huttar, George L. (1968) Relations between prosodic variables and emotions in normal American English utterances. Journal of Speech, Language, and Hearing Research 11(3), 481-487.

Izard, Carroll E. (2007) Basic emotions, natural kinds, emotion schemas, and a new paradigm. Perspectives on Psychological Science 2(3), 260-280.

Jassem, Wiktor (1971) Pitch and compass of the speaking voice. Journal of the International Phonetic Association 1(02), 59-68.

Johnson, William F., Robert N. Emde, Klaus R. Scherer and Mary D. Klinnert (1986) Recognition of emotion from vocal cues. Archives of General Psychiatry 43(3), 280-283.

Johnstone, Tom and Klaus R. Scherer (1999) The effects of emotions on voice quality. In: Proceedings of the XIVth International Congress of Phonetic Sciences. Berkeley, San Francisco: University of California.

Jung, E., A. Th Schwarzbacher, K. Humphreys and R. Lawlor (2002) Application of realtime AMDF pitch-detection in a voice gender normalisation system. In: John H. L. Hansen and Bryan Pellom (eds.) Proceedings of 7th International Conference on Spoken Language Processing. Denver, Colorado: University of Colorado at Boulder.

Kaiser, L. (1962) Communication of affects by single vowels. Synthese 14(4), 300-319.

Kappas, Arvid, Ursula Hess and Klaus R. Scherer (1991) Voice and emotion. In: R. S. Feldman and B. Rim (eds.) Fundamentals of Nonverbal Behavior. Paris, France: Editions de la Maison des Sciences de l'Homme.

Kennedy, Anna (2012) Contextualising the concept of the basic emotion: An historical examination of the theories of Alexander Bain and Herbert Spencer. History and Philosophy of Psychology 14(2), 36-42.

Kenny, Anthony (1963) Action, Emotion and Will. London: Routledge and K. Paul.

Kent, Raymond D. and Charles Read (1992) The Acoustic Analysis of Speech. San Diego, California: Singular Publishing Group.

Klainginna, Paul R. and Anne M. Kleinginna (1981) A categorized list of emotion definitions, with suggestions for a consensual definition. Motivation and Emotion 5(4), 345-379.

Klatt, Dennis H. (1987) Acoustic correlates of breathiness: First harmonic amplitude, turbulence noise, and tracheal coupling. The Journal of the Acoustical Society of America 82(Suppl. 1), S91.

Klatt, Dennis H. and L. C. Klatt (1990) Analysis, synthesis, and perception of voice quality variations among female and male talkers. The Journal Of The Acoustical Society of America 87(2), 820-857. 
Kotlyar, G. M. and V. P. Morozov (1976) Acoustical correlates of emotional content of vocalized speech. Soviet Physics Acoustics - Ussr 22(3), 208-211.

Labarre, Weston (1947) The cultural basis of emotions and gestures. Journal of Personality 16(1), 49-68.

Ladd, D. Robert, Kim EA Silverman, Frank Tolkmitt, Günther Bergmann and Klaus R. Scherer (1985) Evidence for the independent function of intonation contour type, voice quality, and F0 range in signaling speaker affect. The Journal of the Acoustical Society of America 78(2), 435-444.

Latinus, Marianne and Margot J. Taylor (2012) Discriminating male and female voices: Differentiating pitch and gender. Brain Topography 25(2), 194-204.

Leinonen, Lea, Tapio Hiltunen, Ilkka Linnankoski and Maija-Liisa Laakso (1997) Expression of emotional-motivational connotations with a one-word utterance. The Journal of the Acoustical Society of America 102(3), 1853-1863.

Lewinski, Peter, M. Tim and Crystal Butler (2014) Automated facial coding: Validation of basic emotions and FACS AUs in FaceReader. Journal of Neuroscience, Psychology, and Economics 7(4), 227-236.

Linville, Sue Ellen (1996) The sound of senescence. Journal of Voice 10(2), 190-200.

Lyons, William (1980) Emotion. Cambridge: Cambridge University Press.

Machado, Sheron, Emília Duarte, Júlia Teles, Lara Reis and Francisco Rebelo (2012) Selection of a voice for a speech signal for personalized warnings: the effect of speaker's gender and voice pitch. Work 41, 3592-3598.

Markel, Norman N., Monte F. Bein and Judith A. Phillis (1973) The relationship between words and tone-of-voice. Language and Speech 16(1), 15-21.

Mason, William A. and John P. Capitanio (2012) Basic emotions: A reconstruction. Emotion Review 4(3), 238-244.

McAdams, Stephen and Albert Bregman (1979) Hearing musical streams. Computer Music Journal 3(4), 26-60.

McConnell-Ginet, Sally (1983) Intonation in a man's world. In: Barrie Thome, Cheris Kramarae and Nancy Henly (eds.) Language, Gender, and Society. Rowley, MA: New Bury House.

Minitab 16.2.3 Statistical Software [Computer Software] (2012). State College, PA: Minitab, Inc.

Moses, Paul J. (1954) The Voice of Neurosis. Oxford, England: Grune and Stratton.

Mozziconacci, Sylvie Jeanette Laure (1995) Pitch variations and emotion in speech. In: Proceedings of the XIIIth International Congress of Phonetic Sciences. Stockholm.

Mozziconacci, Sylvie Jeanette Laure (1998) Speech variability and emotion: Production and perception. Eindhoven: Technische Universiteit Eindhoven.

Mozziconacci, Sylvie Jeanette Laure and Dik J. Hermes (1997) A study of intonation patterns in speech expressing emotion or attitude: Production and perception. IPO Annual Progress Report 32, 154-160.

Murray, Iain R. and John L. Arnott (1993) Toward the simulation of emotion in synthetic speech: A review of the literature on human vocal emotion. The Journal of the Acoustical Society of America 93(2), 1097-1108.

Murray, Iain R. and John L. Arnott (1995) Implementation and testing of a system for producing emotion-by-rule in synthetic speech. Speech Communication 16(4), 369-390.

Nesse, Randolph M. (1990) Evolutionary explanations of emotions. Human Nature 1(3), 261-289.

Nesse, Randolph M. and Phoebe C. Ellsworth (2009) Evolution, emotions, and emotional disorders. American Psychologist 64(2), 129-139.

Ohara, Yumiko (2003) Performing gender through voice pitch: A cross-cultural analysis of Japanese and American English. In: Ursula Pasero and Friederike Braun (eds.) Wahrnehmung Und Herstellung von Geschlecht. Opladen/Wiesbaden: Westdeutsche Verlag. 
Ortony, Andrew and Terence J. Turner (1990) What's basic about basic emotions? Psychological Review 97(3), 315-331.

Ostwald, Peter F. (1963) Soundmaking. The Acoustic Communication of Emotion. Oxford, England: Charles C. Thomas.

Panksepp, Jaak (2007) Neurologizing the psychology of affects: How appraisal-based constructivism and basic emotion theory can coexist. Perspectives on Psychological Science 2(3), 281-296.

Parris, Eluned S. and Michael J. Carey (1996) Language independent gender identification. In: IEEE International Conference on Acoustics, Speech, and Signal Processing.

Pell, Marc D. (1999) Fundamental frequency encoding of linguistic and emotional prosody by right hemisphere-damaged speakers. Brain and Language 69(2), 161-192.

Pernet, Cyril R. and Pascal Belin (2012) The role of pitch and timbre in voice gender categorization. Frontiers in Psychology 3, Article 23.

Peterson, Gordon E. and Harold L. Barney (1952) Control methods used in a study of the vowels. The Journal of the Acoustical Society of America 24(2), 175-184.

Plutchik, Robert (1980) Emotion: A Psychoevolutionary Synthesis. Harper and Row.

Plutchik, Robert (1997) The circumplex as a general model of the structure of emotions and personality. In: R. Plutchik and H. R. Conte (eds.) Circumplex Models of Personality and Emotions. Washington, DC, US: American Psychological Association.

Plutchik, Robert (2000) Emotions in the Practice of Psychotherapy: Clinical Implications of Affect Theories. Washington, DC, US: American Psychological Association.

Plutchik, Robert (2001a) Integration, differentiation, and derivatives of emotion. Evolution and Cognition 7(2), 114-125.

Plutchik, Robert (2001b) The nature of emotions. American Scientist 89(4), 344-350.

R Development Core Team (2013) R: A Language and Environment for Statistical Computing (Version 3.0.3) [Computer Software]. Vienna, Austria.

Razak, Aishah Abd, Mohd Izani Zainal Abidin and Ryoichi Komiya (2003) Emotion pitch variation analysis in Malay and English voice samples. In: The 9th Asia-Pacific Conference on Communications 2003.

Reisenzein, Rainer (2000) Exploring the strength of association between the components of emotion syndromes: The case of surprise. Cognition and Emotion 14(1), 1-38.

Reubold, Ulrich, Jonathan Harrington and Felicitas Kleber (2010) Vocal aging effects on F0 and the first formant: A longitudinal analysis in adult speakers. Speech Communication 52(7), 638-651.

Rodero, Emma (2011) Intonation and emotion: Influence of pitch levels and contour type on creating emotions. Journal of Voice 25(1), e25-e34.

Rumsey, Deborah J. (2011) Statistics for Dummies. Hoboken, N.J.: John Wiley and Sons.

Russell, James A. (2003) Core affect and the psychological construction of emotion. Psychological Review 110(1), 145-172.

Russell, James A. and Lisa Feldman Barrett (1999) Core affect, prototypical emotional episodes, and other things called emotion: Dissecting the elephant. Journal of Personality and Social Psychology 76(5), 805-819.

Saarimäki, Heini, Athanasios Gotsopoulos, Iiro P. Jääskeläinen, Jouko Lampinen, Patrik Vuilleumier, Riitta Hari, Mikko Sams and Lauri Nummenmaa (2015) Discrete neural signatures of basic emotions. Cerebral Cortex Online publication.

Scheff, Thomas (2015) Toward defining basic emotions. Qualitative Inquiry 21(2), 111-121.

Scherer, Klaus R. (1981) Speech and emotional states. In: J. Darby (ed.) Speech Evaluation in Psychiatry. New York, 26(6), 2563-2573.

Scherer, Klaus R. (1982) Methods of research on vocal communication: Paradigms and parameters. In: Klaus R. Scherer and Paul Ekman (eds.) Handbook of Methods in Nonverbal Behavior Research. Cambridge: Cambridge University Press. 
Scherer, Klaus R. (1986) Vocal affect expression: A review and a model for future research. Psychological Bulletin 99(2), 143-165.

Scherer, Klaus R. (1989) Vocal measurement of emotion. In: Robert Plutchik and Henry Kellerman (eds.) Emotion: Theory, Research, and Experience.

Scherer, Klaus R. (1994) Affect bursts. In: S. Van Goosen, N. Van de Poll and J. Sergeant (eds.) Emotions: Essays on Emotion Theory. Hillsdale, NJ: Lawrence Erlbaum.

Scherer, Klaus R. (1995) Expression of emotion in voice and music. Journal of Voice 9(3), 235-248.

Scherer, Klaus R. and James S. Oshinsky (1977) Cue utilization in emotion attribution from auditory stimuli. Motivation and Emotion 1(4), 331-346.

Schötz, Susanne (2006) Perception, Analysis and Synthesis of Speaker Age. Lund: Lund University.

Schötz, Susanne (2007) Acoustic analysis of adult speaker age. In: Christian Müller (ed.) Speaker Classification, Vol. 4343 of Lecture Notes in Computer Science/Artificial Intelligence. Berlin/Heidelberg/New York: Springer.

Schröder, Marc (2003) Experimental study of affect bursts. Speech Communication 40(1), 99-116.

Schuller, Björn, Martin Wöllmer, Florian Eyben and Gerhard Rigoll (2009) Prosodic, spectral or voice quality? Feature type relevance for the discrimination of emotion pairs. In: Sylvie Hancil (ed.) The Role of Prosody in Affective Speech. New York: Peter Lang.

Skinner, E. Ray (1935) A calibrated recording and analysis of the pitch, force and quality of vocal tones expressing happiness and sadness. Communications Monographs 2(1), 81-137.

Sobin, Christina and Murray Alpert (1999) Emotion in speech: The acoustic attributes of fear, anger, sadness, and joy. Journal of Psycholinguistic Research 28(4), 347-365.

Solomon, Robert (1976) The Passions. Garden City, N.Y.: Anchor Press/Doubleday.

Stibbard, Richard (2000) Automated extraction of ToBI annotation data from the Reading/Leeds emotional speech corpus. In: ISCA Tutorial and Research Workshop (ITRW) on Speech and Emotion. Belfast: Queen's University.

Stocker, Michael (1987) Emotional thoughts. American Philosophical Quarterly 24(1), 59-69.

Stolarski, Łukasz (2015) Pitch patterns in vocal expression of "happiness" and "sadness" in the reading aloud of prose on the basis of selected audiobooks. Research in Language 13(3).

Takagi, Sachiko, Saori Hiramatsu, Ken-ichi Tabei and Akihiro Tanaka (2015) Multisensory perception of the six basic emotions is modulated by attentional instruction and unattended modality. Frontiers in Integrative Neuroscience 9, 1.

Thompson, Jane (1941) Development of facial expression of emotion in blind and seeing children. Archives of Psychology 37, 1-47.

Titze, Ingo R. (1989) Physiologic and acoustic differences between male and female voices. The Journal Of The Acoustical Society Of America 85(4), 1699-1707.

Tolkmitt, F., H. Helfrich, R. Standke and Klaus R. Scherer (1982) Vocal indicators of psychiatric treatment effects in depressives and schizophrenics. Journal of Communication Disorders 15(3), 209-222.

Tooby, John and Leda Cosmides (1990) The past explains the present: Emotional adaptations and the structure of ancestral environments. Ethology and Sociobiology 11(4-5), $375-424$.

Vroomen, Jean, René Collier and Sylvie Jeanette Laure Mozziconacci (1993) Duration and intonation in emotional speech. In: Proceedings of the Third European Conference on Speech Communication and Technology. Berlin: ESCA.

Waksler, Rachelle (2001) Pitch range and women's sexual orientation. Word 52(1), 69-77.

Wallbott, Harald G. and Klaus R. Scherer (1986) Cues and channels in emotion recognition. Journal of Personality and Social Psychology 51(4), 690-699. 
Whitman, E. and D. J. Flicker (1966) A potential new measurement of emotional state: A preliminary report. Newark Beth-Israel Hospital 17, 167-172.

Williams, Carl E. and Kenneth N. Stevens (1969) On determining the emotional state of pilots during flight: An exploratory study. Aerospace Medicine 40, 1369-1372.

Williams, Carl E. and Kenneth N. Stevens (1972) Emotions and speech: Some acoustical correlates. The Journal of the Acoustical Society of America 52(4B), 1238-1250.

$\mathrm{Wu}$, Wei, Thomas Fang Zheng, Ming-Xing Xu and Huanjun Bao (2006) Study on speaker verification on emotional speech. In: Proceedings of Ninth International Conference on Spoken Language Processing, INTERSPEECH. Pittsburgh, Pennsylvania.

Xue, Steve An and Dimitar Deliyski (2001) Effects of aging on selected acoustic voice parameters: Preliminary normative data and educational implications. Educational Gerontology 27(2), 159-168.

Yuasa, Ikuko Patricia (2008) Culture and Gender of Voice Pitch: A Sociophonetic Comparison of the Japanese and Americans. London, Oakville: Equinox Publishing. 
Brno Studies in English 2020, 46 (1)

\begin{tabular}{|c|c|c|c|c|c|c|c|}
\hline مَ & $\stackrel{\bar{m}}{\bar{c}}$ & $\stackrel{\mathbb{F}}{\sigma}$ & $\widetilde{N}$ & $\stackrel{\text { qu}}{\vec{F}}$ & 序 & $\stackrel{+}{:}$ & $\stackrel{m}{\hat{i}}$ \\
\hline \begin{tabular}{l}
0 \\
\multirow{2}{*}{} \\
$\hat{\varphi}$
\end{tabular} & $\stackrel{\substack{\infty \\
\infty}}{\infty}$ & $\stackrel{\widehat{N}}{i}$ & $\begin{array}{l}\frac{\pi}{\tilde{S}} \\
\stackrel{0}{T}\end{array}$ & 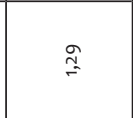 & 总 & $\begin{array}{l}\stackrel{8}{\circ} \\
\text { in }\end{array}$ & a \\
\hline$\stackrel{0}{\infty}$ & $\begin{array}{l}\stackrel{\tilde{b}}{\dot{q}} \\
\dot{q}\end{array}$ & 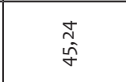 & 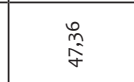 & : & 素 & 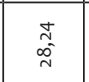 & $\begin{array}{l}\bar{F} \\
\stackrel{j}{4}\end{array}$ \\
\hline 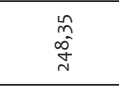 & 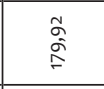 & $\begin{array}{l}\infty \\
\substack{\infty \\
\cdots \\
m}\end{array}$ & $\begin{array}{l}\tilde{\tilde{N}} \\
\tilde{N}\end{array}$ & $\begin{array}{l}\stackrel{\mathscr{h}}{\hat{n}} \\
\stackrel{\hat{n}}{n}\end{array}$ & 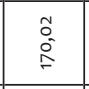 & 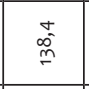 & 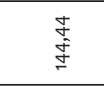 \\
\hline 产 & 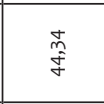 & 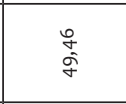 & 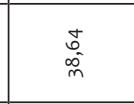 & స్. & 勇 & 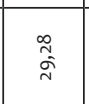 & $\begin{array}{l}\infty \\
\infty \\
\dot{m}\end{array}$ \\
\hline 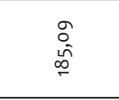 & $\begin{array}{c}\bar{\delta} \\
\substack{\infty \\
\infty}\end{array}$ & $\begin{array}{l}\text { ñ } \\
\text { of } \\
\stackrel{\rho}{n}\end{array}$ & 角 & 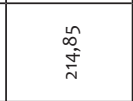 & 离 & $\begin{array}{l}\text { ते } \\
\tilde{\tilde{N}}\end{array}$ & 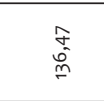 \\
\hline 岕 & 宸 & 岕 & 嵩 & 崖 & 嵩 & 崖 & 密 \\
\hline 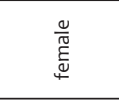 & 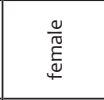 & $\frac{\frac{\alpha}{\tilde{g}}}{\tilde{E}}$ & 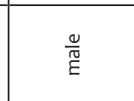 & 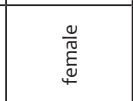 & $\frac{\stackrel{0}{\tilde{E}}}{\frac{\tilde{E}}{E}}$ & $\frac{\stackrel{\varrho}{\tilde{E}}}{\mathrm{E}}$ & $\frac{\stackrel{\varrho}{\tilde{E}}}{\tilde{E}}$ \\
\hline$\dot{\leftrightarrow \dot{\alpha}}$ & 今. & 这 & $\dot{\dot{\omega}}$ & $\stackrel{r}{ }$ & $\dot{\vec{F}}$ & $\dot{s}$ & $\stackrel{\ddot{\alpha}}{\mathrm{a}}$ \\
\hline 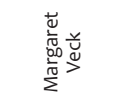 & 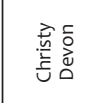 & 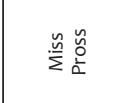 & 商咍 & 玹哀 & 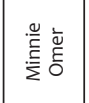 & 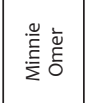 & 意 \\
\hline 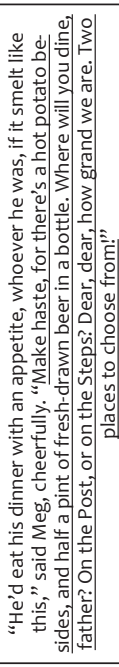 & 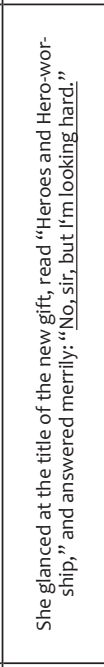 & 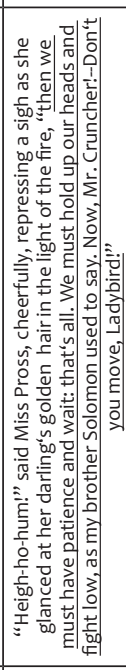 & 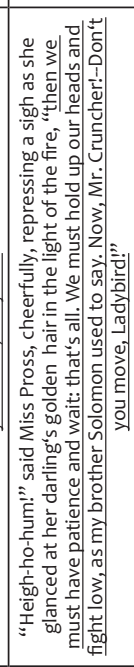 & 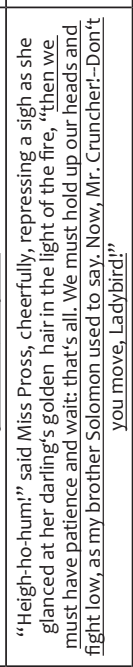 & 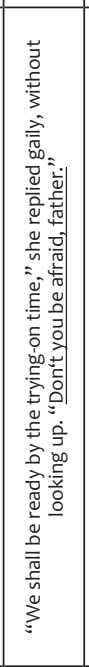 & 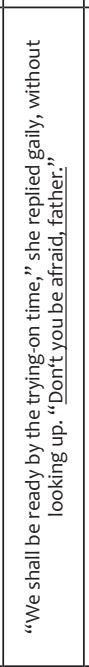 & 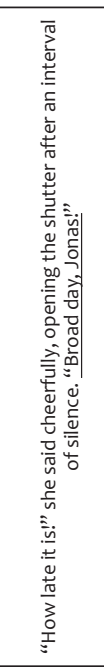 \\
\hline 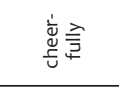 & $\begin{array}{l}\text { 产 } \\
\text { E्ञ }\end{array}$ & 离 & 离彥 & 离 & 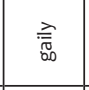 & 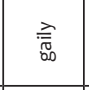 & 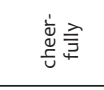 \\
\hline 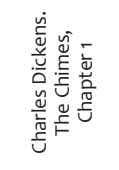 & 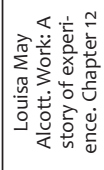 & 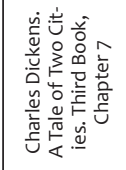 & 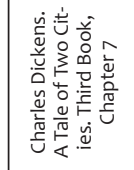 & 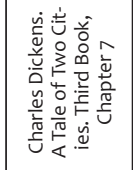 & 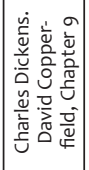 & 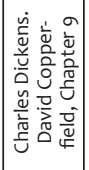 & 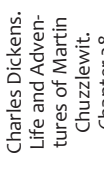 \\
\hline
\end{tabular}


Łukasz Stolarski

\begin{tabular}{|c|c|c|c|c|c|c|c|c|c|}
\hline 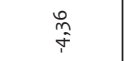 & $\begin{array}{l}m \\
f \\
w\end{array}$ & $\begin{array}{l}\underset{+}{f} \\
\stackrel{f}{f}\end{array}$ & $\begin{array}{l}\text { నิ } \\
\text { ָิ }\end{array}$ & $\begin{array}{l}\stackrel{\infty}{\infty} \\
\stackrel{-}{F}\end{array}$ & के & $\begin{array}{l}\infty \\
\stackrel{0}{F} \\
\stackrel{+}{+}\end{array}$ & $\underset{\infty}{\stackrel{+}{\Delta}}$ & $\stackrel{m}{\hat{m}}$ & 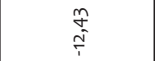 \\
\hline \begin{tabular}{l} 
nू \\
\multirow{\sigma}{\sigma}{}
\end{tabular} & $\begin{aligned} i \\
\text { in }\end{aligned}$ & $\begin{array}{l}\stackrel{0}{\hat{े}} \\
\hat{\varphi}\end{array}$ & $\stackrel{\substack{\infty \\
\infty_{n}^{\infty}}}{n}$ & $\vec{i}$ & $\begin{array}{l}\text { वे } \\
\text { ơ }\end{array}$ & $\begin{array}{l}\hat{m} \\
\underline{\underline{T}} \\
\underline{T}\end{array}$ & $\underset{\tilde{\tilde{\tau}}}{\tilde{\tilde{\tau}}}$ & 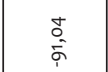 & $\frac{\infty}{p-p}$ \\
\hline 苟 & 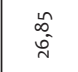 & $\begin{array}{l}m \\
\substack{m \\
\sim \\
\tilde{n}}\end{array}$ & $\begin{array}{l}\stackrel{m}{\hat{N}} \\
\hat{\sim}\end{array}$ & $\stackrel{f}{f}$ & $\stackrel{m}{\stackrel{m}{k}}$ & 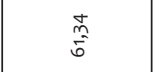 & $\begin{array}{l}m \\
\stackrel{m}{\sigma}\end{array}$ & $\begin{array}{l}\bar{\sigma} \\
\hat{i} \\
\text { n. }\end{array}$ & $\begin{array}{l}\text { 年 } \\
\text { f }\end{array}$ \\
\hline $\begin{array}{l}\hat{n} \\
\stackrel{n}{N}\end{array}$ & $\begin{array}{l}\stackrel{n}{\hat{N}} \\
\stackrel{\hat{N}}{=}\end{array}$ & 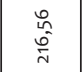 & 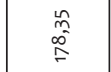 & 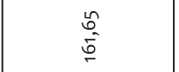 & $\begin{array}{l}\text { ڤ } \\
\text { مे } \\
\text { No }\end{array}$ & $\underset{\substack{\sim \\
\sim \sim \sim}}{\stackrel{\sim}{\sim}}$ & $\begin{array}{c}\infty \\
\stackrel{\infty}{m} \\
\stackrel{m}{\sim}\end{array}$ & 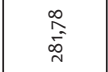 & 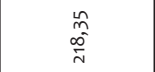 \\
\hline$\frac{\infty}{\frac{\sigma}{\sigma}}$ & $\begin{array}{l}\infty \\
\tilde{\mathcal{J}} \\
\tilde{\mathcal{J}}\end{array}$ & 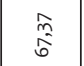 & $\begin{array}{l}\stackrel{0}{u} \\
\hat{f} \\
\tilde{f}\end{array}$ & $\begin{array}{l}\bar{n} \\
\underset{m}{\tilde{m}}\end{array}$ & $\begin{array}{l}\text { ¿े } \\
\hat{6}\end{array}$ & $\begin{array}{l}\text { D } \\
\text { í } \\
\text { in }\end{array}$ & $\begin{array}{l}\hat{b} \\
\infty^{0} \\
\sim\end{array}$ & 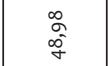 & 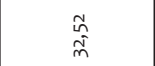 \\
\hline $\begin{array}{l}\hat{n} \\
\hat{\alpha} \\
\stackrel{\Omega}{\sigma}\end{array}$ & 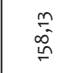 & $\begin{array}{l}\stackrel{0}{0} \\
\circ \\
\stackrel{0}{\sigma}\end{array}$ & 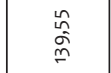 & $\begin{array}{l}\hat{\tilde{N}} \\
\hat{\omega} \\
\stackrel{n}{n}\end{array}$ & $\begin{array}{l}\text { مे } \\
\text { के } \\
\text { ปे }\end{array}$ & $\bar{N}$ & $\stackrel{\circ}{\stackrel{0}{E}}$ & 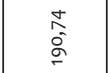 & 突 \\
\hline 岁 & 密 & 崖 & 岕 & 崖 & 崖 & 崖 & 崖 & 岕 & 岕 \\
\hline 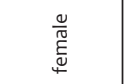 & 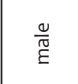 & 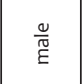 & $\frac{0}{\frac{0}{\pi}}$ & 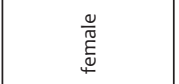 & 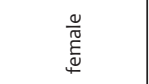 & 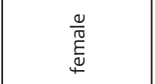 & 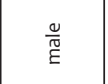 & 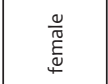 & 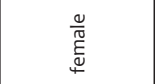 \\
\hline دَد & نّ & $\stackrel{\dot{\varphi}}{\stackrel{\dot{m}}{\dot{\Sigma}}}$ & $\stackrel{\text { ż }}{z}$ & $\stackrel{\stackrel{\dot{\varphi}}{\Sigma}}{\dot{\Sigma}}$ & ن̀ & $\stackrel{\check{\sim}}{\dot{\sim}}$ & $\stackrel{\circ}{\infty}$ & $\dot{z}$ & $\dot{\varphi}$ \\
\hline 逽 & 章营 & 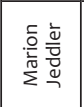 & 高竞 & 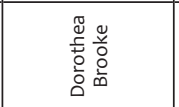 & 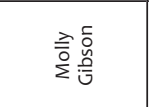 & 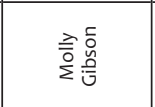 & 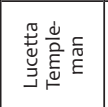 & 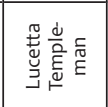 & $\begin{array}{l}\text { 气̃ } \\
\underline{\underline{\sigma}}\end{array}$ \\
\hline 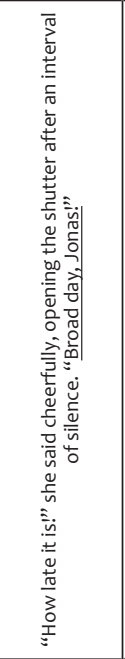 & 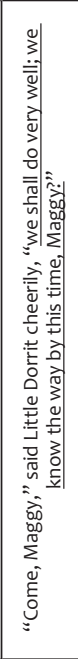 & 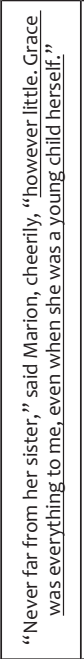 & 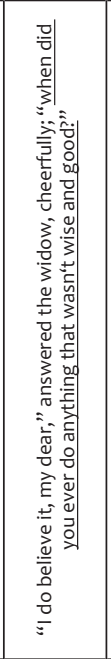 & 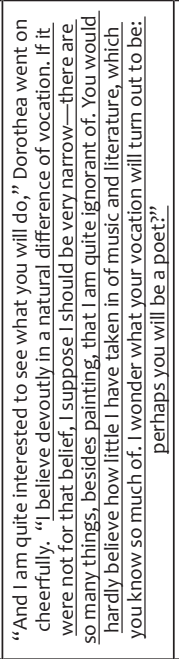 & 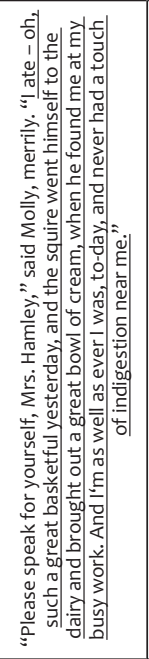 & 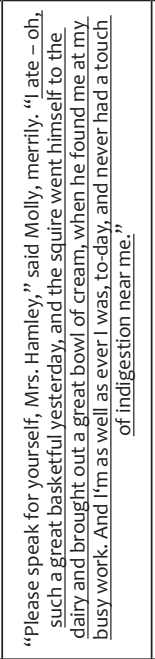 & 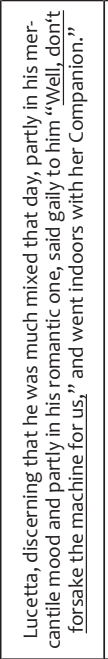 & 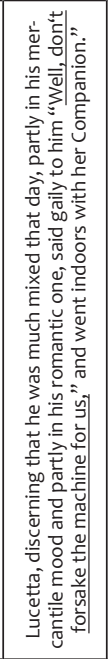 & 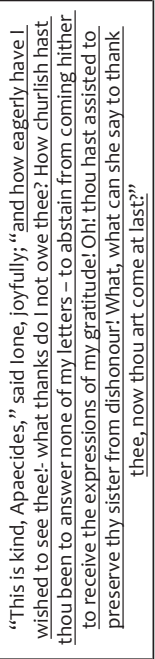 \\
\hline 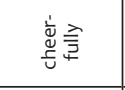 & 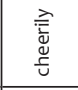 & 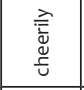 & 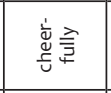 & 这 & $\begin{array}{l}\text { ते } \\
\stackrel{\bar{E}}{\mathrm{E}}\end{array}$ & $\begin{array}{l}\text { 产 } \\
\text { है }\end{array}$ & 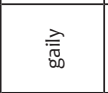 & 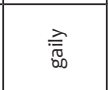 & $\begin{array}{l}\text { 흘 } \\
\text { 产 }\end{array}$ \\
\hline 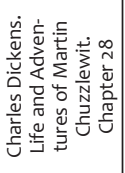 & 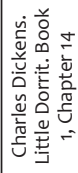 & 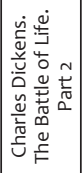 & 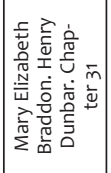 & 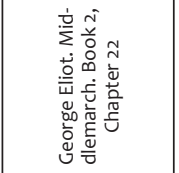 & 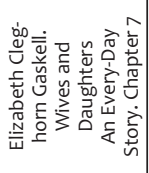 & 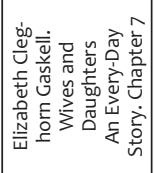 & 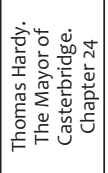 & 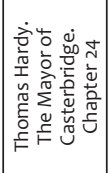 & 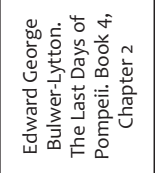 \\
\hline
\end{tabular}


Brno Studies in English 2020, 46 (1)

\begin{tabular}{|c|c|c|c|c|c|c|c|c|c|c|c|c|}
\hline 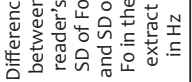 & $\stackrel{m}{m}$ & 商 & م્ & $\begin{array}{l}\overrightarrow{0} \\
\hat{\varphi}\end{array}$ & 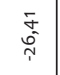 & 总 & $\underset{\substack{\tilde{\sigma} \\
\sim}}{ }$ & 字 & 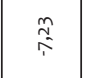 & 吾 & 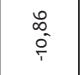 & $\stackrel{\circ}{i}$ \\
\hline 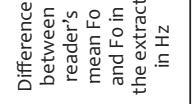 & ते & $\begin{array}{l}\text { के } \\
\hat{n}\end{array}$ & 尊 & 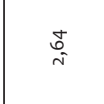 & $\stackrel{n}{\stackrel{n}{F}}$ & 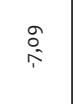 & $\bar{i}$ & 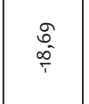 & 誉 & 袋 & 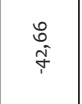 & 昰 \\
\hline 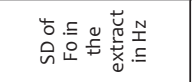 & 点 & 瓷 & 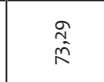 & مُ & 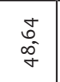 & $\begin{array}{l}m \\
\substack{\alpha \\
\sigma}\end{array}$ & 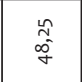 & $\begin{array}{l}\text { o } \\
\text { fo } \\
\end{array}$ & 管 & $\begin{array}{l}\infty \\
\sim \\
\sim \\
\sim\end{array}$ & 季 & $\frac{n}{m}$ \\
\hline 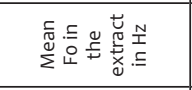 & 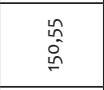 & 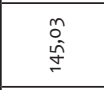 & 足 & 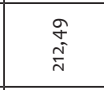 & 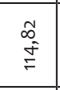 & $\begin{array}{l}\infty \\
\substack{\infty \\
\vdots \\
\vdots \\
\vdots}\end{array}$ & 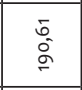 & 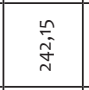 & 商 & 品 & $\begin{array}{l}\text { re } \\
\text { dै }\end{array}$ & 铵 \\
\hline 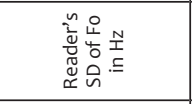 & 畹 & 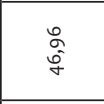 & $\frac{\Omega}{f}$ & 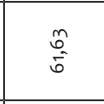 & $\underset{\tilde{\tau}}{\tilde{\tau}}$ & 亲 & బ్ & 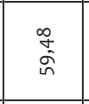 & $\begin{array}{l}\text { के } \\
\text { ळे }\end{array}$ & 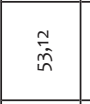 & 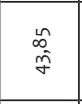 & 岕 \\
\hline 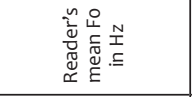 & 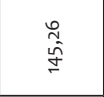 & 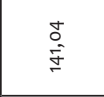 & $\bar{\sigma}$ & $\stackrel{m}{\frac{m}{n}}$ & 㝘 & 商 & 芯 & 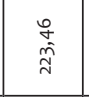 & 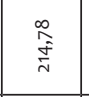 & 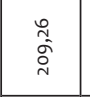 & 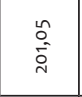 & 孚 \\
\hline 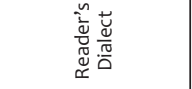 & 崖 & 岕 & 岕 & 岕 & 崖 & 宸 & 崖 & 崖 & 崖 & 宸 & 宸 & 密 \\
\hline 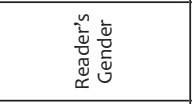 & $\frac{\stackrel{0}{\tilde{E}}}{\underline{E}}$ & 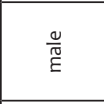 & $\frac{\stackrel{0}{\underline{m}}}{\underline{E}}$ & 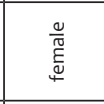 & $\frac{\frac{0}{\pi}}{\underline{E}}$ & 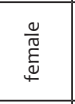 & 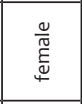 & 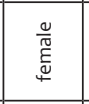 & 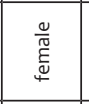 & 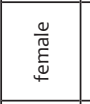 & 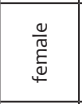 & 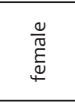 \\
\hline 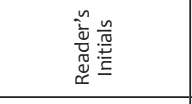 & $\dot{\infty}$ & $\dot{8}$ & ن.j & ப & $\dot{\ddot{c}}$ & 苟 & 竎 & $\stackrel{\breve{v}}{\dot{v}}$ & $\stackrel{\ddot{\Sigma}}{\dot{\Sigma}}$ & $\dot{\text { जे }}$ & $\dot{\Sigma}$ & $\dot{\phi}$ \\
\hline 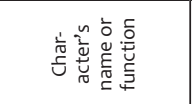 & 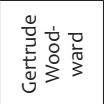 & 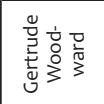 & 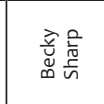 & 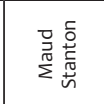 & 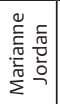 & 兽离 & 范产 & 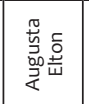 & 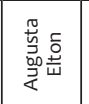 & 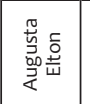 & 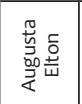 & 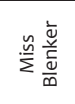 \\
\hline 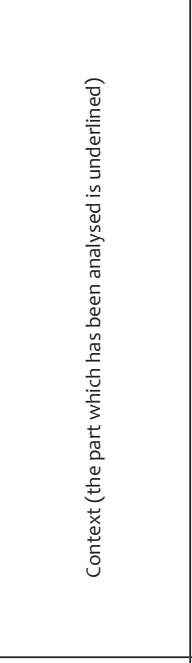 & 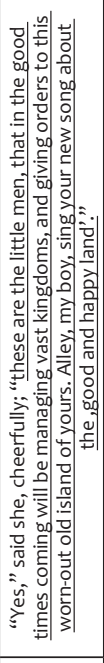 & 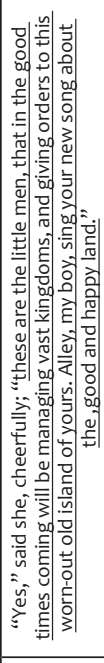 & 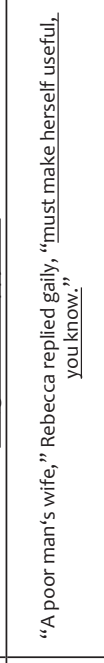 & 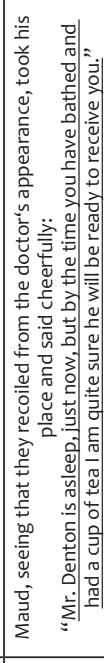 & 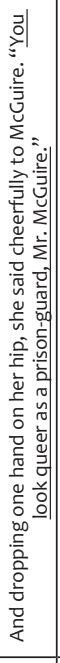 & 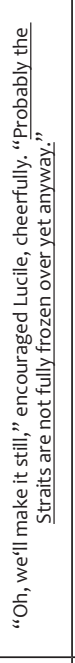 & 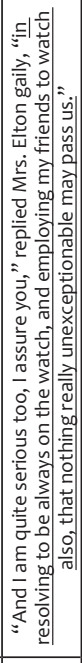 & 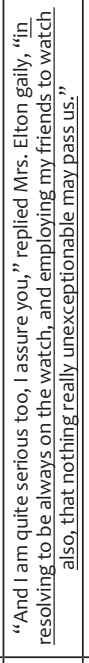 & 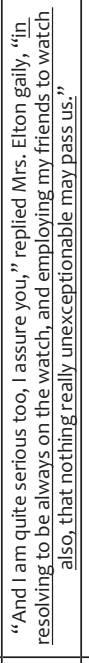 & 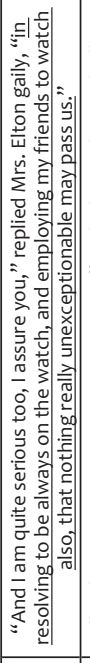 & 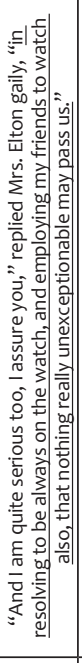 & 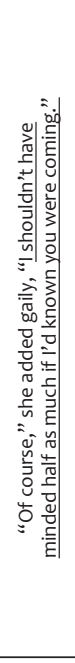 \\
\hline 总要 & 离言 & 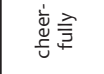 & 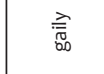 & 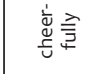 & 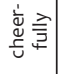 & 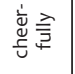 & 商 & 䇏 & 离 & 䇏 & 产 & 䇏 \\
\hline 䓂 & 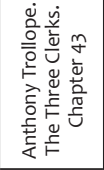 & 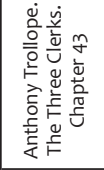 & 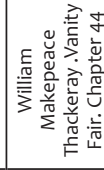 & 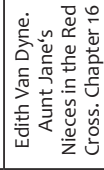 & 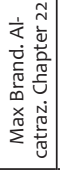 & 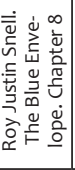 & 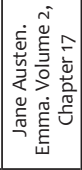 & 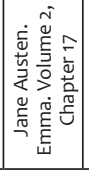 & 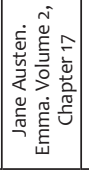 & 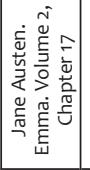 & 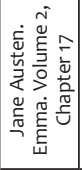 & 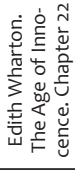 \\
\hline
\end{tabular}




\begin{tabular}{|c|c|c|c|c|c|c|c|c|c|c|}
\hline 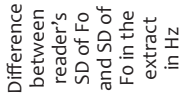 & $\underset{\tilde{N}}{\tilde{\tau}}$ & $\stackrel{a}{i}$ & 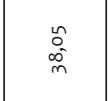 & $\underset{\sim}{\tilde{N}}$ & 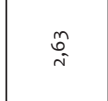 & 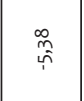 & $\stackrel{\tilde{N}}{\tilde{N}}$ & 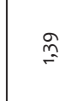 & $\begin{array}{l}\stackrel{\circ}{ } \\
\dot{f} \\
m\end{array}$ & 志 \\
\hline 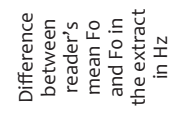 & $\begin{array}{l}\hat{b} \\
\stackrel{n}{n}\end{array}$ & 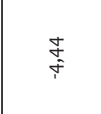 & $\begin{array}{l}\widehat{\alpha} \\
\substack{f \\
f}\end{array}$ & 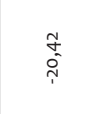 & $\overline{\bar{n}}$ & $\overbrace{\substack{n \\
\text { Int }}}^{\pi}$ & $\begin{array}{l}\text { Dे } \\
\text { in }\end{array}$ & 敫 & $\stackrel{\text { }}{\stackrel{n}{\rho}}$ & $\stackrel{m}{m}$ \\
\hline 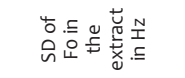 & $\begin{array}{l}\hat{0} \\
\dot{0} \\
\dot{m}\end{array}$ & 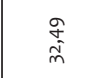 & 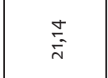 & $\begin{array}{l}\stackrel{+}{\alpha} \\
\infty \\
m\end{array}$ & $\begin{array}{l}\overline{\tilde{m}} \\
\tilde{\sigma}\end{array}$ & is & 声 & $\underset{\tilde{\sigma}}{\tilde{\tilde{\sigma}}}$ & $\begin{array}{l}\hat{m} \\
\hat{i}\end{array}$ & 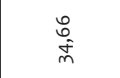 \\
\hline 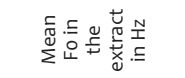 & $\begin{array}{l}m \\
q \\
g \\
\sigma \\
\sigma\end{array}$ & $\stackrel{\infty}{\infty}$ & \begin{tabular}{l}
\multirow{0}{0}{} \\
$\stackrel{0}{\hat{n}}$
\end{tabular} & $\begin{array}{l}\infty \\
\stackrel{\infty}{+} \\
\stackrel{5}{5}\end{array}$ & $\stackrel{m}{\hat{\beta}}$ & 总 & 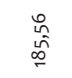 & 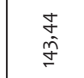 & $\begin{array}{l}\hat{n} \\
\hat{0} \\
\underline{\sigma}\end{array}$ & $\begin{array}{l}\bar{m} \\
\hat{N} \\
\stackrel{n}{\sigma}\end{array}$ \\
\hline 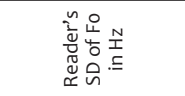 & 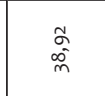 & $\begin{array}{l}\hat{m} \\
\hat{q} \\
\hat{\sigma}\end{array}$ & के & $\begin{array}{l}\text { जे } \\
\text { Fे }\end{array}$ & $\begin{array}{l}\text { वे } \\
\text { fे }\end{array}$ & $\begin{array}{l}\text { No } \\
\text { â }\end{array}$ & $\begin{array}{l}\text { ¿ } \\
\text { Ŵे }\end{array}$ & $\begin{array}{l}\overline{\tilde{\gamma}} \\
\tilde{\gamma}\end{array}$ & $\begin{array}{l}\text { mo } \\
\text { sin }\end{array}$ & $\begin{array}{l}\stackrel{\alpha}{o} \\
\stackrel{\sigma}{\sigma}\end{array}$ \\
\hline 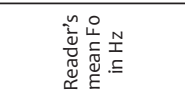 & \begin{tabular}{l}
$\stackrel{\circ}{N}$ \\
\multirow{J}{\sim}{}
\end{tabular} & \begin{tabular}{l}
\multirow{J}{0}{} \\
$\infty$ \\
$\stackrel{0}{0}$
\end{tabular} & 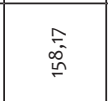 & $\begin{array}{l}\text { : } \\
\text { in }\end{array}$ & \begin{tabular}{l}
\multirow{+}{*}{} \\
$\stackrel{2}{\sigma}$
\end{tabular} & 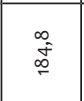 & 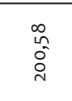 & 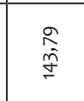 & $\begin{array}{l}+ \\
\stackrel{\sigma}{\sigma} \\
\stackrel{2}{2}\end{array}$ & 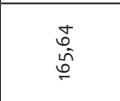 \\
\hline 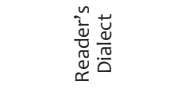 & 崖 & 岕 & 岕 & 岕 & 崖 & 岕 & 崖 & 岕 & 岕 & 岁 \\
\hline 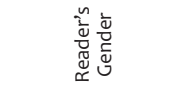 & 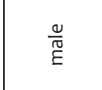 & 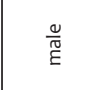 & $\frac{\frac{\varrho}{\pi}}{\varepsilon}$ & $\frac{\frac{\varrho}{\pi}}{E}$ & $\begin{array}{l}\frac{0}{\pi} \\
\underset{\Psi}{\tilde{N}}\end{array}$ & 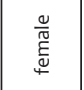 & $\begin{array}{l}\frac{0}{\pi} \\
\underset{w}{\tilde{w}}\end{array}$ & $\frac{\mathscr{\varrho}}{\tilde{\Xi}}$ & 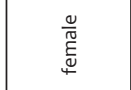 & $\frac{\stackrel{0}{\pi}}{\mathrm{E}}$ \\
\hline 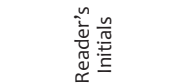 & $\dot{\hat{a}}$ & هُه & 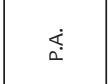 & $\stackrel{\ddot{\omega}}{\dot{\infty}}$ & $\dot{z}$ & $\stackrel{z}{\dot{z}}$ & نُ & نُ & $\underset{\stackrel{\dot{\alpha}}{\dot{\alpha}}}{\dot{j}}$ & $\stackrel{\dot{\leftrightarrow}}{\dot{\alpha}}$ \\
\hline 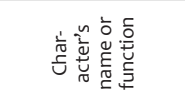 & 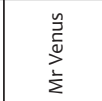 & 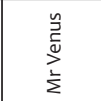 & 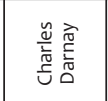 & 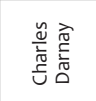 & 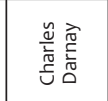 & 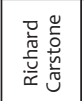 & 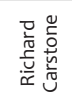 & 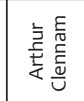 & 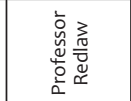 & 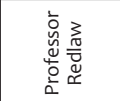 \\
\hline 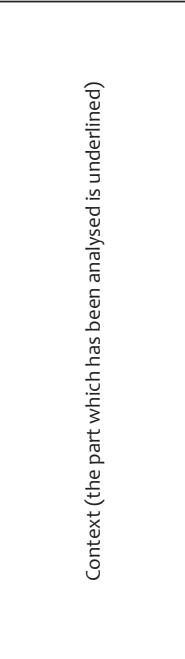 & 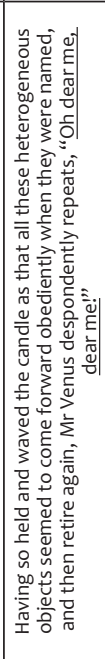 & 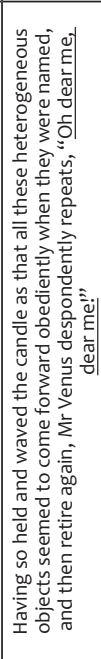 & 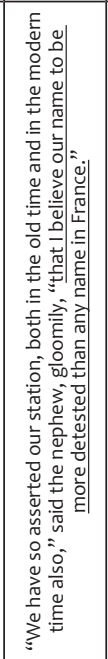 & 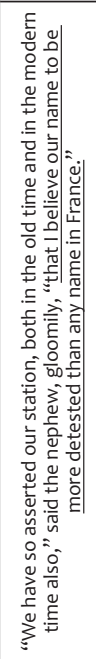 & 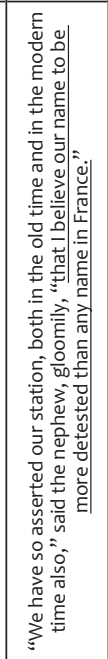 & 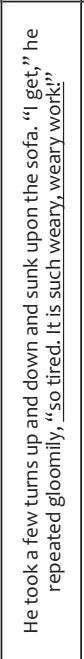 & 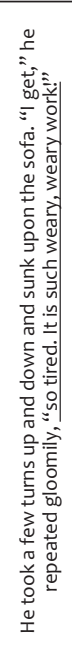 & 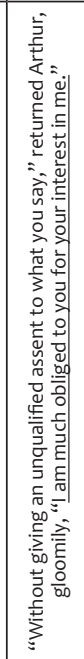 & 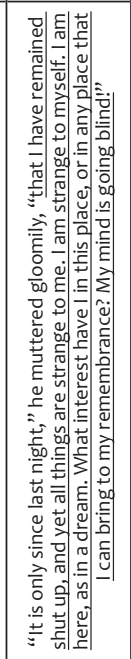 & 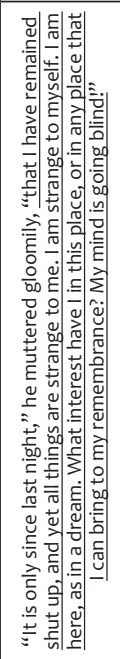 \\
\hline 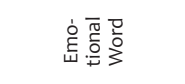 & 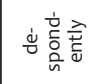 & 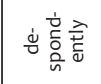 & $\begin{array}{l}\dot{\varepsilon} \\
\frac{\delta}{b 0}\end{array}$ & $\begin{array}{l}\dot{\varepsilon} \\
\frac{\partial}{\infty}\end{array}$ & $\begin{array}{l}\dot{E} \\
\frac{\partial}{b 0}\end{array}$ & $\begin{array}{l}\dot{E} \\
\frac{\delta}{b_{0}}\end{array}$ & $\begin{array}{l}\dot{E} \\
\frac{\dot{\delta}}{20}\end{array}$ & $\begin{array}{l}\dot{E} \\
\frac{\partial}{b 0}\end{array}$ & $\frac{\dot{\varepsilon}}{\frac{\dot{g}}{b 0}}=$ & $\begin{array}{l}\dot{E} \\
\frac{\partial}{\infty 0}\end{array}$ \\
\hline $\begin{array}{l}\stackrel{y}{~} \\
\stackrel{亏}{0}\end{array}$ & 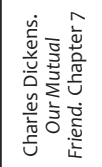 & 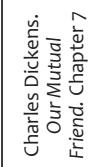 & 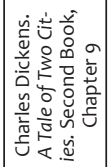 & 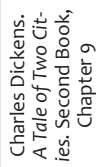 & 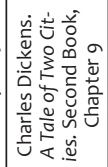 & 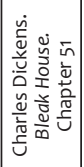 & 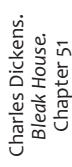 & 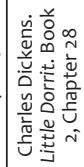 & 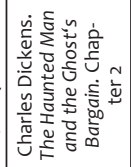 & 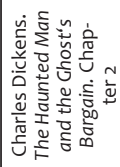 \\
\hline
\end{tabular}


Brno Studies in English 2020, 46 (1)

\begin{tabular}{|c|c|c|c|c|c|c|c|c|c|c|}
\hline 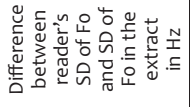 & $\stackrel{\circ}{:}$ & 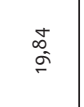 & $\begin{array}{l}\sigma \\
\sigma \\
\sigma^{\sigma}\end{array}$ & $\stackrel{2}{\sigma}$ & $\begin{array}{l}\bar{\delta} \\
\dot{f}\end{array}$ & $\stackrel{\bar{i}}{i}$ & $\stackrel{\infty}{\stackrel{\infty}{=}}$ & $\underset{\sim}{\stackrel{m}{\sim}}$ & 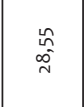 & $\begin{array}{l}\hat{\sigma} \\
\hat{f}\end{array}$ \\
\hline 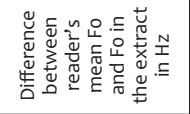 & $\underset{i}{N}$ & î & $\begin{array}{l}\text { sa } \\
\text { Oे }\end{array}$ & 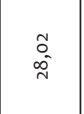 & $\begin{array}{l}\sigma \\
\vec{i}\end{array}$ & $\frac{\sigma}{\sigma}$ & 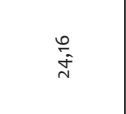 & $\underset{j}{\bar{f}}$ & $\stackrel{\sigma}{\tilde{m}}$ & $\approx$ \\
\hline 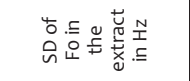 & $\frac{5}{5}$ & $\begin{array}{l}\infty \\
\infty \\
\tilde{m}\end{array}$ & $\begin{array}{l}\hat{\text { N}} \\
\hat{i}\end{array}$ & के & : & $\hat{\dot{q}}$ & $\underset{\bar{m}}{\bar{E}}$ & 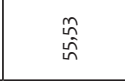 & $\begin{array}{l}\text { d } \\
\dot{m}\end{array}$ & 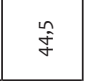 \\
\hline 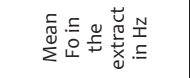 & $\begin{array}{l}m \\
\hat{\sigma} \\
\underline{\sigma}\end{array}$ & \begin{tabular}{c}
$\hat{N}$ \\
\multirow{\infty}{\infty}{} \\
$\stackrel{\infty}{\infty}$
\end{tabular} & $\stackrel{n}{\cong}$ & $\begin{array}{l}\stackrel{n}{0} \\
\stackrel{0}{=}\end{array}$ & 离 & $\begin{array}{l}\infty \\
\stackrel{\infty}{1} \\
\stackrel{N}{N}\end{array}$ & 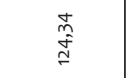 & $\begin{array}{l}m \\
\stackrel{m}{m} \\
m\end{array}$ & 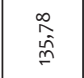 & 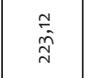 \\
\hline 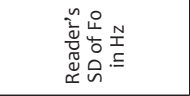 & مิ & $\underset{\substack{\text { N} \\
\hat{n}}}{ }$ & $\begin{array}{c}\stackrel{0}{h} \\
\text { on } \\
m\end{array}$ & 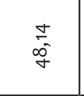 & $\begin{array}{c}\hat{y} \\
\text { ô } \\
0\end{array}$ & 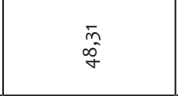 & $\begin{array}{l}\stackrel{a}{0} \\
\tilde{\gamma}\end{array}$ & 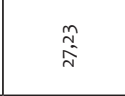 & $\begin{array}{l}\stackrel{a}{a} \\
\stackrel{\sigma}{\sigma}\end{array}$ & $\begin{array}{l}\text { ò } \\
\text { oे }\end{array}$ \\
\hline 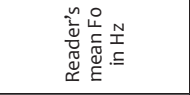 & 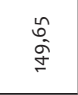 & $\begin{array}{l}\underset{m}{0} \\
\infty \\
\infty \\
\infty\end{array}$ & 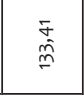 & $\begin{array}{l}\text { 亲 } \\
\dot{q}\end{array}$ & 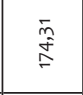 & 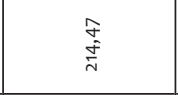 & $\begin{array}{l}L_{0}^{n} \\
\text { of } \\
\underline{\sigma}\end{array}$ & $\stackrel{\pi}{\tilde{0}}$ & \begin{tabular}{l}
$\infty$ \\
0 \\
0 \\
\multirow{\sigma}{+}{}
\end{tabular} & 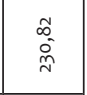 \\
\hline 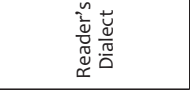 & 岕 & 岁 & 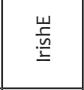 & 岕 & 岁 & 岁 & 岕 & 岕 & 岕 & 崖 \\
\hline 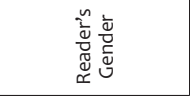 & 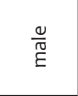 & 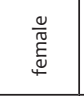 & 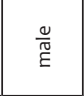 & $\frac{\frac{\nu}{\tilde{\varpi}}}{E}$ & $\frac{\frac{\sigma}{\tilde{N}}}{E}$ & 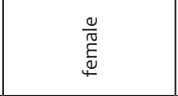 & $\frac{\frac{\varrho}{\pi}}{E}$ & $\frac{\frac{\varrho}{\pi}}{E}$ & 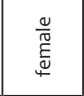 & 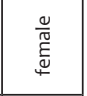 \\
\hline 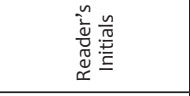 & $\stackrel{\text { }}{\dot{\omega}}$ & ذُ & $\stackrel{\dot{I}}{⺊}$ & வ் & 号 & $\stackrel{\leftrightarrow}{>}$ & $\stackrel{\dot{\varphi}}{a}$ & ن & $\bar{ن}$ & $\stackrel{\dot{\alpha}}{\dot{\alpha}}$ \\
\hline 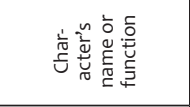 & 高 & 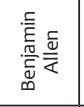 & 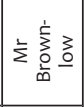 & 产竞总 & 产产道 & 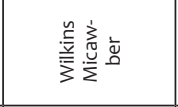 & 旁崩 & 立 & $\sum \frac{\substack{\overline{0} \\
\frac{10}{\Sigma}}}{\frac{10}{2}}$ & 言高离 \\
\hline 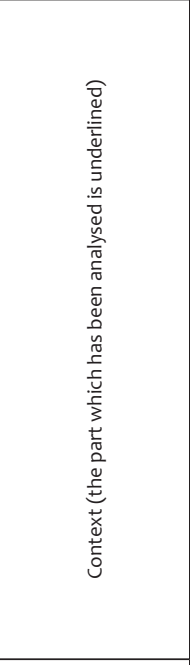 & 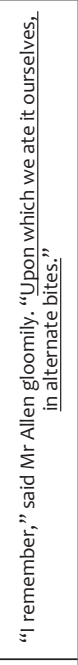 & 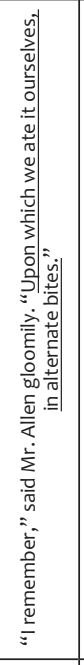 & 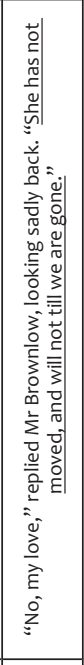 & 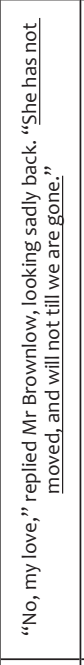 & 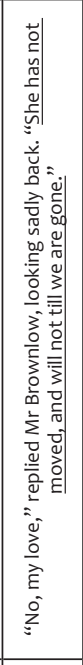 & 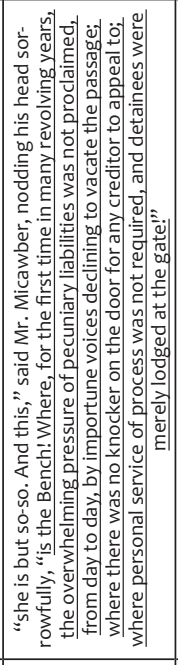 & 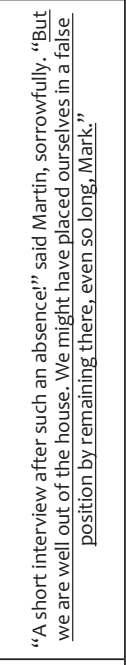 & 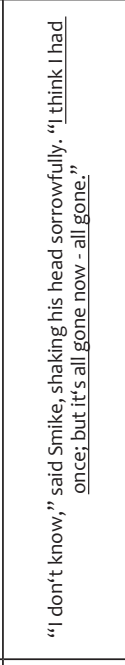 & 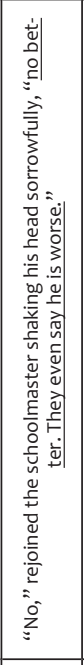 & 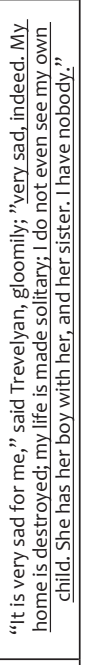 \\
\hline 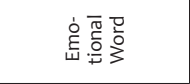 & $\begin{array}{l}\dot{E} \\
\frac{O}{D 0}\end{array}$ & $\begin{array}{l}\dot{\dot{E}} \\
\frac{\mathrm{o}}{\mathrm{D}} \cong\end{array}$ & 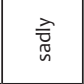 & 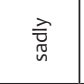 & $\begin{array}{l}\text { خे } \\
\text { जे }\end{array}$ & $\begin{array}{l}3 \\
0 \\
0 \\
0 \\
0 \\
0\end{array}$ & 产文 & 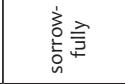 & 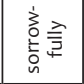 & $\frac{\dot{E}}{\frac{\dot{\delta}}{00}} \cong$ \\
\hline 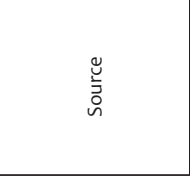 & 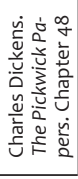 & 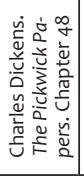 & 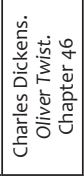 & 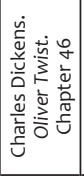 & 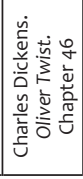 & 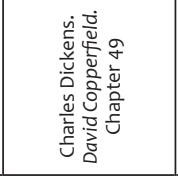 & 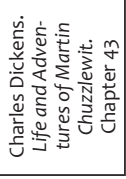 & 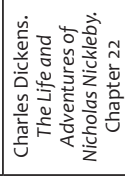 & 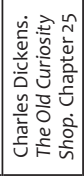 & 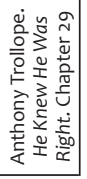 \\
\hline
\end{tabular}


Łukasz Stolarski

\begin{tabular}{|c|c|c|c|c|c|c|c|c|c|}
\hline $\begin{array}{l}\bar{m} \\
\hat{\sigma}\end{array}$ & $\begin{array}{l}\bar{m} \\
\stackrel{\tilde{\sigma}}{\sigma}\end{array}$ & $\underset{\infty}{m}$ & $\begin{array}{l}\stackrel{m}{\circ} \\
\stackrel{\circ}{\sigma}\end{array}$ & $\begin{array}{l}\stackrel{m}{f} \\
\stackrel{f}{f}\end{array}$ & $\begin{array}{l}\stackrel{a}{0} \\
\sigma_{1}^{0}\end{array}$ & $\stackrel{\stackrel{\circ}{\aleph}}{\aleph}$ & $\stackrel{0}{\circ}$ & $\frac{d}{d}$ & $\begin{array}{l}\stackrel{N}{\sim} \\
\stackrel{0}{\sim}\end{array}$ \\
\hline $\begin{array}{l}\text { શ } \\
\hat{\sigma}\end{array}$ & 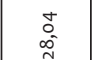 & $\begin{array}{l}\text { oे } \\
\text { in }\end{array}$ & $\begin{array}{l}\text { un } \\
\text { fo } \\
i\end{array}$ & $\begin{array}{l}\tilde{\omega} \\
\tilde{r}\end{array}$ & $\stackrel{\cong}{\cong}$ & 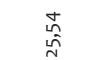 & f & $\begin{array}{l}\hat{\partial} \\
\hat{\sigma}\end{array}$ & $\underset{\stackrel{\sim}{N}}{\stackrel{\sim}{n}}$ \\
\hline $\begin{array}{l}\hat{\sigma} \\
\hat{i}\end{array}$ & $\begin{array}{l}\hat{n} \\
\hat{\tilde{\sigma}}\end{array}$ & 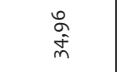 & $\hat{s}$ & 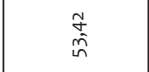 & f & $\begin{array}{l}\stackrel{0}{0} \\
\text { 它 }\end{array}$ & $\begin{array}{l}\tilde{\infty} \\
\dot{N}^{\prime}\end{array}$ & $\begin{array}{l}\stackrel{q}{m} \\
\dot{m}\end{array}$ & $\begin{array}{l}\hat{\alpha} \\
\hat{n} \\
\hat{n}\end{array}$ \\
\hline $\begin{array}{l}\hat{\sigma} \\
\hat{N} \\
\end{array}$ & $\begin{array}{l}\hat{\sigma} \\
\hat{f} \\
\stackrel{f}{0}\end{array}$ & 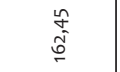 & $\begin{array}{l}\stackrel{\infty}{\stackrel{2}{\sigma}} \\
\stackrel{F}{=}\end{array}$ & g & 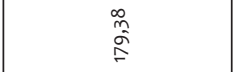 & 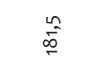 & $\stackrel{\stackrel{J}{\circ}}{\stackrel{5}{\rightleftharpoons}}$ & 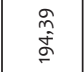 & $\begin{array}{l}\stackrel{2}{2} \\
\kappa\end{array}$ \\
\hline$\underset{m}{+}$ & $\begin{array}{l}+ \\
\infty \\
\infty \\
\infty\end{array}$ & $\begin{array}{l}\text { शे } \\
\text { ซु }\end{array}$ & $\stackrel{m}{\underline{0}}$ & $\begin{array}{l}\stackrel{o}{0} \\
\infty_{m}^{-\infty}\end{array}$ & $\underset{\substack{m \\
\hat{\sigma}}}{2}$ & $\begin{array}{l}\tilde{\tilde{y}} \\
\tilde{f}\end{array}$ & $\begin{array}{l}\bar{\delta} \\
\dot{j} \\
\dot{m}\end{array}$ & 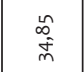 & $\underset{\substack{f \\
m}}{\frac{a}{f}}$ \\
\hline $\begin{array}{l}\stackrel{0}{\Lambda} \\
\stackrel{N}{\simeq}\end{array}$ & $\begin{array}{l}\hat{m} \\
\hat{N} \\
\stackrel{w}{r}\end{array}$ & 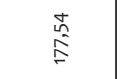 & $\underset{\stackrel{m}{o}}{\stackrel{m}{g}}$ & $\begin{array}{l}\stackrel{n}{\hat{N}} \\
\hat{\alpha}\end{array}$ & $\underset{\overline{0}}{\overline{0}}$ & $\begin{array}{l}\stackrel{+}{0} \\
\stackrel{0}{\circ} \\
\stackrel{\sim}{n}\end{array}$ & 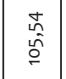 & $\begin{array}{l}0 \\
\tilde{\tilde{N}} \\
\tilde{y}\end{array}$ & $\begin{array}{l}\infty \\
\infty \\
\infty \\
\infty \\
\stackrel{\infty}{=}\end{array}$ \\
\hline 岁 & 崖 & 岁 & 崖 & 岁 & 岁 & 岁 & 宸 & 岁 & 宸 \\
\hline $\begin{array}{l}\frac{0}{\tilde{\pi}} \\
\stackrel{\tilde{\Psi}}{\Psi}\end{array}$ & 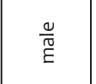 & 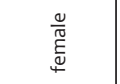 & 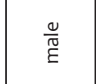 & $\frac{\varrho}{\stackrel{\varrho}{\pi}}$ & $\begin{array}{l}\frac{0}{\tilde{\pi}} \\
\stackrel{\underline{\Psi}}{\Psi}\end{array}$ & 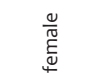 & 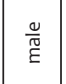 & 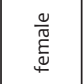 & $\frac{\stackrel{\nu}{\widetilde{\sigma}}}{\mathrm{E}}$ \\
\hline تี & 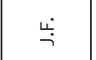 & $\dot{<}$ & 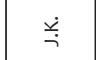 & نَ & 今. & 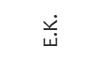 & $\dot{\ddot{~}}$ & 完 & $\stackrel{\dot{u}}{\stackrel{\dot{\zeta}}{\dot{\Sigma}}}$ \\
\hline 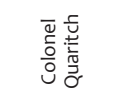 & 동 离 & 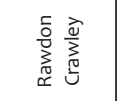 & $\begin{array}{l}\text { 荀 } \\
\stackrel{5}{5} \\
\text { 音 }\end{array}$ & 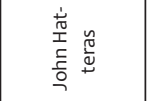 & 号 & 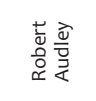 & 施产 & 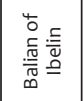 & 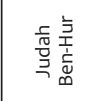 \\
\hline 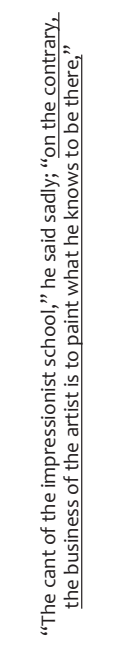 & 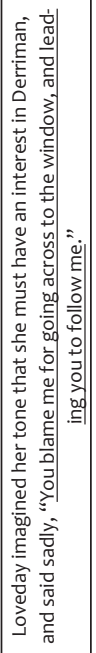 & 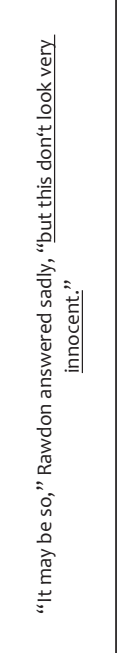 & 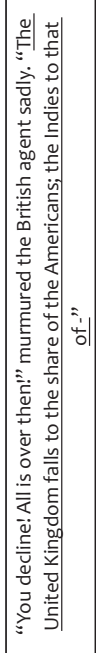 & 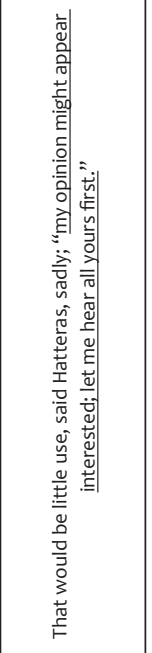 & 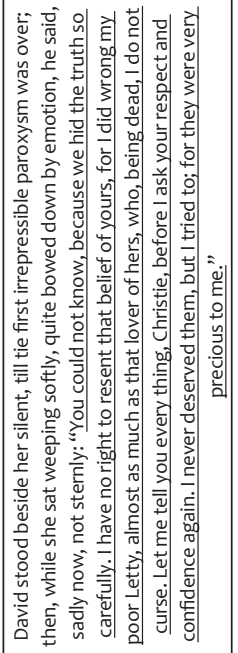 & 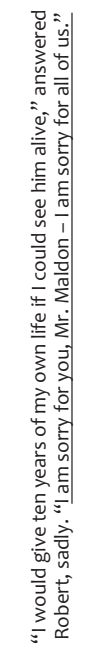 & 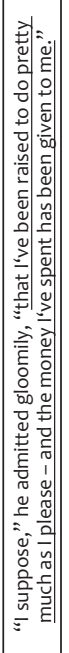 & 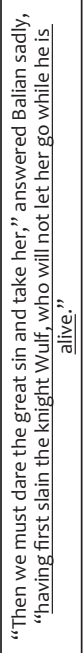 & 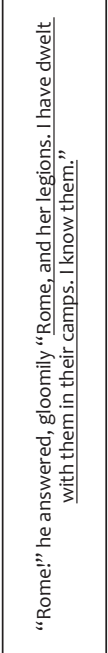 \\
\hline 商 & 商 & 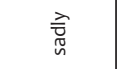 & 츢 & 춤 & 흐 & 䓂 & $\mid \dot{\underline{\varepsilon}} \geq$ & 商 & $\frac{\dot{\delta}}{D_{0}} \overline{\bar{E}}$ \\
\hline 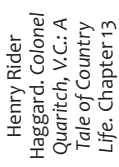 & 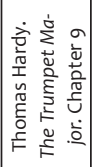 & 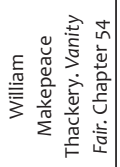 & 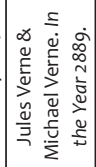 & 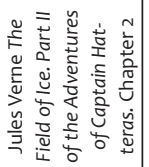 & 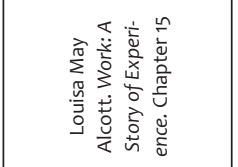 & 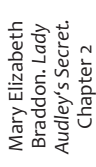 & 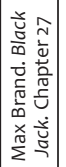 & 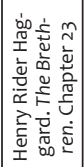 & 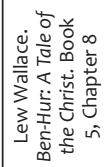 \\
\hline
\end{tabular}


Brno Studies in English 2020, 46 (1)

\begin{tabular}{|c|c|c|c|c|c|c|c|c|c|c|}
\hline 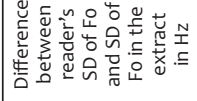 & 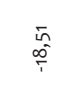 & $\begin{array}{l}\mathcal{f} \\
\dot{f}\end{array}$ & $\begin{array}{l}\text { స్ } \\
\text { సे }\end{array}$ & 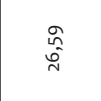 & बे & 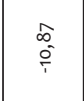 & $\frac{a}{i}$ & $\begin{array}{l}\hat{\varphi} \\
\hat{n}\end{array}$ & $\stackrel{\hat{\hat{n}}}{\hat{\hat{n}}}$ & 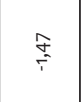 \\
\hline 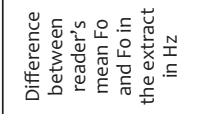 & 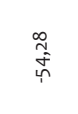 & $\begin{array}{l}\text { ma } \\
\hat{0} \\
\text { on }\end{array}$ & $\begin{array}{l}\text { 岀 } \\
\text { aे } \\
\text { jo }\end{array}$ & $\begin{array}{l}\circ \\
\infty \\
\infty\end{array}$ & $\begin{array}{l}\text { to } \\
\text { i }\end{array}$ & 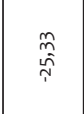 & $\begin{array}{l}\circ \\
\stackrel{f}{f} \\
\dot{1}\end{array}$ & $\frac{\sigma}{\hat{\varphi}}$ & 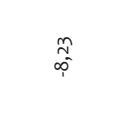 & $=$ \\
\hline 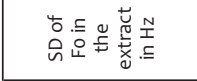 & $\begin{array}{l}\text { ñ } \\
\hat{\tilde{N}}\end{array}$ & 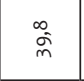 & $\begin{array}{l}\tilde{N} \\
\dot{m} \\
\dot{n}\end{array}$ & $\bar{i}$ & $\begin{array}{l}\text { के } \\
\text { के }\end{array}$ & م્ & $\stackrel{m}{\stackrel{m}{i}}$ & 站 & $\stackrel{\sigma}{f}$ & \begin{tabular}{l}
$n$ \\
\multirow{2}{\sigma}{} \\
$\tilde{\sigma}$
\end{tabular} \\
\hline 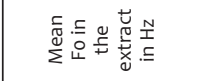 & 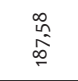 & in & 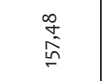 & $\underset{\substack{n \\
\infty}}{\stackrel{n}{m}}$ & m & $\begin{array}{l}\bar{\delta} \\
\dot{s} \\
m\end{array}$ & $\begin{array}{l}\frac{n}{5} \\
\frac{\sigma}{g}\end{array}$ & $\underset{\substack{N \\
\sim}}{\stackrel{\sim}{\sim}}$ & $\begin{array}{l}\stackrel{+}{\Delta} \\
\stackrel{\tilde{m}}{\sim}\end{array}$ & $\begin{array}{l}\stackrel{m}{\sim} \\
\stackrel{N}{\sim}\end{array}$ \\
\hline 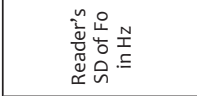 & \begin{tabular}{l}
$\stackrel{d}{\mathcal{J}}$ \\
\multirow{2}{*}{}
\end{tabular} & 趈 & $\begin{array}{l}\text { f } \\
\text { o } \\
\text { f }\end{array}$ & $\stackrel{\substack{0 \\
i n}}{n}$ & $\begin{array}{l}\infty \\
\infty \\
\omega_{n}^{-}\end{array}$ & $\begin{array}{l}\bar{\alpha} \\
\dot{f} \\
n\end{array}$ & $\underset{n}{\stackrel{5}{5}}$ & $\begin{array}{c}\text { r̂n } \\
\text { g }\end{array}$ & $\begin{array}{l}\bar{n} \\
\text { gे }\end{array}$ & 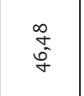 \\
\hline 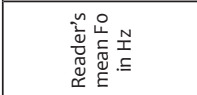 & $\stackrel{m}{m}$ & $\begin{array}{l}\text { fo } \\
\text { ó } \\
\alpha\end{array}$ & 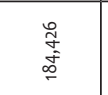 & 吾 & $\begin{array}{l}0 \\
\vdots \\
0 \\
n\end{array}$ & $\begin{array}{l}\infty \\
\stackrel{\infty}{\circ}\end{array}$ & $\begin{array}{l}\stackrel{a}{0} \\
\dot{b} \\
\text { r }\end{array}$ & 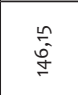 & 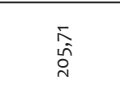 & 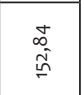 \\
\hline 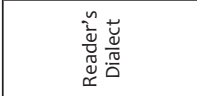 & 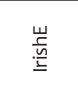 & 岁 & 岕 & 岕 & 崖 & 崖 & 岕 & 岕 & 崖 & 岕 \\
\hline 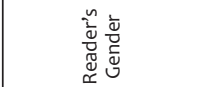 & $\frac{\mathscr{0}}{\stackrel{\varpi}{\pi}}$ & 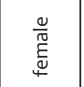 & 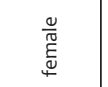 & 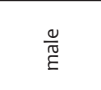 & 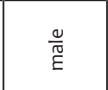 & $\frac{\frac{\alpha}{\pi}}{\frac{\pi}{E}}$ & 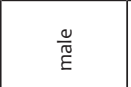 & $\frac{\varrho}{\frac{\varrho}{\pi}}$ & 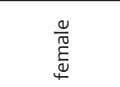 & 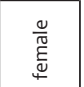 \\
\hline 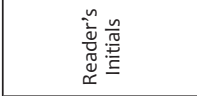 & $\dot{\vec{r}}$ & $\dot{\Delta}$ & $\begin{array}{l}\dot{z} \\
\dot{\Sigma}\end{array}$ & $\stackrel{\dot{\Psi}}{\dot{\Psi}}$ & $\dot{\Delta}$ & 将 & $\stackrel{\dot{\leftrightarrow}}{\circ}$ & نّ & نे & $\overline{\dot{u}}$ \\
\hline 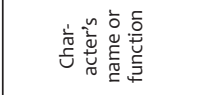 & 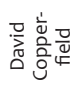 & 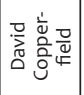 & 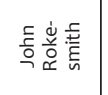 & 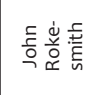 & 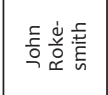 & 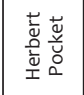 & 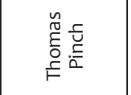 & 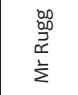 & 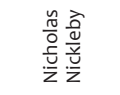 & 立高 \\
\hline 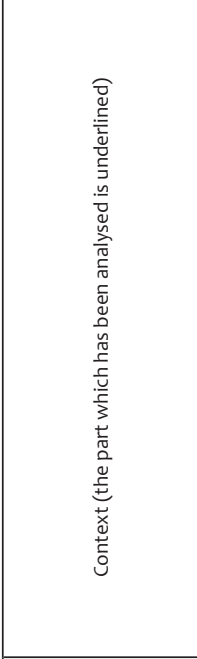 & 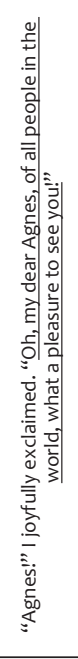 & 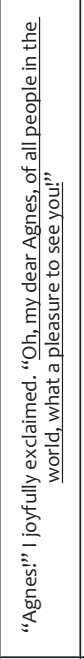 & 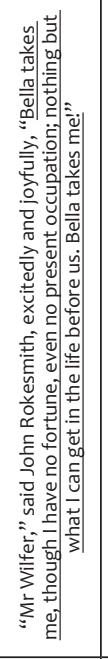 & 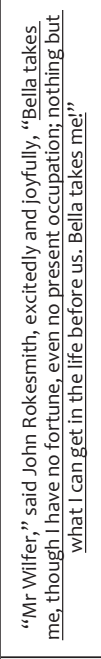 & 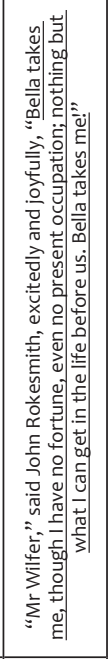 & 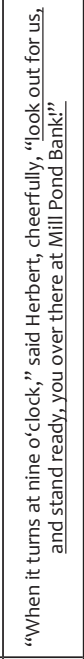 & 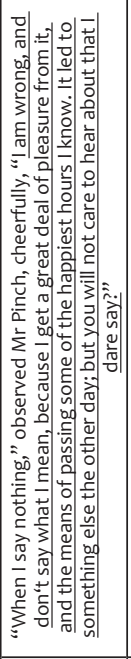 & 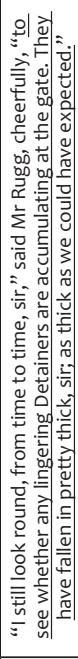 & 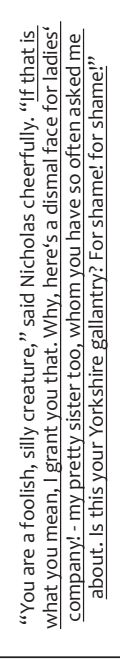 & 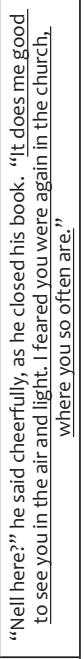 \\
\hline 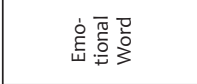 & 초호․ & 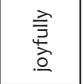 & 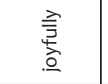 & $\begin{array}{l}\text { 츨 } \\
\text { 产 } \\
\text {. }\end{array}$ & 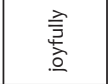 & 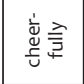 & $\begin{array}{l}\text { 这文 } \\
\text { 这 }\end{array}$ & 离文 & $\begin{array}{l}\text { 离文 } \\
\text { 过产 }\end{array}$ & 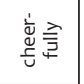 \\
\hline 苂 & 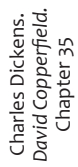 & 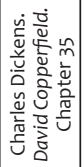 & 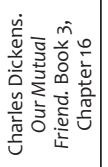 & 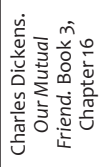 & 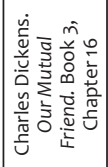 & 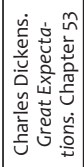 & 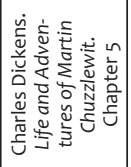 & 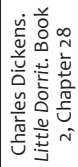 & 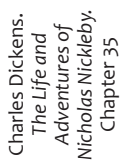 & 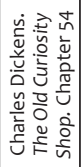 \\
\hline
\end{tabular}




\begin{tabular}{|c|c|c|c|c|c|c|c|c|c|c|}
\hline $\begin{array}{l}\hat{\hat{c}} \\
\text { ते }\end{array}$ & 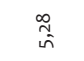 & 芳 & $\begin{array}{l}\stackrel{0}{\infty} \\
\stackrel{\infty}{T}\end{array}$ & 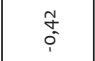 & $\begin{array}{l}\infty \\
\alpha \\
\alpha \\
1\end{array}$ & $\begin{array}{l}\text { बे } \\
\text { ปิ }\end{array}$ & $\begin{array}{l}n \\
\hat{n} \\
\underline{n}\end{array}$ & $\stackrel{\tilde{\sim}}{\sim}$ & $\begin{array}{l}\overline{5} \\
\tilde{T}\end{array}$ & 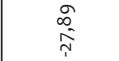 \\
\hline 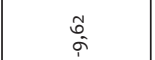 & $\stackrel{2}{7}$ & $\begin{array}{c}\tilde{N} \\
\widehat{n}\end{array}$ & 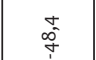 & $\begin{array}{l}\stackrel{m}{\sim} \\
\stackrel{f}{f}\end{array}$ & $\begin{array}{l}\text { mo } \\
\text { for } \\
0\end{array}$ & $\stackrel{\vec{T}}{\vec{T}}$ & $\begin{array}{l}a \\
i \\
i\end{array}$ & 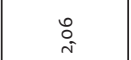 & $\begin{array}{c}\stackrel{0}{p} \\
\stackrel{m}{w}\end{array}$ & 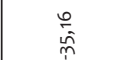 \\
\hline $\begin{array}{l}n \\
\stackrel{n}{n} \\
i\end{array}$ & $\stackrel{\substack{n \\
N}}{N}$ & $\begin{array}{c}\mathcal{M} \\
\text { م⿸ } \\
0\end{array}$ & $\begin{array}{l}\bar{T} \\
\text { for }\end{array}$ & $\underset{\infty}{+}$ & $\begin{array}{l}0 \\
i=n \\
i n\end{array}$ & 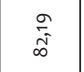 & $\begin{array}{l}\text { बे } \\
\text { d. }\end{array}$ & $\begin{array}{l}\text { oे } \\
\text { in }\end{array}$ & $\underset{m}{\tilde{z}}$ & $\begin{array}{l}\hat{n} \\
\infty^{n} \\
n^{2}\end{array}$ \\
\hline 童 & $\underset{\mathfrak{I}}{\simeq}$ & 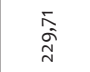 & ڤ్ & 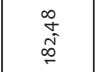 & 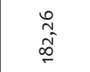 & $\begin{array}{l}0 \\
\stackrel{0}{n} \\
\end{array}$ & $\begin{array}{c}\hat{\overbrace{}} \\
\stackrel{\hat{\vartheta}}{\stackrel{0}{0}}\end{array}$ & 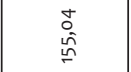 & 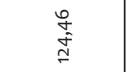 & $\begin{array}{l}\hat{N} \\
\hat{\tilde{N}}\end{array}$ \\
\hline $\begin{array}{l}\stackrel{0}{0} \\
\stackrel{\alpha}{\sigma}\end{array}$ & $\begin{array}{c}\infty \\
\infty \\
\tilde{m}\end{array}$ & $\begin{array}{l}\infty \\
0 \\
0 \\
0\end{array}$ & F & D. & $\begin{array}{l}\stackrel{n}{0} \\
\dot{\sigma}\end{array}$ & 瓷 & 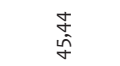 & & $\begin{array}{l}\hat{\sigma} \\
\hat{f}\end{array}$ & $\begin{array}{l}\frac{0}{0} \\
\text { in }\end{array}$ \\
\hline $\begin{array}{l}\infty \\
\stackrel{\infty}{0} \\
\stackrel{0}{\sigma}\end{array}$ & $\begin{array}{l}\bar{c} \\
\stackrel{\Sigma}{E} \\
\stackrel{E}{*}\end{array}$ & $\stackrel{\substack{n \\
E}}{E}$ & 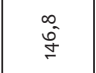 & $\begin{array}{l}\stackrel{n}{f} \\
\stackrel{f}{m}\end{array}$ & 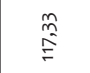 & $\begin{array}{l}\infty \\
\infty \\
\bar{m}\end{array}$ & $\begin{array}{l}\stackrel{\infty}{\infty} \\
\stackrel{0}{\circ} \\
\stackrel{0}{0}\end{array}$ & i & ô & 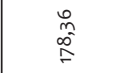 \\
\hline 崖 & 崖 & 崖 & 岕 & 岕 & 岕 & 崖 & 岕 & 崖 & 崖 & 崖 \\
\hline 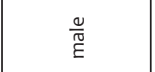 & 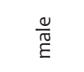 & 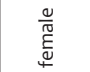 & $\frac{\varrho}{\stackrel{0}{\pi}}$ & 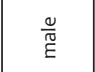 & $\frac{0}{\frac{0}{\pi}}$ & 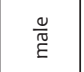 & 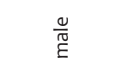 & 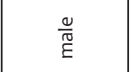 & $\frac{\varrho}{\tilde{\Xi}}$ & 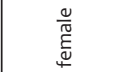 \\
\hline$\stackrel{亡}{3}$ & نं & تُه & $\stackrel{\dot{山}}{\dot{\infty}}$ & İ & $\sum_{\Sigma}^{\bar{\Sigma}}$ & $\stackrel{\infty}{\Sigma}$ & 岁 & İ: & $\stackrel{\dot{\sim}}{\check{\alpha}}$ & تี \\
\hline 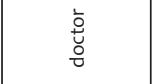 & 怘 & 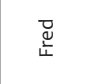 & 岧 & 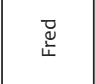 & 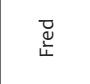 & 总 & & 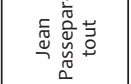 & 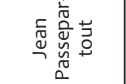 & 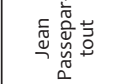 \\
\hline 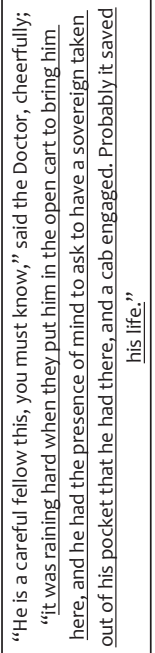 & 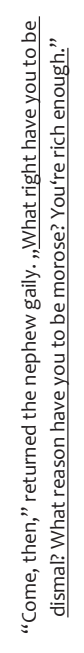 & 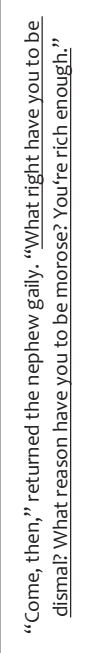 & 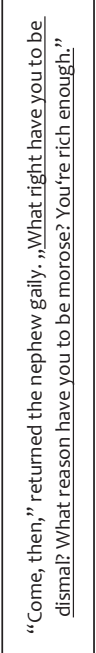 & 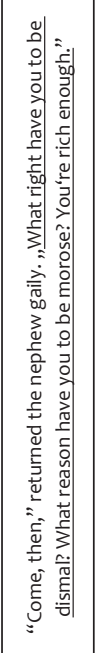 & 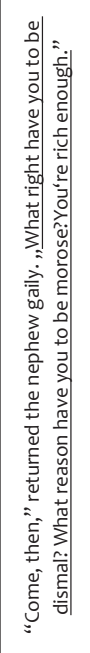 & 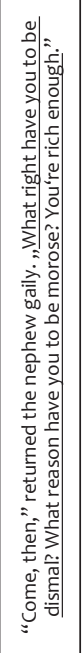 & 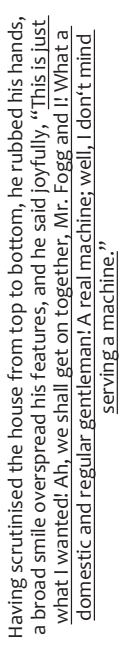 & 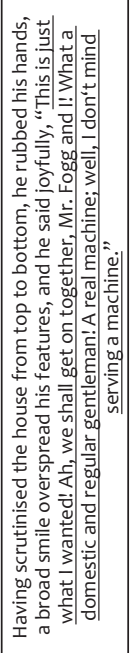 & 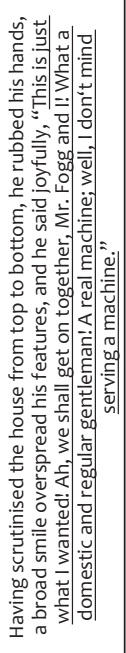 & 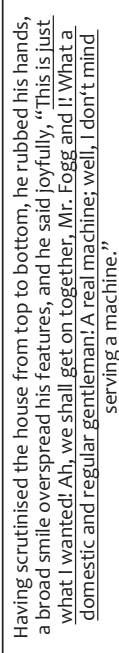 \\
\hline 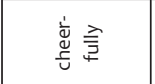 & $\begin{array}{l}\text { 商 } \\
\text { 品 }\end{array}$ & 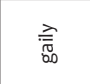 & $\begin{array}{l}\text { 㨔 } \\
\end{array}$ & 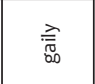 & 䇏 & 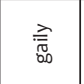 & 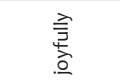 & 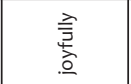 & 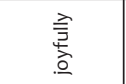 & 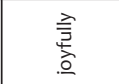 \\
\hline 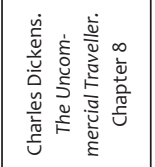 & 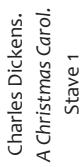 & 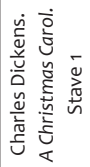 & 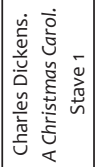 & 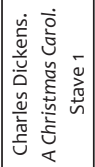 & 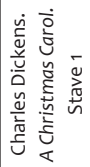 & 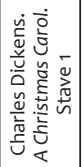 & 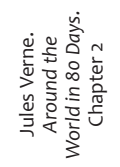 & 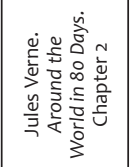 & 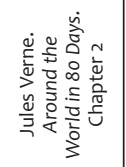 & 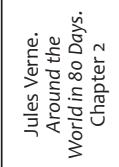 \\
\hline
\end{tabular}


Brno Studies in English 2020, 46 (1)

\begin{tabular}{|c|c|c|c|c|c|c|c|c|c|}
\hline 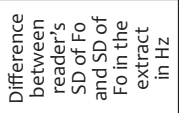 & $\stackrel{\bar{F}}{\bar{m}}$ & $\begin{array}{l}n \\
m \\
m\end{array}$ & $\stackrel{\overbrace{}}{\stackrel{r}{r}}$ & ટ્ & $\begin{array}{l}\infty \\
\hat{\alpha} \\
\hat{i}\end{array}$ & $\begin{array}{c}\text { to } \\
\stackrel{+}{+}\end{array}$ & مे & $\begin{array}{l}\infty^{+} \\
\infty \\
\infty\end{array}$ & $\begin{array}{l}\stackrel{2}{\circ} \\
\text { ب̂ }\end{array}$ \\
\hline 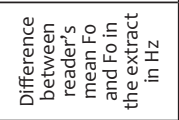 & 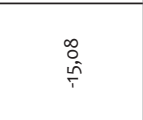 & $\frac{N}{\bar{T}}$ & 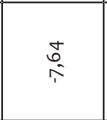 & $\begin{array}{l}\stackrel{2}{r} \\
\dot{p}\end{array}$ & 20 & 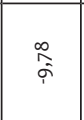 & $\begin{array}{c}0 \\
y_{\infty}^{\circ}\end{array}$ & $\underset{\mathfrak{q}}{\mathfrak{f}}$ & \begin{tabular}{l}
$\infty$ \\
\multirow{0}{0}{} \\
$\infty$
\end{tabular} \\
\hline 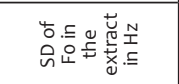 & $\begin{array}{l}\tilde{N} \\
\tilde{f}\end{array}$ & $\begin{array}{l}\infty \\
\stackrel{+}{+} \\
\dot{\sigma}\end{array}$ & $\begin{array}{l}\hat{n} \\
\hat{\vdots} \\
0\end{array}$ & $\underset{\mathrm{f}}{\stackrel{f}{N}}$ & $\begin{array}{l}\infty \\
\stackrel{7}{*} \\
\stackrel{0}{0}\end{array}$ & $\underset{\substack{\infty \\
\text { N }}}{\mathbb{2}}$ & $\stackrel{\substack{m \\
\infty_{m}^{\infty}}}{n}$ & $\stackrel{\sim}{\infty}$ & 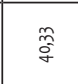 \\
\hline 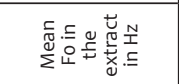 & $\begin{array}{l}0 \\
\hat{0} \\
\stackrel{0}{0}\end{array}$ & $\begin{array}{l}\bar{\sigma} \\
\overline{\tilde{n}}\end{array}$ & $\begin{array}{l}\stackrel{a}{2} \\
\infty \\
\stackrel{\sigma}{\sigma}\end{array}$ & $\begin{array}{l}\stackrel{n}{=} \\
\stackrel{m}{m}\end{array}$ & 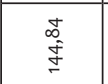 & $\begin{array}{l}\hat{\sigma} \\
\text { ô } \\
\stackrel{5}{2}\end{array}$ & $\begin{array}{l}\infty \\
\infty \\
\vdots \\
\vdots\end{array}$ & 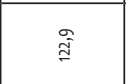 & 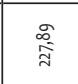 \\
\hline 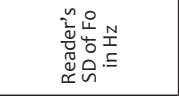 & $\begin{array}{l}\overline{1} \\
\stackrel{1}{m}\end{array}$ & $\begin{array}{l}\stackrel{m}{f} \\
\hat{f}\end{array}$ & $\begin{array}{l}\stackrel{2}{0} \\
\text { in }\end{array}$ & $\stackrel{m}{\stackrel{m}{\rho}}$ & $\hat{\hbar}$ & $\underset{\text { mi }}{\bar{F}}$ & $\begin{array}{l}\stackrel{\sigma}{\dot{\sigma}} \\
\dot{\sigma}\end{array}$ & $\begin{array}{l}\stackrel{\circ}{\circ} \\
\text { 心) }\end{array}$ & 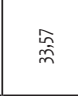 \\
\hline 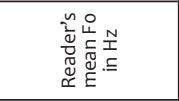 & \begin{tabular}{l}
$n$ \\
\multirow{f}{f}{} \\
$\dot{f}$
\end{tabular} & 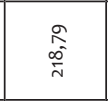 & $\begin{array}{l}0 \\
\stackrel{0}{0} \\
\vdots\end{array}$ & 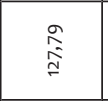 & 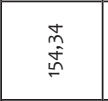 & $\begin{array}{l}\frac{a}{5} \\
\stackrel{5}{5}\end{array}$ & $\begin{array}{c}m \\
\stackrel{m}{i}\end{array}$ & $\underset{m}{\stackrel{m}{\equiv}}$ & 商 \\
\hline 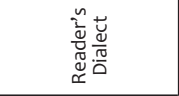 & 崖 & 岕 & 岁 & 岁 & 岕 & 崖 & 岁 & 岁 & 崖 \\
\hline 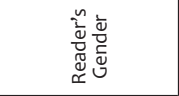 & $\frac{\Delta}{\tilde{\pi}}$ & $\begin{array}{l}\frac{\mathscr{0}}{\tilde{\pi}} \\
\stackrel{\tilde{\Psi}}{\Psi}\end{array}$ & 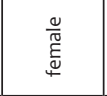 & $\frac{\frac{\nu}{0}}{\underline{\underline{\pi}}}$ & $\frac{\varrho}{\widetilde{\varpi}}$ & $\frac{\varrho}{\tilde{\Xi}}$ & $\begin{array}{l}\frac{0}{\pi} \\
\underset{\Psi}{\tilde{T}} \\
\Psi\end{array}$ & $\frac{\varrho}{\tilde{\Xi}}$ & 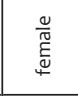 \\
\hline 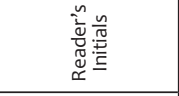 & $\dot{\breve{~}}$ & $\dot{\breve{~}}$ & $\sum_{\dot{x}}^{N}$ & $\stackrel{+}{\dot{\alpha}}$ & $\dot{\Delta}$ & $\stackrel{\stackrel{\leftrightarrow}{\circ}}{ }$ & 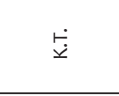 & 离 & 孚 \\
\hline 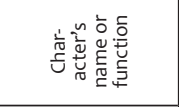 & 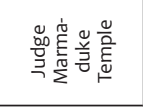 & 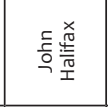 & 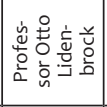 & $\begin{array}{l}\stackrel{n}{E} \\
\text { 空 }\end{array}$ & 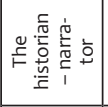 & 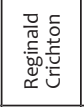 & 离 & 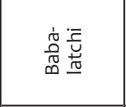 & $\frac{4}{3}$ \\
\hline 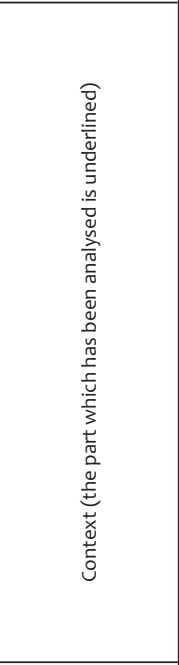 & 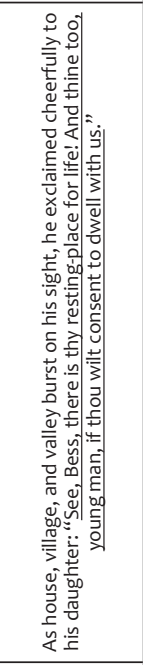 & 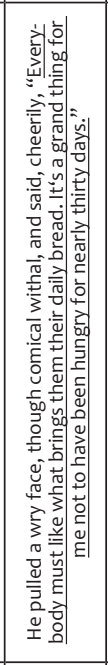 & 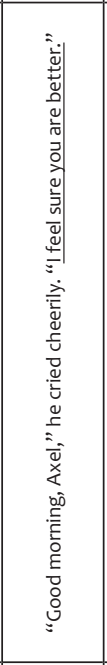 & 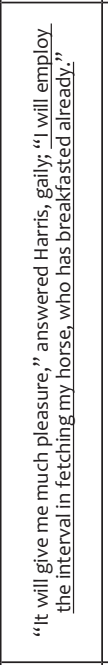 & 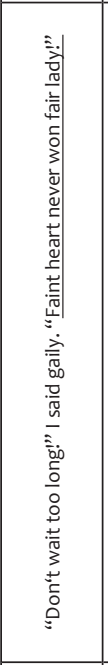 & 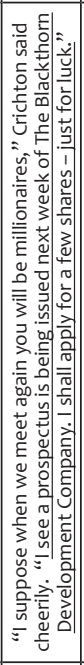 & 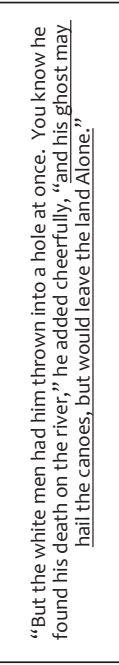 & 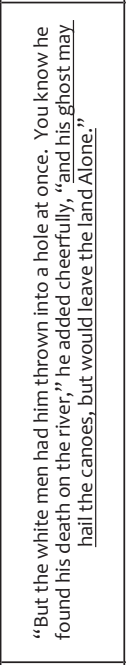 & 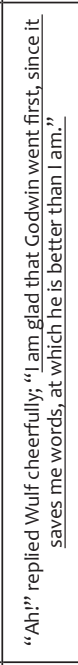 \\
\hline 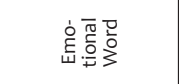 & $\begin{array}{l}\text { 离 } \\
\frac{\mathrm{d}}{\mathrm{S}} \overline{\bar{z}}\end{array}$ & 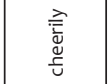 & $\begin{array}{l}\text { 言 } \\
\text { बूँ }\end{array}$ & 彥 & 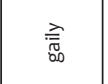 & 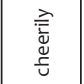 & $\begin{array}{l}\frac{1}{\bar{v}} \\
\frac{\mathrm{d}}{\mathrm{U}} \overline{\bar{z}}\end{array}$ & 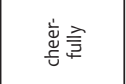 & 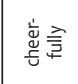 \\
\hline 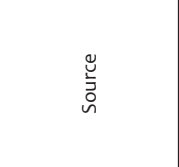 & 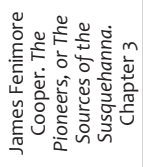 & 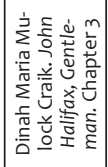 & 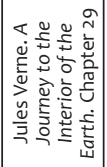 & 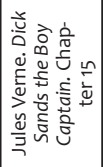 & 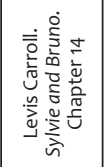 & 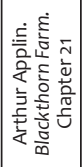 & 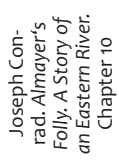 & 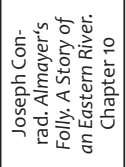 & 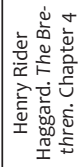 \\
\hline
\end{tabular}




\begin{tabular}{|c|c|c|c|c|c|c|c|c|c|}
\hline 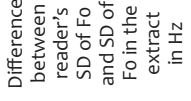 & $\stackrel{m}{p}$ & 亲 & $\begin{array}{l}\infty \\
: \\
T\end{array}$ & $\stackrel{\bar{m}}{\bar{m}}$ & $\begin{array}{l}\infty \\
\text { î } \\
\text { in }\end{array}$ & 吕 & $\stackrel{\infty}{\stackrel{f}{*}}$ & 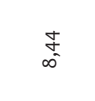 & $\infty_{\infty}^{m}$ \\
\hline 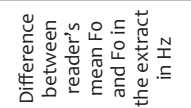 & 我 & $\begin{array}{l}\frac{0}{1} \\
\stackrel{1}{1}\end{array}$ & 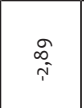 & $\begin{array}{l}\bar{f} \\
\text { Hit }\end{array}$ & 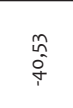 & 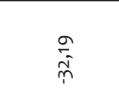 & 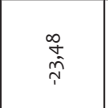 & 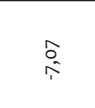 & $\begin{array}{l}\stackrel{n}{f} \\
f\end{array}$ \\
\hline 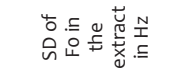 & $\begin{array}{l}\text { 豙 } \\
\dot{a}\end{array}$ & 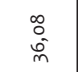 & \begin{tabular}{l}
$\stackrel{0}{\mathcal{\gamma}}$ \\
\multirow{\gamma}{\gamma}{}
\end{tabular} & d & $\begin{array}{l}\stackrel{8}{0} \\
\dot{\gamma}\end{array}$ & $\begin{array}{l}n \\
\hat{g}\end{array}$ & $\begin{array}{l}\text { do } \\
\text { aे } \\
\text { a }\end{array}$ & $\bar{d}$ & 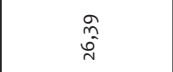 \\
\hline 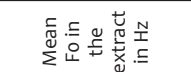 & $\stackrel{m}{\stackrel{m}{0}}$ & 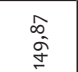 & 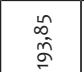 & 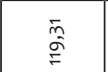 & 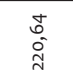 & Iิ & 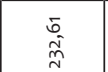 & 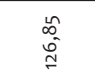 & 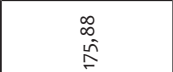 \\
\hline 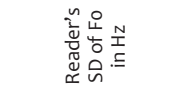 & $\underset{\substack{n \\
m}}{\stackrel{m}{m}}$ & $\begin{array}{c}\hat{n} \\
\text { on } \\
\text { on }\end{array}$ & 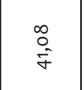 & $\begin{array}{l}\text { oे } \\
\text { ô } \\
\text { ô. }\end{array}$ & 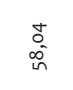 & 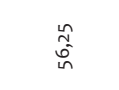 & $\stackrel{n}{\stackrel{n}{n}}$ & $\begin{array}{l}\stackrel{n}{\hat{N}} \\
\tilde{m}\end{array}$ & $\begin{array}{l}\stackrel{a}{0} \\
\dot{p}\end{array}$ \\
\hline 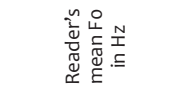 & 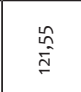 & $\begin{array}{c}\bar{\alpha} \\
\text { co }\end{array}$ & 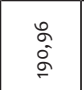 & $\stackrel{\circ}{\stackrel{\hat{m}}{=}}$ & $\begin{array}{l}\bar{c} \\
\stackrel{0}{0} \\
\stackrel{0}{\infty}\end{array}$ & $\begin{array}{l}\infty \\
0 \\
0 \\
\sigma \\
\sigma\end{array}$ & mo & $\begin{array}{l}\stackrel{\infty}{\circ} \\
\stackrel{0}{=}\end{array}$ & 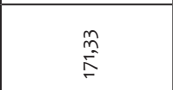 \\
\hline 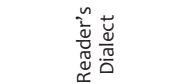 & 岕 & 岕 & 崖 & 崖 & 岕 & 崖 & 崖 & 颜 & 岁 \\
\hline 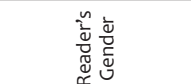 & $\frac{\stackrel{0}{\tilde{n}}}{\tilde{\varepsilon}}$ & $\frac{0}{\frac{0}{\pi}}$ & 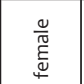 & $\frac{\frac{\nu}{\pi}}{\frac{\pi}{E}}$ & 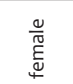 & $\frac{\frac{0}{\pi}}{\frac{\pi}{E}}$ & 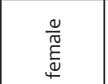 & $\frac{\frac{\nu}{\pi}}{E}$ & 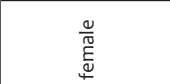 \\
\hline 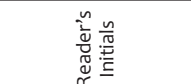 & $\underset{\dot{x}}{\dot{ن}}$ & نُّ & $\sum_{0}^{\infty}$ & نُ & $\dot{z}_{\dot{z}}^{\dot{z}}$ & $\stackrel{\dot{u}}{\stackrel{\dot{u}}{\Sigma}}$ & $\dot{\check{x}}$ & $\dot{\rightleftarrows}$ & ن̀ \\
\hline 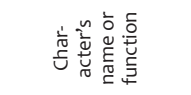 & 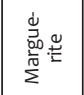 & 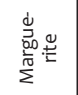 & 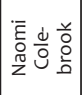 & 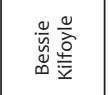 & 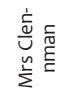 & 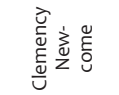 & 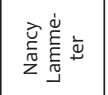 & 窟害 & 﨎亭 \\
\hline 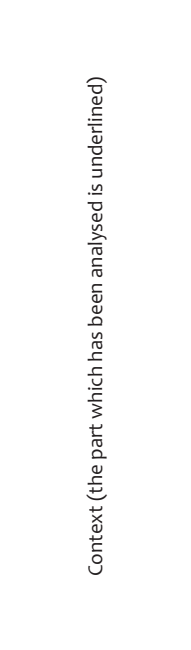 & 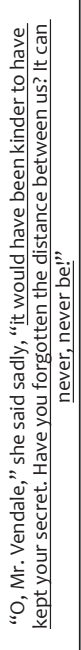 & 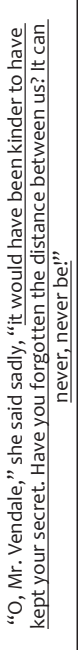 & 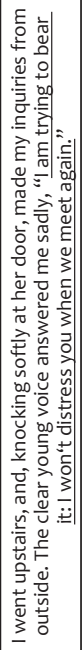 & 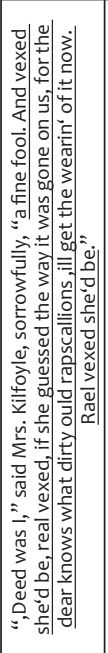 & 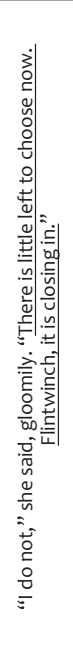 & 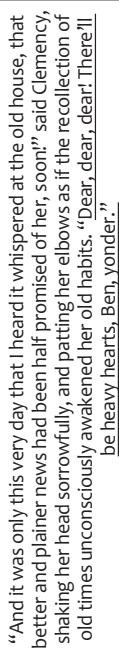 & 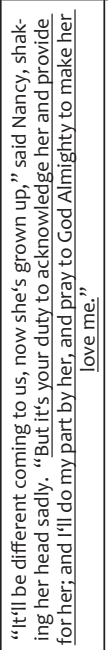 & 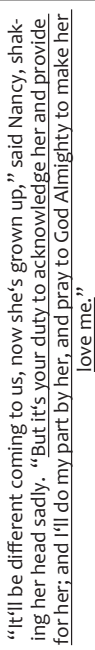 & 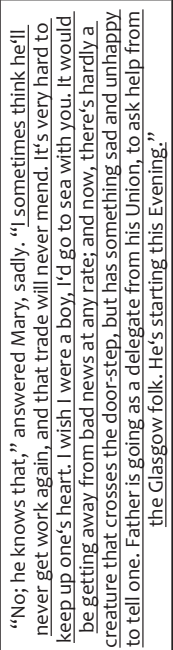 \\
\hline 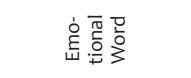 & 密 & 흚 & స్ & 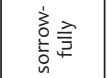 & $\begin{array}{l}\dot{\varepsilon} \\
\frac{\partial}{\infty 0}\end{array}$ & 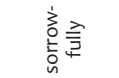 & 굶 & 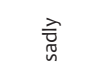 & 춤 \\
\hline 䓂 & 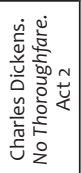 & 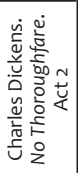 & 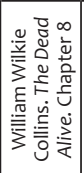 & 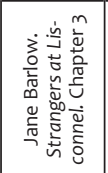 & 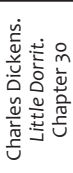 & 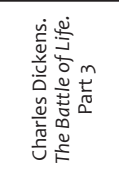 & 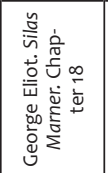 & 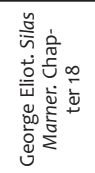 & 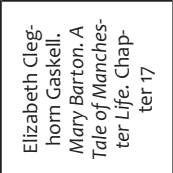 \\
\hline
\end{tabular}


Brno Studies in English 2020, 46 (1)

\begin{tabular}{|c|c|c|c|c|c|c|c|c|c|}
\hline 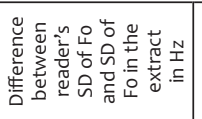 & $\stackrel{ \pm}{:}$ & 壱 & $\stackrel{\infty}{\stackrel{\infty}{\sim}} \stackrel{-}{\leftarrow}$ & $\stackrel{\tilde{N}}{\tilde{n}}$ & $\begin{array}{l}\overline{5} \\
\dot{f}\end{array}$ & $\begin{array}{l}\text { to } \\
\text { i } \\
\text { int }\end{array}$ & $\begin{array}{l}\infty \\
0 \\
0 \\
0\end{array}$ & $\stackrel{\infty}{f}$ & $\bar{E}$ \\
\hline 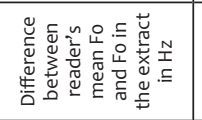 & $\vec{i}$ & $\frac{\substack{m \\
\bar{m}}}{m}$ & $\begin{array}{l}\text { n } \\
\text { st }\end{array}$ & $\stackrel{N}{\tilde{m}}$ & $\underset{\substack{m \\
\stackrel{\infty}{\infty}}}{ }$ & 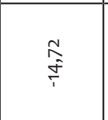 & 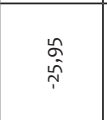 & 答 & \begin{tabular}{l}
\multirow{2}{*}{} \\
ôे
\end{tabular} \\
\hline 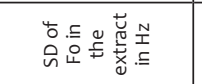 & $\begin{array}{l}\stackrel{\infty}{2} \\
\stackrel{\sigma}{n}\end{array}$ & 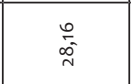 & $\begin{array}{l}\bar{\infty} \\
\bar{\sigma} \\
\bar{\sigma}\end{array}$ & 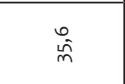 & 命 & 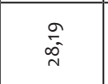 & 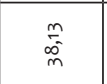 & $\begin{array}{l}\hat{0} \\
\dot{f}\end{array}$ & $\frac{a}{f}$ \\
\hline 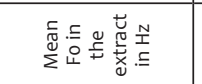 & $\underset{\substack{\stackrel{m}{N} \\
\tilde{N}}}{\sim}$ & $\begin{array}{l}\text { O̊ } \\
\text { ơ } \\
\text { N }\end{array}$ & 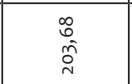 & $\frac{a}{\frac{d}{n}}$ & $\begin{array}{l}n \\
0 \\
0 \\
0\end{array}$ & $\begin{array}{l}\stackrel{\infty}{ } \\
\stackrel{0}{0} \\
\stackrel{\sim}{\simeq}\end{array}$ & $\stackrel{m}{\stackrel{m}{\sim}}$ & 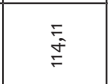 & 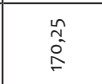 \\
\hline 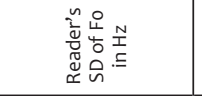 & $\begin{array}{l}\infty_{0}^{2} \\
0 \\
0\end{array}$ & 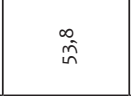 & $\begin{array}{l}\frac{9}{9} \\
\stackrel{5}{0}\end{array}$ & No & $\frac{d}{\frac{d}{2}}$ & 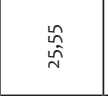 & 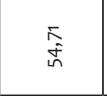 & $\begin{array}{l}\hat{D} \\
\text { ò } \\
m\end{array}$ & 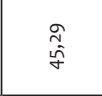 \\
\hline 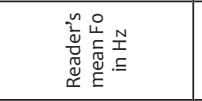 & 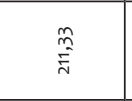 & $\stackrel{n}{N}$ & $\begin{array}{l}\stackrel{m}{0} \\
\stackrel{\sim}{N}\end{array}$ & $\begin{array}{l}\stackrel{2}{2} \\
\hat{0} \\
\stackrel{0}{\sigma}\end{array}$ & 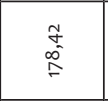 & $\begin{array}{l}\stackrel{\circ}{\circ} \\
\stackrel{\circ}{\circ}\end{array}$ & $\begin{array}{l}\stackrel{n}{m} \\
\stackrel{\infty}{\infty} \\
\stackrel{\infty}{\infty}\end{array}$ & 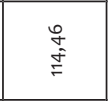 & 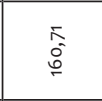 \\
\hline 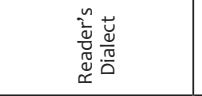 & 崖 & 岁 & 岁 & 岁 & 崖 & 崖 & 岕 & 岕 & 岁 \\
\hline 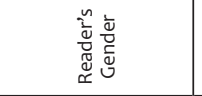 & $\frac{\stackrel{0}{\frac{\pi}{\pi}}}{\stackrel{\Psi}{\Psi}}$ & $\begin{array}{l}\frac{\mathscr{0}}{\pi} \\
\stackrel{\tilde{\Psi}}{\Psi}\end{array}$ & 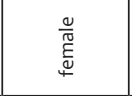 & $\begin{array}{l}\frac{0}{\pi} \\
\underset{\tilde{\pi}}{\tilde{N}}\end{array}$ & $\begin{array}{l}\frac{\mathscr{\nu}}{\pi} \\
\stackrel{\tilde{\Phi}}{\Psi}\end{array}$ & $\frac{\varrho}{\tilde{\Xi}}$ & 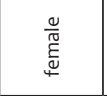 & 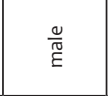 & 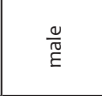 \\
\hline 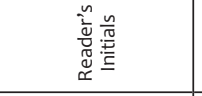 & نُ & 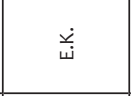 & $\vdash$ & ن山 & نُ & $\stackrel{\circ}{\dot{\infty}}$ & $\dot{z}$ & $\stackrel{\circ}{\dot{\alpha}}$ & $\dot{\infty}$ \\
\hline 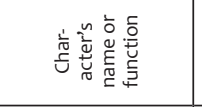 & 点部 & 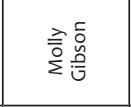 & 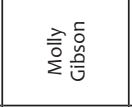 & $\begin{array}{l}\frac{\pi}{0} \frac{0}{\overline{0}} \\
\frac{\pi}{\underline{0}} \bar{\Sigma}\end{array}$ & 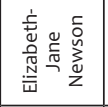 & 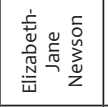 & 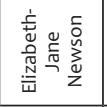 & 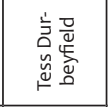 & 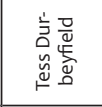 \\
\hline 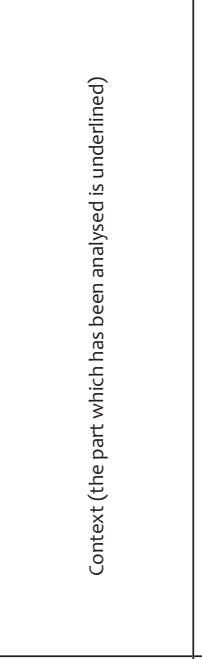 & 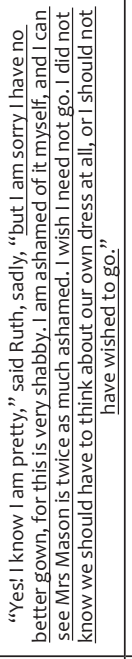 & 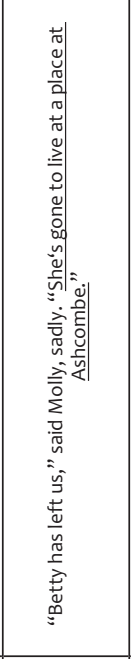 & 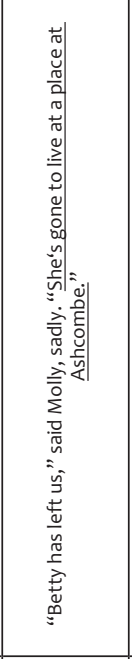 & 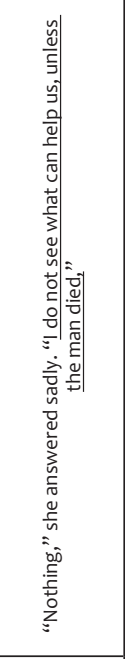 & 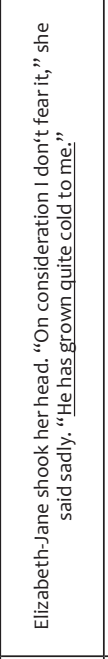 & 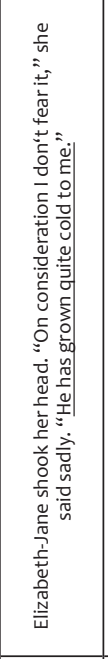 & 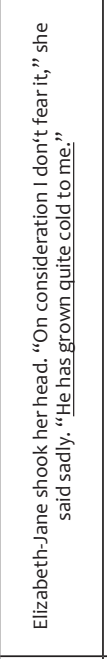 & 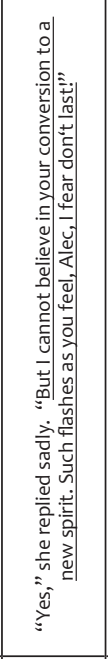 & 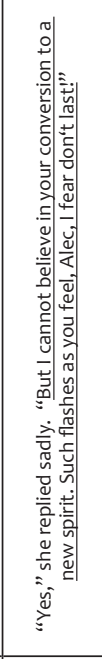 \\
\hline 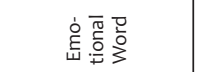 & 훔 & $\begin{array}{l}\text { 育 } \\
\text { ज़ }\end{array}$ & 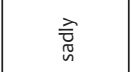 & 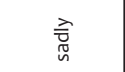 & 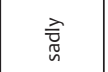 & 䐱 & 츰 & 츨 & 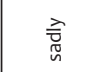 \\
\hline 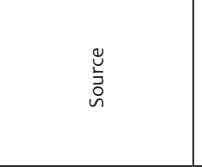 & 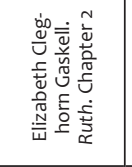 & 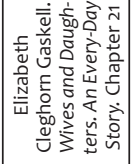 & 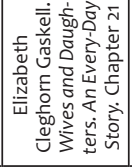 & 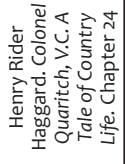 & 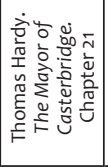 & 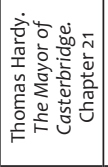 & 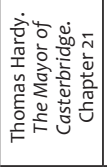 & 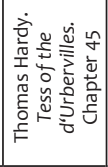 & 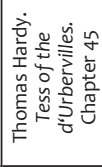 \\
\hline
\end{tabular}


Łukasz Stolarski

\begin{tabular}{|c|c|c|c|c|c|c|c|c|}
\hline $\begin{array}{l}\tilde{\sigma} \\
\tilde{\simeq}\end{array}$ & $\stackrel{+}{\stackrel{D}{=}}$ & 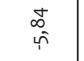 & $\stackrel{\substack{\infty \\
\sim}}{i}$ & $\overline{\bar{\Xi}}$ & $\stackrel{\infty}{:}$ & $\begin{array}{l}\text { ते } \\
\hat{n}\end{array}$ & $\underset{j}{\bar{N}}$ & $\begin{array}{l}\Delta \\
\text { in }\end{array}$ \\
\hline के & $\stackrel{\substack{+\dot{m}}}{n}$ & $\begin{array}{c}n \\
\hat{T}\end{array}$ & $\begin{array}{l}\text { ma } \\
\hat{i} \\
\hat{i}\end{array}$ & $\underset{\sigma}{\kappa}$ & ì & $\frac{m}{\frac{d}{d}}$ & $\begin{array}{l}\hat{n} \\
\hat{\sigma} \\
\underline{\hat{n}}\end{array}$ & $\stackrel{5}{\check{5}}$ \\
\hline$\stackrel{n}{\hat{m}}$ & 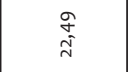 & $\hat{a}$ & 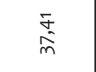 & $\begin{array}{l}0 \\
0 \\
0 \\
0\end{array}$ & 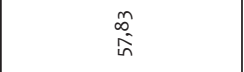 & $\begin{array}{c}\infty^{0} \\
\infty \\
\infty \\
m\end{array}$ & $\begin{array}{l}\text { जे } \\
\text { n }\end{array}$ & 突 \\
\hline ڤ & $\begin{array}{l}\text { वे } \\
\text { के } \\
\text { ते }\end{array}$ & 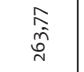 & 命 & $\begin{array}{l}\infty \\
\infty \\
\infty \\
\infty \\
\infty^{-1}\end{array}$ & 党 & 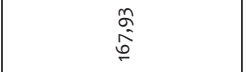 & $\stackrel{\stackrel{0}{\stackrel{M}{N}}}{\stackrel{N}{N}}$ & $\begin{array}{c}\stackrel{\Omega}{\hat{\rho}} \\
\stackrel{\rho}{Q}\end{array}$ \\
\hline $\begin{array}{l}0 \\
\text { ơ } \\
\text { ô }\end{array}$ & $\begin{array}{c}m \\
\stackrel{m}{f} \\
\dot{m}\end{array}$ & 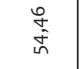 & $\begin{array}{l}\text { స̃ } \\
\text { î }\end{array}$ & $\stackrel{n}{i}$ & $\begin{array}{l}m \\
\text { ì } \\
\text { in }\end{array}$ & $\stackrel{0}{\tilde{m}}$ & $\begin{array}{l}n \\
\stackrel{n}{-} \\
\dot{0} \\
m\end{array}$ & 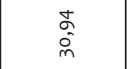 \\
\hline $\begin{array}{l}\infty \\
0 \\
\infty \\
\infty \\
\infty\end{array}$ & $\begin{array}{l}\bar{\infty} \\
\dot{\omega} \\
\stackrel{\infty}{\infty}\end{array}$ & 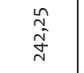 & م. & $\begin{array}{l}\stackrel{n}{0} \\
\stackrel{\infty}{\sim} \\
\stackrel{\sim}{n}\end{array}$ & $\begin{array}{l}\text { fo } \\
\stackrel{n}{\pi}\end{array}$ & 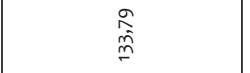 & $\begin{array}{l}\stackrel{a}{0} \\
\infty \\
\text { âd }\end{array}$ & 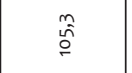 \\
\hline 岕 & 崖 & 崖 & 岁 & 岕 & 岁 & 崖 & 岁 & 宸 \\
\hline 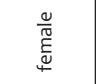 & $\begin{array}{l}\frac{0}{\pi} \\
\stackrel{\pi}{\pi} \\
\stackrel{\varpi}{\pi}\end{array}$ & $\begin{array}{l}\frac{0}{\pi} \\
\stackrel{\pi}{\pi} \\
\stackrel{\varpi}{\pi}\end{array}$ & 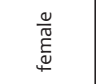 & 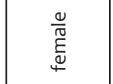 & 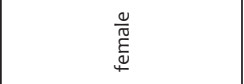 & $\frac{0}{\stackrel{0}{\pi}}$ & 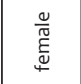 & $\frac{0}{\pi}$ \\
\hline $\overrightarrow{⿱ 亠 乂}$ & $\stackrel{\dot{\infty}}{\dot{\varphi}}$ & $\stackrel{\dot{x}}{\dot{x}}$ & $\stackrel{\dot{\leftrightarrow}}{\grave{3}}$ & 今 & $\dot{\dot{\varphi}}$ & 京 & 字 & $\stackrel{\dot{\check{c}}}{\stackrel{\dot{\alpha}}{\alpha}}$ \\
\hline 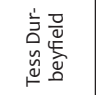 & 詞 & 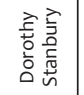 & $\begin{array}{l}\text { 咅言 } \\
\text { 品 }\end{array}$ & 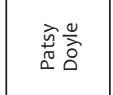 & 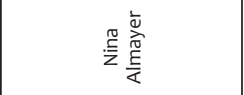 & 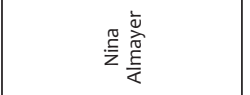 & 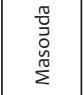 & 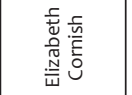 \\
\hline 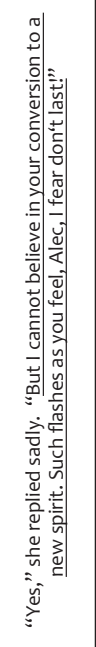 & 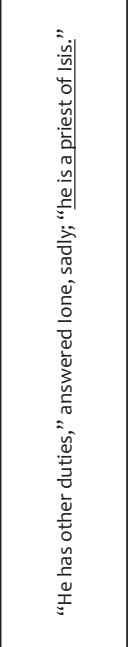 & 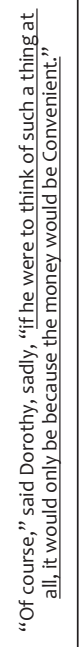 & 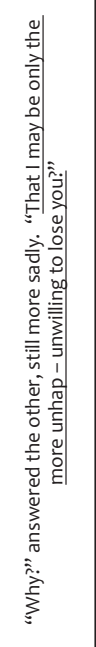 & 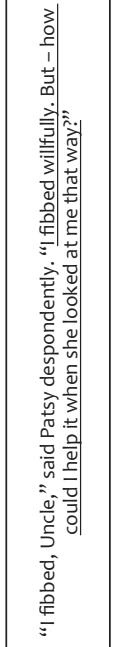 & 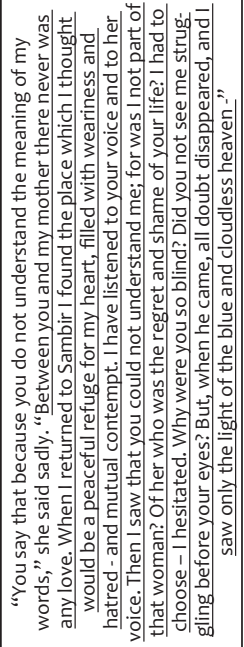 & 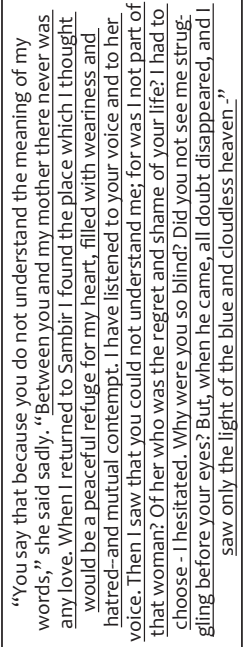 & 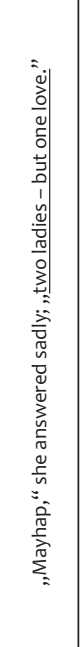 & 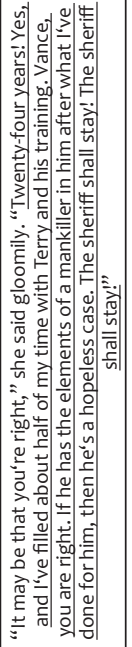 \\
\hline ㅊㅎㅎ & 츻 & 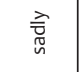 & 空 & 过产 产 & 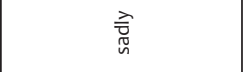 & 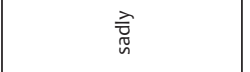 & 髇 & $\begin{array}{l}\dot{\varepsilon} \\
\frac{\dot{g}}{20} \geqq\end{array}$ \\
\hline 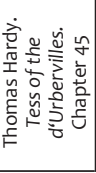 & 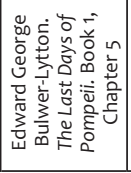 & 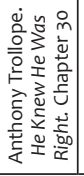 & 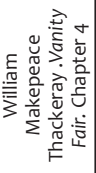 & 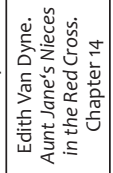 & 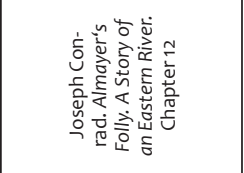 & 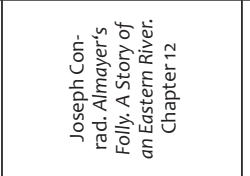 & 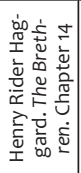 & 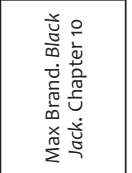 \\
\hline
\end{tabular}




\begin{tabular}{|c|c|c|c|}
\hline 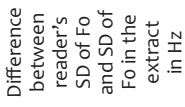 & $\stackrel{\infty}{\stackrel{m}{p}}$ & $\bar{S}_{0}^{\circ}$ & 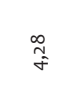 \\
\hline 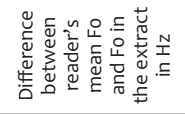 & $\begin{array}{l}m \\
\hat{\vec{f}}\end{array}$ & $\underset{\infty}{\tilde{N}}$ & $\stackrel{\Gamma}{\sigma}$ \\
\hline 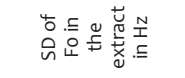 & $\begin{array}{l}\bar{f} \\
\text { fo }\end{array}$ & 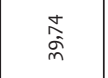 & $\begin{array}{l}\bar{\delta} \\
\tilde{j} \\
\tilde{m}\end{array}$ \\
\hline 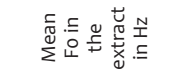 & 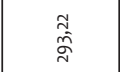 & 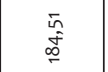 & \begin{tabular}{l}
$\infty$ \\
\multirow{\alpha}{\alpha}{} \\
$\sigma$
\end{tabular} \\
\hline 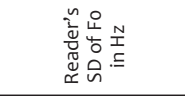 & 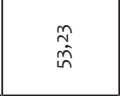 & $\begin{array}{l}\stackrel{m}{m} \\
\hat{q}\end{array}$ & 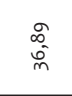 \\
\hline 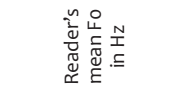 & 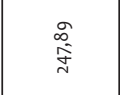 & $\underset{\substack{\tilde{N} \\
\stackrel{m}{\sigma}}}{ }$ & $\begin{array}{l}\hat{\sigma} \\
\hat{\alpha} \\
\alpha\end{array}$ \\
\hline 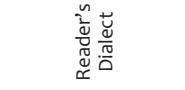 & 岕 & 岕 & 岕 \\
\hline 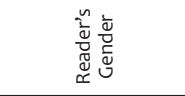 & 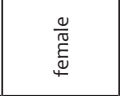 & 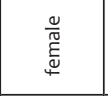 & 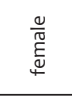 \\
\hline 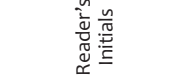 & ن & 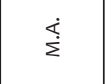 & $\stackrel{\check{\sim}}{\dot{v}}$ \\
\hline 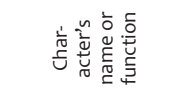 & 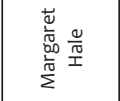 & 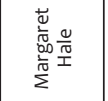 & 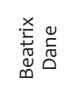 \\
\hline 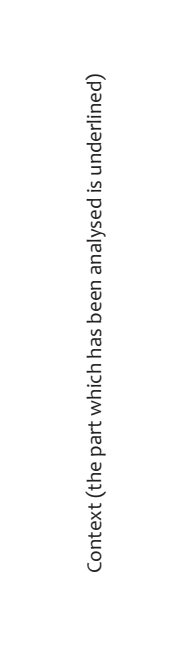 & 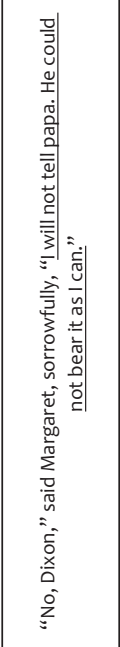 & 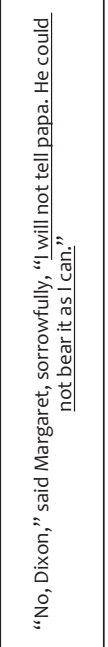 & 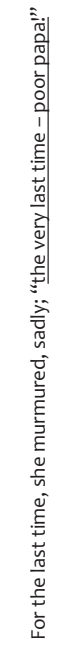 \\
\hline 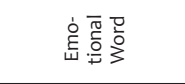 & 产高 & 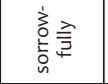 & 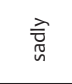 \\
\hline 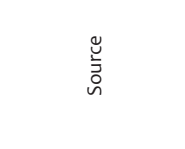 & 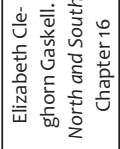 & 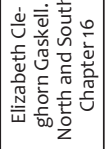 & 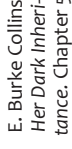 \\
\hline
\end{tabular}


Łukasz Stolarski, PhD, is currently employed at Jan Kochanowski University in Kielce, Poland. He is a linguist specialising in phonetics. His projects concern selected phonetic phenomena, such as palatalization or articulation of individual segments, but he has also worked on more interdisciplinary problems, such as size-sound symbolism or the interface between phonetics and pragmatics. Moreover, his research interests include other branches of linguistics, such as sociolinguistics or dialectology. He also has considerable experience in corpus linguistics methodology and in recent years he has developed a keen interest in computational linguistics.

Address: Łukasz Stolarski, PhD, Jan Kochanowski University in Kielce, Institute of Foreign Languages, Department of Linguistics, ul. Świętokrzyska 21D, 25-406 Kielce, Poland. [email: lukasz.stolarski@ujk.edu.pl] 
